Criptografia RSA

Daniele Helena Bonfim 

SERVIÇO DE PÓS-GRADUAÇÃO DO ICMC-USP

Data de Depósito:

Assinatura:

\section{Daniele Helena Bonfim}

\section{Criptografia RSA}

Dissertação apresentada ao Instituto de Ciências Matemáticas e de Computação - ICMC-USP, como parte dos requisitos para obtenção do título de Mestra em Ciências - Programa de Mestrado Profissional em Matemática. VERSÃO REVISADA

Área de Concentração: Matemática

Orientador: Prof. Dr. Marcelo Rempel Ebert 
Ficha catalográfica elaborada pela Biblioteca Prof. Achille Bassi e Seção Técnica de Informática, ICMC/USP, com os dados fornecidos pelo(a) autor(a)

Bonfim, Daniele Helena
Criptografia RSA / Daniele Helena Bonfim; orientador
Marcelo Rempel Ebert. -- São Carlos -- SP, 2017.
91 p.
Dissertação (Mestrado - Programa de Pós-graduação em
Mestrado Profissional em Matemática em Rede Nacional)
-- Instituto de Ciências Matemáticas e de Computação,
Universidade de São Paulo, 2017.
1. Criptografia. 2. RSA. 3. Congruência modular.
4. Teoria dos Números. I. Ebert, Marcelo Rempel, orient.
II. Título.




\section{Daniele Helena Bonfim}

\section{Cryptography RSA}

Master dissertation submitted to the Instituto de Ciências Matemáticas e de Computação - ICMCUSP, in partial fulfillment of the requirements for the degree of Mathematics Professional Master's Program. FINAL VERSION

Concentration Area: Mathematics

Advisor: Prof. Dr. Marcelo Rempel Ebert

\section{USP - São Carlos}

March 2017 

Dedico este trabalho á minha mãe, Maria José; ao meu marido, Pedro; à minha irmãzinha Ana Luiza; à minha vó Maria da Penha; ao meu pai Lázaro; ao professor Luciano Pedroso que me apresentou ao PROFMAT, assim como aos meus professores da graduação Maria de Fátima Bernades, Wagner Bernardes, Waldemar Gianini e Fernando Oliveira; aos meu queridos alunos do PIC: Deivid Cezar da Silva, Gustavo Teixeira Simões, Jonas Cassiano Costa, André Rodrigues Gomes Silva, Leonardo Siqueira Aprile Pires, Cibele Louise de Almeida Cardoso, Rafael Vasconcelos Martins, Vanessa de Oliveira, Pedro Henrique Silva Alves, Jean Lima Alves, Layane Avila, Matheus de Oliveira Gonçalves, Hugo Rodrigues Salomão, Leticia Maria Costa, Merhy End Dias Faria; aos meu professores Marcelo Rempel Ebert, Kátia Andréia Gonçalves de Azevedo e Vanessa Rolnik Artioli do PROFMAT. 

Agradeço primeiramente à Deus e à minha mãe, que me deu muito apoio em todos os momentos. Ao meu marido, Pedro, que teve extrema paciência e sempre me apoiou. Ao IMPA que teve a iniciativa de proporcionar o PROFMAT, à USP, ao meu orientador Marcelo Rempel Ebert e à CAPES que proporcionou a aplicação nas aulas do Programa de Iniciação Científica da Obmep, assim como a todos os professores que me ajudaram a aprofundar meus conhecimentos e a realizar este sonho. 

"Precisamos nos comunicar Da rotina escapar Ao amor nos entregar. Algumas coisas gritamos ao mundo, Outras guardadas estão bem lá no fundo Da alma, ou do coração. Mas pra sempre assim não ficarão. Muitas vezes não queremos falar, Porque nem todos precisam escutar, Por isso minha mensagem vou criptografar Para que só alguns possam receptar" (Daniele Helena Bonfim) 



\section{RESUMO}

BORGES, DANIELE H. B.. Criptografia RSA. 2017. 91 f. Dissertação (Mestrado em Ciências - Programa de Mestrado Profissional em Matemática) - Instituto de Ciências Matemáticas e de Computação (ICMC/USP), São Carlos - SP.

Neste trabalho é apresentado um pouco da história da criptografia, assim como sua importância nos dias atuais, a base da teoria dos números e de congruência modular necessárias para compreender a criptografia RSA, que é o foco deste trabalho. A criptografia RSA é a mais usada atualmente por causa da dificuldade em ser decodificada. Foi elaborada e apresentada uma aula aos alunos do ensino fundamental e médio participantes do Programa de Iniciação Científica Júnior da OBMEP, sendo mostrado o porquê ela funciona, os métodos de codificação e decodificação.

Palavras-chave: Criptografia, RSA, Congruência modular, Teoria dos Números. 



\section{ABSTRACT}

BORGES, DANIELE H. B.. Criptografia RSA. 2017. 91 f. Dissertação (Mestrado em Ciências - Programa de Mestrado Profissional em Matemática) - Instituto de Ciências Matemáticas e de Computação (ICMC/USP), São Carlos - SP.

In this work some of the history of cryptography is presented, as well as its nowadays applications. The RSA encryption is the most widely used because of the difficulty to being decoded. In order to understand the RSA encryption, which is the focus of this work, we recall some basis of number theory and modular congruence. Also, it was prepared and presented a lecture to the students of middle and high school participants in the Program of Junior Scientific Initiation of OBMEP, being shown why it works, methods of encoding and decoding.

Keywords: Cryptography, RSA, Modular congruence, Number Theory. 



\section{LISTA DE ILUSTRAÇÕES}

Figura 1 - Crivo de Eratóstenes . . . . . . . . . . . . . . . . . 44

Figura 2 - Criptografia em sites . . . . . . . . . . . . . . 49

Figura 3 - Criptografia em sites . . . . . . . . . . . . . . 50

Figura 4 - Como funciona a criptografia . . . . . . . . . . . . . 52

Figura 5 - Citale Espartano . . . . . . . . . . . . . . . 54

Figura 6 - Frequência das letras no alfabeto (Brasil) . . . . . . . . . . . . 54

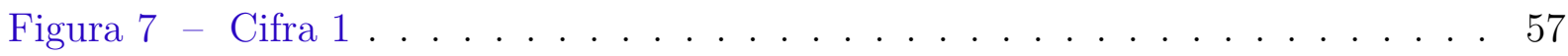

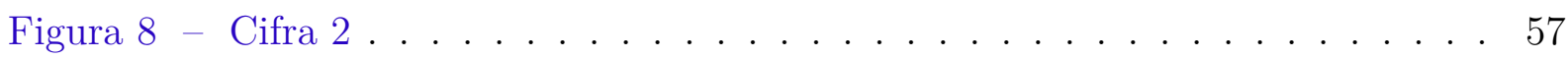

Figura $9-$ Cifra $3 \ldots \ldots \ldots \ldots \ldots$

Figura $10-3 \times 2$ - Três linhas por duas colunas . . . . . . . . . . . . . . . 58

Figura 11 - Tabela de consulta para letras e números em Braille . . . . . . . . . . . 59

Figura 12 - Programação dos Primeiros Encontros do G4 . . . . . . . . . . . . . . 74

Figura 13 - Programação dos Primeiros Encontros do G3 . . . . . . . . . . . . . . 74

Figura 14 - Encontrando $N \ldots \ldots \ldots \ldots \ldots$. . . . . . . . . . . . . . . . . .

Figura 15 - Encontrando $\varphi_{N} \ldots \ldots \ldots \ldots \ldots$

Figura 16 - Fatoração de $\varphi_{N} \ldots \ldots \ldots \ldots \ldots$. . . . . . . . . . . . . . . . . . . . . .

Figura 17 - Encontrando $d \ldots \ldots \ldots$. . . . . . . . . . . . 77

Figura 18 - Codificando a mensagem . . . . . . . . . . . . . . . . . . 77

Figura 19 - Codificando a mensagem . . . . . . . . . . . . . . . . 78

Figura 20 - Decodificando a mensagem . . . . . . . . . . . . . . 78

Figura 21 - Decodificando a mensagem . . . . . . . . . . . . . . . . . . 79 

Tabela 1 - Diagrama - Algoritmo de Euclides . . . . . . . . . . . . . 28

Tabela 2 - Maiores pares de primos gêmeos conhecidos . . . . . . . . . . 45

Tabela 3 - Tabela para Cifra de Blaise de Vigenère . . . . . . . . . . . . . . . 56

Tabela 4 - Criptografando com a Cifra de Blaise . . . . . . . . . . . . 56

Tabela 5 - Código Morse . . . . . . . . . . . . . . . . 62

Tabela 6 - Criptografia convencional e de chave pública . . . . . . . . . . 63

Tabela 7 - Tabela Para Conversão . . . . . . . . . . . . . . . . 64 

INTRODUÇÃO ........................ 21

ARITMÉTICA BÁSICA . . . . . . . . . . . . . . . 25

2.1 Divisão nos Inteiros . . . . . . . . . . . . . . . . 25

$2.2 \quad 0$ algoritmo de Euclides . . . . . . . . . . . . . 26

2.3 Equações diofantinas lineares . . . . . . . . . . . . . . . 32

$2.4 \quad$ Os números primos . . . . . . . . . . . . . . . . . . 34

2.5 Congruência e Propriedades . . . . . . . . . . . . . 37

2.6 Congruências Lineares . . . . . . . . . . . . . . . . . . . . . . 39

2.7 Teorema Chinês do Resto . . . . . . . . . . . . . . . . . . . 41

2.8 Métodos Para Achar Números Primos . . . . . . . . . . . . . . 43

2.9 Como Encontrar Números Primos Grandes . . . . . . . . . . . . . . 43

$2.10 \quad$ Teste de Primalidade . . . . . . . . . . . . . . . . 46

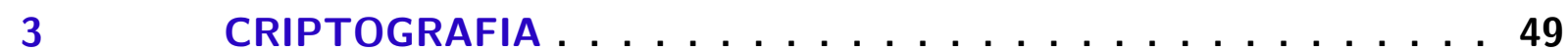

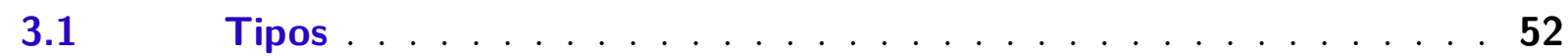

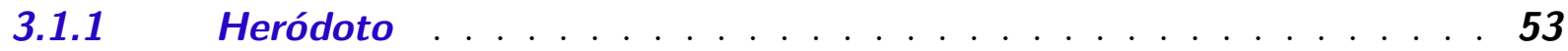

3.1.2 Bastão de Licurgo . . . . . . . . . . . . . . . . . . . . . . . . 53

3.1.3 Método de César . . . . . . . . . . . . . . . . 53

3.1.4 Anagrama . . . . . . . . . . . . . . . . 55

3.1.5 Blaise de Vigenère . . . . . . . . . . . . . . . . . . 55

3.1.6 A cifra de Beale . . . . . . . . . . . . . . . . . . . . 55

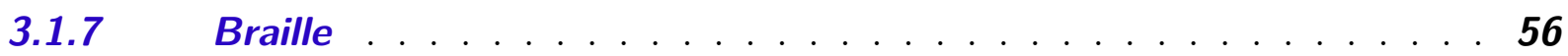

3.1.8 Disco de Alberti . . . . . . . . . . . . . . . . . . . 58

3.1 .9 Máquina Enigma . . . . . . . . . . . . . . . . . . . . 60

3.1.10 Máquina Colossus . . . . . . . . . . . . . . . . . . . 61

3.1.11 Código Morse . . . . . . . . . . . . . . . . . . . . . . . . 61

3.1.12 Sistema Binário . . . . . . . . . . . . . . . . . . . . 6 61

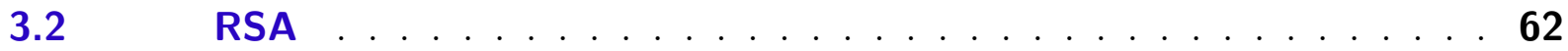

3.2.1 Como Funciona? . . . . . . . . . . . . . . . . . . 63

3.2.2 Por que funciona? . . . . . . . . . . . . . . . . 70

3.2.3 Segurança ......................... 71 


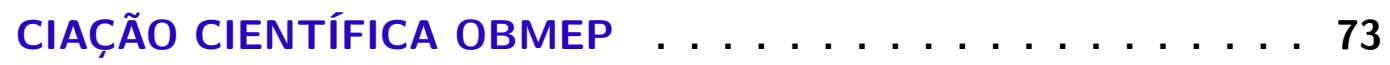

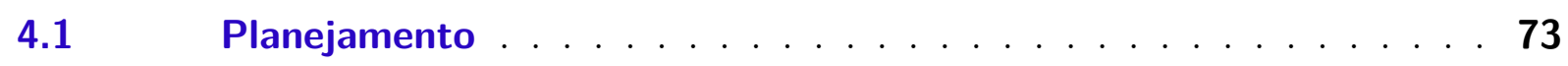

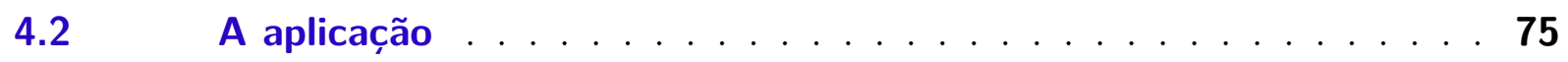

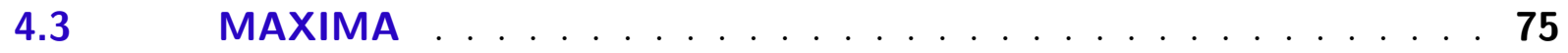

$4.4 \quad$ Resultados . . . . . . . . . . . . . . . . 79

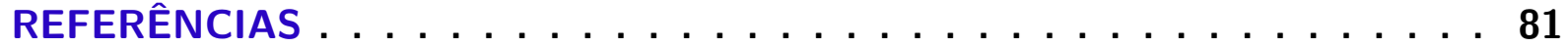

APÊNDICE A PROPRIEDADE ARQUIMEDIANA . . . . . 85

APÊNDICE B OS PROBLEMAS DO PRÊMIO MILLENNIUM . . . 87

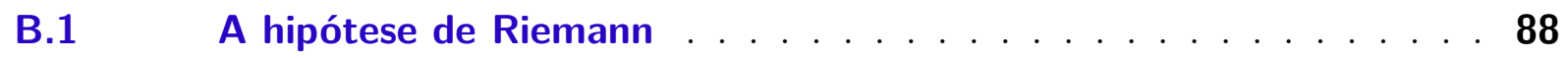

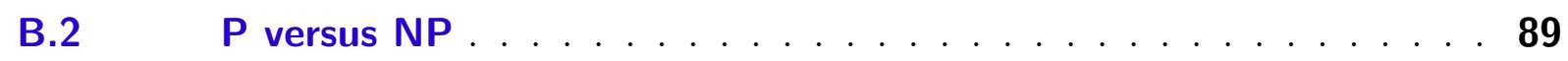

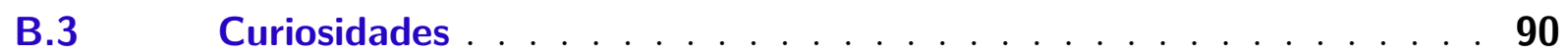


Neste trabalho será apresentado a Criptografia, que estuda o ato de cifrar mensagens, derivada do grego cryptos que significa "secreto, oculto", usada para codificar mensagens de forma que somente o destinatário e o remetente compreendam. Segundo Coutinho (2008, p. 1) é o estudo dos: "métodos para codificar uma mensagem de modo que só seu destinatário consiga interpretá-la”.

Durante a história é possível perceber o quanto a Criptografia evoluiu para que as mensagens ficassem mais seguras de serem transmitidas, já que, com seu surgimento também veio a Criptoanálise que estuda os métodos de quebrar ou decifrar mensagens cifradas.

Para compreender melhor o processo veja o exemplo: Ana quer enviar uma mensagem à Felipe, contudo ela quer que somente ele leia e compreenda a mensagem, para isso ela irá escrever a mensagem e cifrá-la ou codificá-la antes de enviar, de modo que, quando Felipe receber ele terá que decifrar a mesma. O ato de Ana é para que caso uma terceira pessoa intercepte a mensagem, esta não possa ler ou compreender.

Segundo Diffie e Hellman (2007, p. 30): "A criptografia é o estudo de sistemas "matemáticos" envolvendo dois tipos de problemas de segurança: privacidade e autenticação".

Atualmente está presente na linguagem de computadores, quando é enviado um e-mail, nas senhas de bancos e redes sociais, dentre outros, mas ela não é um conteúdo presente no Ensino Médio atual. No Conteúdo Básico Comum (CBC) de Minas Gerais (CARNEIRO; SPIRA; SABATUCCI, 2016) ela não aparece, nem nos Parâmetros Curriculares Nacionais (PCNs) de Matemática (BRASIL, 1997).

Contudo, segundo os PCNs, é preciso que haja contextualização nos conteúdos ensinados, pois todo conhecimento envolve uma relação entre sujeito e objeto, ou seja, 
entre o aluno e a matéria, assim se o conhecimento é trabalhado de modo contextualizado a escola irá retirar o aluno da sua condição de expectador passivo e fazer com que ele se interesse mais pelo conteúdo (BRASIL, 1997).

No CBC de Minas Gerais é possível observar a abertura para o estudo de situações problemas envolvendo conteúdos abordados em sala de aula, para que haja uma fixação maior e também, como método de conseguir um interesse maior por parte do aluno (CARNEIRO; SPIRA; SABATUCCI, 2016).

Muitos estudiosos defendem a contextualização do conteúdo como forma não só de reter a atenção do aluno por mais tempo, mas também fazer com que ele compreenda a utilização daquele conhecimento. De acordo com Fonseca (1995, p. 53):

As linhas de frente da Educação Matemática tem hoje um cuidado crescente com o aspecto sociocultural da abordagem Matemática. Defendem a necessidade de contextualizar o conhecimento matemático a ser transmitido, buscar suas origens, acompanhar sua evolução, explicitar sua finalidade ou seu papel na interpretação e na transformação da realidade do aluno. É claro que não se quer negar a importância da compreensão, nem tampouco desprezar a aquisição de técnicas, mas busca-se ampliar a repercussão que o aprendizado daquele conhecimento possa ter na vida social, nas opções, na produção e nos projetos de quem aprende. (FONSECA, 1995, p. 53)

D’Ambrosio (1997) também defende a contextualização, principalmente em matemática, para que o aluno possa levar os conteúdos para o cotidiano com o objetivo de fazer com que ele a entenda e compreenda, não somente decore conteúdos os quais não vê finalidade.

Segundo Tamarozzi (2004, p. 69): "a criptografia é tão antiga quanto a própria escrita; já estava presente no sistema de escrita hieroglífica dos egípcios", por isso é uma importante ferramenta, seja no Ensino Fundamental ou Médio, para a construção de um material útil como atividades e jogos de codificação, de forma com que o aluno possa fixar conteúdos matemáticos, como, por exemplo, funções e matrizes.

De acordo com Cantoral (2003), o tema Criptografia é uma ferramenta atual, que permite contextualizar algumas matérias, fazendo com que o aluno se interesse mais e desperte a atenção pelos conteúdos desenvolvidos na sala de aula.

Trivinos (1987) defende o estudo da exploração por parte do aluno, de modo que ele possa aumentar a experiência em torno de um problema, aprofundando os estudos em sua realidade específica.

De acordo com BRASIL (1997, p. 19):

Recursos didáticos como jogos, livros, vídeos, calculadoras, computadores e outros materiais têm um papel importante no processo de ensino e aprendizagem. Contudo, eles precisam estar integrados a situações que levem ao exercício da análise e da reflexão, em última instância, a base da atividade matemática. 
A criptografia pode ser então uma motivadora em algumas situações problemas para o processo de ensino-aprendizagem, podendo ser uma matéria auxiliar inclusive no ensino do uso da calculadora.

Neste trabalho será visto em específico a Criptografia RSA e a base aritmética necessária para sua compreensão, também sendo mostrado um pouco da história por trás da linguagem dos códigos.

Além disso será abordado um pouco sobre o programa MAXIMA, que foi usado como auxiliar já que, para exemplos mais complexos de criptografia RSA cálculos à mão tornam-se impossíveis, precisando assim de auxílio de programas.

O objetivo deste trabalho é abordar principalmente a criptografia RSA, de forma a introduzir ao aluno um pouco da história, alguns métodos mais simples, a Teoria dos Números e por fim o método RSA, abordando: sua importância, o porquê ele é seguro, como ele funciona e alguns exercícios e atividades para exploração do conteúdo.

Com este método de criptografia é possível aprofundar conteúdos com os alunos que são introduzidos deste os primeiros anos do Ensino Fundamental, levando-o a observar a importância desses, aumentando o interesse em matemática. 

CAPÍTULO

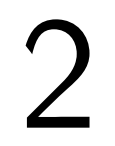

(1)

\section{ARITMÉTICA BÁSICA}

\subsection{Divisão nos Inteiros}

Dados dois números $d, m \in \mathbb{Z}$, dizemos que $d$ divide $m$, ou que $m$ é um múltiplo de $d$, ou ainda que $d$ é um divisor de $m$ se existir um número $q \in \mathbb{Z}$ tal que $m=q d$. Neste caso, usa-se a notação $d \mid m$.

Se isso não acontecer, ou seja, se $d$ não dividir $m$ escreve-se $d \nmid m$.

Lema 1. Sejam $a, b, c, d \in \mathbb{Z}$. Tem-se:

(1) ("d divide") Se $d \mid a$ e $d \mid b$ então $d \mid(a x+b y)$ para qualquer combinação linear de $a$ e $b$ com coeficientes $x, y \in \mathbb{Z}$.

(2) (Limitação) Se $d \mid a$ então $a=0$ ou $|d| \leq|a|$.

(3) (Transitividade) Se $a \mid b$ e $b \mid c$ então $a \mid c$.

Demonstração. Se $d \mid a$ e $d \mid b$, então pode-se escrever $a=d q_{1}$ e $b=d q_{2}$ com $q_{1}, q_{2} \in \mathbb{Z}$, $\operatorname{logo} a x+b y=d\left(q_{1} x+q_{2} y\right)$. Como $q_{1} x+q_{2} y \in \mathbb{Z}$, tem-se $d \mid a x+b y$, donde conclui-se (1).

Para mostrar (2), suponha que $d \mid a$ e $a \neq 0$. Neste caso, $a=d q$ com $q \neq 0$, assim $|q| \geq 1$ e $|a|=|d||q| \geq|d|$.

Finalmente provaremos (3). Se $a \mid b$ e $b \mid c$, então existem $q_{1}, q_{2} \in \mathbb{Z}$ tais que $b=a q_{1}$ e $c=b q_{2}, \operatorname{logo} c=a q_{1} q_{2}$ e portanto $a \mid c$.

Teorema 1. (Divisão Euclidiana) Dados $a, b \in \mathbb{Z} \operatorname{com} b \neq 0$, então existem únicos $q, r \in \mathbb{Z}$ tais que

$$
a=b q+r \text { e } 0 \leq r<|b| .
$$

Neste caso $q$ é chamado de quociente e $r$ de resto. 
Demonstração. Considere o conjunto:

$$
S=\{x=a-b y ; y \in \mathbb{Z}\} \cap(\mathbb{N} \cup\{0\}) .
$$

Como o conjunto dos Naturais não permite cota superior (Propriedade Arquimediana), existe $n \in \mathbb{Z}$ tal que $n(-b)>-a, \operatorname{logo} a-n b>0$, mostrando que $S$ não é vazio.

O conjunto $S$ é limitado inferiormente por 0, logo, pelo princípio da Boa Ordenação, tem-se que $S$ possui um menor elemento $r$.

Suponhamos então que $r=a-b q$. Sabendo que $r \geq 0$ é preciso mostrar que $r<|b|$.

Presuma por absurdo que $r \geq|b|$, isso implica que existe $s \in \mathbb{N} \cup\{0\}$ tal que $r=|b|+s$, com $0 \leq s<r$. Mas isso contradiz o fato de $r$ ser um menor elemento de $S$, pois $s=a-(q \pm 1) b \in S, \operatorname{com} s<r$.

Para provarmos a unicidade, suponha que $a=b q+r=b q^{\prime}+r^{\prime}$, onde $q, q^{\prime}, r, r^{\prime} \in \mathbb{Z}$, $0 \leq r<|b|$ e $0 \leq r^{\prime}<|b|$. Assim tem-se que $-|b|<-r \leq r^{\prime}-r \leq r^{\prime}<|b|$. Logo, $\left|r^{\prime}-r\right|<|b|$. Por outro lado, $b\left(q-q^{\prime}\right)=r^{\prime}-r$, o que implica que $|b|\left|q-q^{\prime}\right|=\left|r^{\prime}-r\right|<|b|$, o que só é possível se $q=q^{\prime}$ e consequentemente, $r=r^{\prime}$.

\subsection{0 algoritmo de Euclides}

Dados $a$ e $b$ ambos diferentes de zero e pertencentes ao conjunto dos números inteiros, cada um pode ser associado à um conjunto finito de divisores $D_{a}$ e $D_{b}$ de $a$ e $b$, respectivamente. Temos que a intersecção destes conjuntos nunca é vazia, pois pelo menos o número 1 é comum aos dois conjuntos. Como a intersecção é não vazia e finita (já que os dois conjuntos o são) pode-se determinar um maior elemento nesta intersecção, chamado de Máximo Divisor Comum (mdc). Por razões técnicas, usaremos a seguinte definição equivalente:

Definição 1. Dado um número inteiro $d \geq 0$ e $d$ é um máximo divisor comum de $a$ e $b$, se possuir as seguintes propriedades:

1. $d$ é um divisor comum de $a$ e $b$, e

2. $d$ é divisível por todo divisor comum de $a$ e $b$.

A notação usada para Máximo Divisor Comum entre $a$ e $b$ é $(a, b)$.

Observação 1. Sejam $a$ e $b$ números inteiros não nulos, e suponha que exista $d=(a, b)$. Seja $c$ um divisor comum de $a$ e $b$, então $|c|$ divide $d$ e, portanto $c \leq|c| \leq d$. Isso nos mostra que o máximo divisor comum de dois números, não ambos nulos, quando existe, é efetivamente o maior entre todos os divisores comuns desses números. Desta maneira, conclui-se a existência do mdc conforme definição acima. 
Proposição 1. O máximo divisor comum de $a$ e $b$ é único.

Demonstração. A segunda condição implica que, se $d$ e $d^{\prime}$ são dois mdc de um mesmo par de números, então, $d \mid d^{\prime}$ e $d^{\prime} \mid d$, o que juntamente com as condições $d \geq 0$ e $d^{\prime} \geq 0$, implica que $d=d^{\prime}$. Ou seja, o mdc de dois números, quando existe é único.

Exemplo 1. Temos que $(28,36)=4$, pois $D_{28}=\{ \pm 1, \pm 2, \pm 4, \pm 7, \pm 14, \pm 28\}$ e $D_{36}=$ $\{ \pm 1, \pm 2, \pm 3, \pm 4, \pm 6, \pm 9, \pm 12, \pm 18, \pm 36\}$.

Como o mdc de $a$ e $b$ não depende da ordem em que $a$ e $b$ são tomados, temos que

$$
(a, b)=(b, a)
$$

Se $a$ é um número inteiro, tem-se claramente que $(0, a)=|a|,(1, a)=1$ e que $(a, a)=|a|$. Para todo $b \in \mathbb{Z}$, temos que

$$
a|b \Leftrightarrow(a, b)=| a \mid
$$

De fato, se $a \mid b$, temos que $|a|$ é um divisor comum de $a$ e $b$, e se $c$ é um divisor de $a$ e $b$, então $c$ divide $|a|$, o que mostra que $|a|=(a, b)$. Reciprocamente, se $(a, b)=|a|$, segue-se que $|a|$ divide $b, \log a \mid b$.

Dados $a, b \in \mathbb{Z}$, se existir o mdc entre $a$ e $b$, então

$$
(a, b)=(-a, b)=(a,-b)=(-a,-b)
$$

Assim para efeito do cálculo do mdc de dois números, podemos supô-los não negativos.

O algoritmo de Euclides ou algoritmo das divisões sucessivas é uma forma eficiente de encontrar o mdc entre dois números. Tal algoritmo se baseia na divisão euclidiana.

Lema 2. (Euclides) Se $a=b q+r$, então $(a, b)=(b, r)$.

Demonstração. Para provar este teorema é preciso verificar se $D_{a} \cap D_{b}=D_{b} \cap D_{r}$. Se $d \in$ $D_{a} \cap D_{b}$ tem-se que $d \mid a$ e $d|b, \log d|(a-b q) \Leftrightarrow d \mid r$ e portanto $d \in D_{b} \cap D_{r}$.

Por outro lado, se $d \in D_{b} \cap D_{r}$ implica que $d \mid b$ e $d \mid r$, logo $d|(b q+r) \Leftrightarrow d| a$. Logo $d \in D_{a} \cap D_{b}$. Portanto $D_{a} \cap D_{b}=D_{b} \cap D_{r}$ e $(a, b)=(b, r)$.

No que segue, vamos aplicar o Lema 2 para calcular o $(a, b)$. Vamos supor que $1<b<a$. Se $b \mid a$ então $(a, b)=b$. Se $b \nmid a$, pela divisão euclidiana, pode-se escrever: $a=b q_{1}+r_{1}$ com $0<r_{1}<b$, e pelo Lema 2 tem-se duas possibilidades:

(1) $r_{1} \mid b \Leftrightarrow(a, b)=\left(r_{1}, b\right)=r_{1}$ 
(2) $r_{1} \nmid b$, então pode-se efetuar a divisão euclidiana de $b$ por $r_{1}$, obtendo $b=r_{1} q_{2}+r_{2}$ com $0<r_{2}<r_{1}$. Novamente há duas possibilidades $r_{2}$ dividir ou não $r_{1}$, podendo ser aplicado o algoritmo sucessivamente, gerando uma sequência decrescente finita de $r_{j}, j=1,2, \cdots$. (o que sempre ocorre, pois o conjunto dos Naturais tem um menor elemento).

Este algoritmo pode ser escrito da seguinte forma de diagrama:

1. $a=b q_{1}+r_{1}$, com $0<r_{1}<b$;

2. $b=r_{1} q_{2}+r_{2}$, com $0<r_{2}<r_{1}$;

3. $r_{1}=r_{2} q_{3}+r_{3}$, com $0<r_{3}<r_{2}$;

4. $r_{n-2}=r_{n-1} q_{n}+r_{n}$, com $0<r_{n}<r_{n-1}$;

5. $r_{n-1}=r_{n} q_{n+1}$.

\begin{tabular}{c|c|c|c|c|c|c|c} 
& $q_{1}$ & $q_{2}$ & $q_{3}$ & $\cdots$ & $q_{n-1}$ & $q_{n}$ & $q_{n+1}$ \\
\hline$a$ & $b$ & $r_{1}$ & $r_{2}$ & $\cdots$ & $r_{n-2}$ & $r_{n-1}$ & $r_{n}=(a, b)$ \\
\hline$r_{1}$ & $r_{2}$ & $r_{3}$ & $r_{4}$ & $\cdots$ & $r_{n}$ & &
\end{tabular}

Tabela 1 - Diagrama - Algoritmo de Euclides

Desta forma, conclui-se que $r_{n}=(a, b)$.

No que segue, apresentamos outra idéia relacionada ao cálculo do mdc. Sejam $a$, $b \in \mathbb{Z}$ define-se o conjunto:

$$
I(a, b)=\{x a+y b ; x, y \in \mathbb{Z}\} .
$$

Observa-se que se $a$ e $b$ não são simultaneamente nulos, então $I(a, b) \cap \mathbb{N} \neq \emptyset$. De fato, tem-se que $a^{2}+b^{2}=a \times a+b \times b \in I(a, b) \cap \mathbb{N}$.

Teorema 2. Sejam $a, b \in \mathbb{Z}$, não ambos nulos. Se $d=\min I(a, b) \cap \mathbb{N}$, então:

(1) $d$ é o mdc de $a$ e $b$; e

(2) $I(a, b)=d \mathbb{Z}$

Para provar que $d=(a, b)$ basta verificar que:

i) $d \mid a$ e $d \mid b$, 
ii) Se $c \mid a$ e $c \mid b$, então $c \mid d$.

Demonstração. (Teorema 2)

(1) Suponha que $c$ divida $a$ e $b$, logo $c$ divide todos os números naturais da forma $x a+y b$. Portanto, $c$ divide todos os elementos de $I(a, b)$, e, consequentemente, $c \mid d$. Para mostrar que $d$ divide todos os elementos de $I(a, b)$ : seja $z \in I(a, b)$ e suponha, por absurdo, que $d \nmid z$. Logo pela divisão Euclidiana,

$$
z=d q+r, \operatorname{com} 0<r<d
$$

Como $z=x a+y b$ e $d=m a+n b$ para alguns $x, y, n, m \in \mathbb{Z}$, segue-se de (2.1) que

$$
r=(x-q m) a+(y-q n) b \in I(a, b) \cap \mathbb{N},
$$

o que é um absurdo, pois $d=\min I(a, b) \cap \mathbb{N}$ e $r<d$. Em particular, $d \mid a$ e $d \mid b$. Assim, fica provado que $d$ é o mdc de $a$ e $b$.

(2) Dado que todo elemento $I(a, b)$ é divisível por $d$, tem-se que $I(a, b) \subset d \mathbb{Z}$. Por outro lado, para todo $l d \in d \mathbb{Z}$, tem-se que:

$$
l d=l(m a+n b)=(\operatorname{lm}) a+(\ln ) b \in I(a, b)
$$

e, portanto, $d \mathbb{Z} \subset I(a, b)$. Em conclusão, tem-se que $I(a, b)=d \mathbb{Z}$.

Corolário 1. Quaisquer que sejam $a, b \in \mathbb{Z}$, não ambos nulos, e $n \in \mathbb{N}$, tem-se que

$$
(n a, n b)=n(a, b)
$$

Demonstração. Note inicialmente que

$$
I(n a, n b)=n I(a, b)(=\{n z, z \in I(a, b)\}) .
$$

Logo, segue do Teorema 2

$$
(n a, n b)=\min \{I(n a, n b) \cap \mathbb{N}\}=\min \{n I(a, b) \cap \mathbb{N}\}=n \min \{I(a, b) \cap \mathbb{N}\}=n(a, b) .
$$

Definição 2. Dois números inteiros $a$ e $b$ são primos entre si se $(a, b)=1$.

Proposição 2. Dois números inteiros $a$ e $b$ são primos entre si se, e somente se, existem números inteiros $m$ e $n$ tais que $m a+n b=1$. 
Demonstração. Suponha que $a$ e $b$ são primos entre si, i.e., $(a, b)=1$. Logo, pelo Teorema 2 , temos que existem números inteiros $m$ e $n$ tais que $m a+n b=1$, donde segue a primeira parte da proposição.

Reciprocamente, suponha que existam números inteiros $m$ e $n$ tais que $m a+n b=1$. Se $d=(a, b)$, temos que $d \mid((m a+n b)$, o que mostra que $d \mid 1$, e, portanto, $d=1$.

Teorema 3. (Lema de Gauss) Sejam $a, b$ e $c$ números inteiros. Se $a \mid b c$ e $(a, b)=1$, então $a \mid c$.

Demonstração. Se $a \mid b c$, então existe $e \in \mathbb{Z}$ tal que $b c=a e$.

Se $(a, b)=1$, então, pela Proposição 2 , temos que existem $m, n \in \mathbb{Z}$ tais que

$$
m a+n b=1 .
$$

Multiplicando por $c$ ambos os lados da igualdade acima, temos que

$$
c=m a c+n b c
$$

Substituindo $b c$ por ae nesta última igualdade, temos que

$$
c=m a c+n a e=a(m c+n e),
$$

e portanto $a \mid c$.

Dados dois números inteiros $a$ e $b$, dizemos que $c$ é um múltiplo comum de $a$ e $b$, se $c$ é múltiplo simultaneamente de $a$ e $b$. Defini-se o mínimo múltiplo comum (mmc) entre $a$ e $b$ como o menor múltiplo comum entre estes dois números. Por razões técnicas, usaremos a seguinte definição equivalente:

Definição 3. Um inteiro $m \geq 0$ é dito um mínimo múltiplo comum dos números inteiros $a$ e $b$, se possuir as seguintes propriedades:

1. $m$ é um múltiplo comum de $a$ e $b$, e

2. se $c$ é um múltiplo comum de $a$ e $b$, então $m \mid c$.

A notação usada para Mínimo Múltiplo Comum entre $a$ e $b$ é $[a, b]$.

Observação 2. Se $m$ é o mmc de $a b$ e $c$ é um múltiplo comum de $a$ e $b$, então $m \mid c$. Portanto se $c$ é positivo, temos que $m \leq c$, mostrando-se que $m$ é o menor dos múltiplos comuns positivos de $a$ e $b$.

Exemplo 2. Temos que $[2,5]=10,[3,5]=15$ e $[6,8]=24$. 
Proposição 3. O mínimo múltiplo comum dos números inteiros $a$ e $b$ é unico.

Demonstração. Se $m$ e $m^{\prime}$ são dois mínimos múltiplos comuns de $a$ e $b$, então, do segundo item da definição acima, temos que $m \mid m^{\prime}$ e $m^{\prime} \mid m$. Como $m$ e $m^{\prime}$ são números inteiros não negativos, temos que $m=m^{\prime}$, o que mostra que o mínimo múltiplo comum é único.

É possível calcular o mmc entre dois números em termos do mdc pela proposição abaixo:

Proposição 4. Sejam $a$ e $b$ dois números naturais, então

$$
(a, b) \times[a, b]=a b .
$$

Para provar que $m=[a, b]$ basta verificar que:

i) $a \mid m$ e $b \mid m$;

ii) se $a \mid c$ e $b \mid c$, então $m \mid c$.

Demonstração. Se $a=0$ ou $b=0$, a igualdade é satisfeita. Sejam $a, b \in \mathbb{N}$ e $m=\frac{a b}{(a, b)}$. Como $m=a \frac{b}{(a, b)}=b \frac{a}{(a, b)}$.

Desta forma $a \mid m$ e $b \mid m$, portanto $m$ é um múltiplo comum de $a$ e $b$.

Seja $c$ um múltiplo comum de $a$ e $b, \operatorname{logo} c=n a=n^{\prime} b$. Segue assim que: $n \frac{a}{(a, b)}=$ $n^{\prime} \frac{b}{(a, b)}$.

Como $\frac{a}{(a, b)}$ e $\frac{b}{(a, b)}$ são primos entre si (já que $a$ e $b$ são divididos pelo máximo divisor entre eles), $\frac{a}{(a, b)}$ divide $n^{\prime}$, e, portanto, $m=\frac{a}{(a, b)} b$ divide $n^{\prime} b$ que é igual a $c$.

As nocões de mdc e mmc podem ser generalizadas.

Proposição 5. Dados números inteiros $n_{1}, n_{2}, \cdots, n_{m}$ todos não nulos, existe o seu mdc $\mathrm{e}$

$$
\left(n_{1}, n_{2}, \cdots, n_{m}\right)=\left(n_{1}, \cdots n_{m-2},\left(n_{m-1}, n_{m}\right)\right)
$$

Demonstração. Provaremos por indução sobre $m \geq 2$. É fácil ver que para $m=2$, o resultado é válido. Partiremos do princípio que o resultado vale para $m$.

Para provar que o resultado é válido para $m+1$, basta mostrar que se $d$ é o mdc de $n_{1}, \cdots,\left(n_{m}, n_{m+1}\right)$, então $d$ é o mdc de $n_{1}, \cdots, n_{m}, n_{m+1}$.

Seja $d$ o mdc de $n_{1}, \cdots,\left(n_{m}, n_{m+1}\right)$. Logo $d\left|n_{1}, d\right| n_{2}, \cdots, d \mid n_{m-1}$, e $d \mid\left(n_{m}, n_{m+1}\right)$. Portanto, $d\left|n_{1}, d\right| n_{2}, \cdots, d\left|n_{m-1}, d\right| n_{m} d \mid n_{m+1}$. 
Por outro lado, seja $c$ divisor comum de $n_{1}, n_{2}, \cdots, n_{m}, n_{m+1}$, $\operatorname{logo} c$ é um divisor comum de $n_{1}, n_{2}, \cdots, n_{m-1}$ e $\left(n_{m}, n_{m+1}\right)$, e, portanto, $c \mid d$.

Proposição 6. Sejam $n_{1}, n_{2}, \cdots, n_{k}$ números inteiros não nulos. Então existe o número $\left[n_{1}, n_{2}, \cdots, n_{k}\right] \mathrm{e}$

$$
\left[n_{1}, n_{2}, \cdots, n_{k}\right]=\left[n_{1}, n_{2}, \cdots, n_{k-2},\left[n_{k-1}, n_{k}\right]\right]
$$

Demonstração. Sejam $m=\left[n_{1}, n_{2}, \cdots, n_{k-2},\left[n_{k-1}, n_{k}\right]\right]$. Logo, $n_{1}, n_{2}, \cdots, n_{k-2}$ e $\left.\left[n_{k-1}, n_{k}\right]\right]$ dividem $m$. Como $n_{k-1} \mid\left[n_{k-1}, n_{k}\right]$ e $n_{k} \mid\left[n_{k-1}, n_{k}\right]$, segue que $m$ é um múltiplo comum de $n_{1}$, $n_{2}, \cdots, n_{k}$.

Por outro lado, suponha que $c$ seja múltiplo comum de $n_{1}, n_{2}, \cdots, n_{k}$. Logo, $n_{1} \mid c$, $n_{2}\left|c, \cdots, n_{k-2}\right| c$ e $\left[n_{k-1}, n_{k}\right] \mid c$, daí segue que $c$ é múltiplo de $m=\left[n_{1}, n_{2}, \cdots, n_{k-2},\left[n_{k-1}, n_{k}\right]\right]$.

Proposição 7. Sejam $a_{1}, a_{2}, \cdots, a_{r}$ números inteiros não nulos então vale:

$$
\left(a_{1},\left[a_{2}, a_{3}, \cdots, a_{r}\right]\right)=\left[\left(a_{1}, a_{2}\right),\left(a_{1}, a_{3}\right), \cdots,\left(a_{1}, a_{r}\right)\right] .
$$

Demonstração. Seja $d$ o mdc entre $a_{1}$ e $\left[a_{2}, a_{3}, \cdots, a_{r}\right]$ isso implica que $d \mid a_{1}$ e $d \mid\left[a_{2}, a_{3}, \cdots, a_{r}\right]$. De acordo com o Lema 1: $d \leq a_{1}$ e $d \leq\left[a_{2}, a_{3}, \cdots, a_{r}\right]$.

Seja $d^{\prime}=\left[\left(a_{1}, a_{2}\right),\left(a_{1}, a_{3}\right), \cdots,\left(a_{1}, a_{r}\right)\right]$ isso implica que $\left(a_{1}, a_{2}\right)\left|d^{\prime},\left(a_{1}, a_{3}\right)\right| d^{\prime}, \cdots$, $\left(a_{1}, a_{r}\right) \mid d^{\prime}$, além disso $\left(a_{1}, a_{2}\right)\left|a_{1},\left(a_{1}, a_{3}\right)\right| a_{1}, \cdots,\left(a_{1}, a_{r}\right) \mid a_{1}$, como cada elemento $a_{2}, a_{3}$, $\cdots, a_{r}$ pode não ter divisor em comum com $a_{1}: d^{\prime} \leq a_{1}$ e $d^{\prime} \mid a_{1}$ implicando que $d^{\prime}=d$.

\subsection{Equações diofantinas lineares}

As equações diofantinas lineares em duas variáveis são equações na forma:

$$
a X+b Y=c,
$$

em que $a, b, c \in \mathbb{Z}$, são dados, e busca-se por soluções inteiras $X, Y$.

Nem sempre este tipo de equação tem solução no conjunto dos inteiros, sendo que condições necessárias e suficientes dão dadas na seguinte proposição:

Proposição 8. Sejam $a, b, c \in \mathbb{Z}$ e $d=(a, b)$. A equação $a X+b Y=c$ admite solução nos números inteiros se, e somente se, $d \mid c$.

Demonstração. Pelo Teorema 2, tem-se que:

$$
I(a, b)=\{m a+n b ; m, n \in \mathbb{Z}\}=d \mathbb{Z},
$$

em que $d=(a, b)$. Assim é claro que a equação $a X+b Y=c$ admite solução se, e somente se, $c \in I(a, b)$, o que é equivalente a $c \in d \mathbb{Z}$, que por sua vez, é equivalente a $d \mid c$. 
Suponda que $(a, b)=1$. Pelo resultado anterior, temos que (2.2) admite solução. No que segue, vamos caracterizar o conjunto de todas as soluções.

Proposição 9. Seja $x_{0}, y_{0}$ uma solução da equação $a X+b Y=c$, onde $(a, b)=1$. Então, as soluções $x, y$ em $\mathbb{Z}$ da equação são

$$
x=x_{0}+t b, y=y_{0}-t a ; t \in \mathbb{Z} .
$$

Demonstração. Sejam $x, y$ uma solução de $a X+b Y=c$, logo,

$$
a x_{0}+b y_{0}=a x+b y=c .
$$

Consequentemente, $a\left(x-x_{0}\right)=b\left(y_{0}-y\right)$. Como $(a, b)=1$, segue-se que $b \mid\left(x-x_{0}\right)$. Logo, $x-x_{0}=t b, t \in \mathbb{Z}$.

Substituindo a expressão de $x-x_{0}$ em (2.3), segue-se que

$$
y_{0}-y=t a
$$

o que prova que as soluções são do tipo exibido.

Por outro lado, $x, y$, como no enunciado, é solução, pois

$$
a x+b y=a\left(x_{0}+t b\right)+b\left(y_{0}-t a\right)=a x_{0}+b y_{0}=c .
$$

Desta proposição segue que a equação diofantina $a X+b Y=c, \operatorname{com}(a, b)=1$, admite infinitas soluções em $\mathbb{Z}$.

Um método para encontrar uma solução particular de uma equação diofantina é obtido usando o algoritmo de euclidiano estendido, a saber, supondo que $(a, b)=1$, pela Proposição 2 existem $m, n \in \mathbb{Z}$ tais que

$$
m a+n b=1 .
$$

Multiplicando ambos os membros da igualdade acima por $c$, obtêm-se

$$
c m a+c n b=c .
$$

Logo, $x_{0}=c m$ e $y_{0}=c n$ é uma solução particular da equação e usando a Proposição 9 é possível encontrar as demais soluções. 


\subsection{Os números primos}

Nesta seção apresentaremos alguns resultados sobre números primos, cujo conceito é fundamental para a aritmética e uma base para a teoria de criptografia.

Definição 4. Um número natural maior que 1 que só possui como divisores positivos 1 e ele próprio é chamado de número primo.

Proposição 10. Dados dois números primos $p$ e $q$ e um número inteiro $a$ qualquer. Temos que:

I) Se $p \mid q$, então $p=q$.

II) Se $p \nmid a$, então $(p, a)=1$.

Demonstração. (I) Como $p \mid q$ e sendo $q$ primo, temos que $p=1$ ou $p=q$. Sendo $p$ primo, tem-se que $p>1$, o que acarreta $p=q$.

(II) Seja $(p, a)=d$, temos que $d \mid p$ e $d \mid a$. Portanto, $d=p$ ou $d=1$. Mas $d \neq p$, pois $p \nmid a$ e, consequentemente, $d=1$.

Se um número $n$ não é primo diz-se que ele é composto. Portanto, se um número natural $n>1$ é composto, existirá um divisor natural $n_{1}$ de $n$ tal que $1<n_{1}<n$. Logo, existirá um número natural $n_{2}$ tal que:

$$
n=n_{1} n_{2}, \operatorname{com} 1<n_{1}<n \text { e } 1<n_{2}<n
$$

Por exemplo, 2, 3, 5, 7, 11 e 13 são números primos, enquanto que 4, 6, 8, 9, 10 e 12 são compostos.

Proposição 11. (Lema de Euclides) Sejam $a, b, p \in \mathbb{Z}$, com $p$ primo. Se $p \mid a b$, então $p \mid a$ ou $p \mid b$.

Demonstração. Basta provar que, se $p \mid a b$ e $p \nmid a$, então $p \mid b$. Mas, se $p \nmid a$, temos que $(p, a)=1$, e o resultado seque-se do Lema de Gauss (Teorema 3).

Lembrando algumas propriedades da divisibilidade de acordo com o Lema 1.

Todo número natural pode ser escrito na forma fatorada por números primos:

Teorema 4. (Teorema Fundamental da Aritmética). Sejam $n \geq 2$ um número natural, pode-se escrever $n$ de uma única forma como um produto

$$
n=p_{1} \cdots p_{m}
$$

onde $m \geq 1$ é um natural e $p_{1} \leq \cdots \leq p_{m}$ são primos. 
Demonstração. Se $n$ é um número primo não há o que demonstrar, pois basta que se faça $m=1 \Rightarrow p_{1}=n$. Se $n$ é composto, seja $p_{1}>1$ o menor dos divisores positivos de $n$. Pode-se provar que $p_{1}$ é primo. De fato, caso contrário existiria um $p$, com $1<p<p_{1}$ tal que $p \mid p_{1}$, donde $p \mid n$, o que iria contradizer a escolha de $p_{1}$ como menor divisor. Assim $n$ pode ser escrito como $n=p_{1} n_{1}$.

Se $n_{1}$ for primo a prova está finalizada, mas se $n_{1}$ for composto, seja $p_{2}>1$ o menor dos divisores positivos de $n_{1}$. Pode-se provar que $p_{2}$ é primo, logo $n=p_{1} p_{2} n_{2}$. Repete-se o processo até que encontra-se um $n_{r}$ primo.

Como $n_{1}, n_{2}, n_{3}, \cdots, n_{r}$ é uma sequência decrescente, onde todos os termos pertencem aos naturais, será finita.

Os primos da sequência $p_{1}, p_{2}, p_{3}, p_{4}, \cdots, p_{m}$ não são necessariamente distintos, assim a forma de $n$ será:

$$
n=p_{1}^{\alpha_{1}} p_{2}^{\alpha_{2}} p_{3}^{\alpha_{3}} p_{4}^{\alpha_{4}} \cdots p_{m}^{\alpha_{m}}
$$

Precisa-se provar a unicidade da fatoração. Para $n=2$ a afirmação é verdadeira. Se $n$ for primo também não há nada o que provar. Para isso suponha que $n$ seja composto e tenha duas fatorações:

$$
n=p_{1} p_{2} p_{3} p_{4} \cdots p_{m}=q_{1} q_{2} q_{3} q_{4} \cdots q_{n} .
$$

É preciso provar que $m=n$ e que cada $p_{i}$ é igual a algum dos $q_{j}$. Como $p_{1}$ divide $q_{1} q_{2} q_{3} q_{4} \cdots q_{n}$, e como ambos são primos, $\log$ o $p_{1}$ divide um dos fatores $q_{j}$, donde a menos da ordem podemos supor $p_{1}=q_{1}$. Da mesma forma $p_{2}$ divide um dos fatores $q_{j}$, como ambos são primos, implica que $p_{2}=q_{2}$, repetindo o processo por indução tem-se que $m=n, \operatorname{logo}$ as fatorações $p_{1} p_{2} p_{3} p_{4} \cdots p_{m}$ e $q_{1} q_{2} q_{3} q_{4} \cdots q_{n}$ são idênticas.

Teorema 5. A sequência dos números primos é infinita.

Demonstração. Suponhamos que a sequência de números primos seja finita.

Deste modo temos que a listagem de todos os primos é $p_{1}, p_{2}, p_{3}, p_{4}, \cdots, p_{m}$. Agora considere o número $K=p_{1} p_{2} p_{3} p_{4} \cdots p_{m}+1$, ele não pode ser divisível por nenhum dos números primos listados, como $K$ é maior que qualquer um dos primos listados e não é divisível por nenhum deles, pelo Teorema 4, $K$ é um número primo ou é composto (escrito em fatores primos), desta forma há um primo que não pertence à nossa lista, implicando que a sequência de números primos não pode ser finita.

Além de Euclides, outros matemáticos provaram este teorema como, por exemplo, Kummer, Hermite, Goldbach, Euler, Thue, Perott, Auric, Métrod, dentre outros (RIBENBOIM, 2012). 
Lema 3. Seja $p$ um número primo. Os números $\left(\begin{array}{l}p \\ i\end{array}\right)=\frac{p !}{(p-i) ! i !}$, onde $0<i<p$, são todos divisíveis por $p$.

Demonstração. É trivial para $i=1$. Para $1<i<p$, como

$$
\left(\begin{array}{c}
p \\
i
\end{array}\right)=\frac{p(p-1) \cdots(p-i+1)}{i !}
$$

é um inteiro, segue que $i ! \mid p(p-1) \cdots(p-i+1)$. Por outro lado, como $(i !, p)=1$, então $i ! \mid(p-1) \cdots(p-i+1)$, donde por definição $p \mid\left(\begin{array}{l}p \\ i\end{array}\right)$.

Teorema 6. (Pequeno Teorema de Fermat) Seja $p$ um número primo, tem-se que $p$ divide o número $a^{p}-a$, para todo número inteiro $a$.

Demonstração. Se $p=2$ então $2 \mid\left(a^{2}-a\right)$ já que $a^{2}-a=a(a-1)$ e $a$ ou $a-1$ é par.

Para $p$ ímpar provaremos o resultado por indução, assumindo que $a \geq 0$. O resultado é óbvio para $a=0$, pois $p \mid 0$. Suponha que seja válido para $a$, provaremos para $a+1$. Pela fórmula do Binômio de Newton:

$$
(a+1)^{p}-(a+1)=a^{p}-a+\left(\begin{array}{c}
p \\
1
\end{array}\right) a^{p-1}+\cdots+\left(\begin{array}{c}
p \\
p-1
\end{array}\right) a .
$$

Pelo Lema 3 e pela hipótese de indução, o segundo membro da equação é divisível por $p$.

Para concluir a prova no caso $a<0$, basta observar que $(-a)^{p}-(-a)=-a^{p}+a=$ $-\left[a^{p}-a\right]$.

Deste teorema é possível concluir o Corolário abaixo:

Corolário 2. Se $p$ é um número primo e se $a$ é um número inteiro não divisível por $p$, então $p$ divide $a^{p-1}-1$

Demonstração. De acordo com o Teorema 6 , temos que $p\left|a^{p}-a \Leftrightarrow p\right| a\left(a^{p-1}-1\right)$. Como $(a, p)=1$ então $p$ divide $a^{p-1}-1$.

Pelo algoritmo da divisão quando divide-se um número por 6, os restos possíveis são $0,1,2,3,4$ e 5, ou seja, qualquer número pode ser escrito em uma das formas $6 k$, $6 k+1,6 k+2,6 k+3,6 k+4$ ou $6 k+5$.

Se $p$ é um número primo maior que 3 ele não pode ser par, logo ele é da forma $6 k+1,6 k+3$, ou $6 k+5$, mas como todo número da forma $6 k+3$ é divisível por $3, p$ só pode ser da forma $6 k+1$ ou $6 k+5$.

Proposição 12. Existem infinitos primos da forma $6 k+5$. 
Demonstração. Para provar que existem infinitos números primos da forma $6 k+5$ suponha, por absurdo, que existe um número finito de primos nesta forma.

Sejam estes números: $5, p_{1}, p_{2}, p_{3}, \cdots, p_{n}$, todos distintos, e considere o número $P=6 p_{1} p_{2} p_{3} \cdots p_{n}+5, P$ não é divisível por nenhum dos primos $5, p_{1}, p_{2}, p_{3}, \cdots, p_{n}$.

Podemos afirmar que $P$ possui um fator primo da forma $6 k+5$ distinto dos anteriores. De fato, caso contrário, se todos fossem da forma $6 k+1$, como o produto de dois números desta forma é sempre igual a outro da forma $6 k^{\prime}+1$, donde uma contradição.

No que segue, enunciamos um resultado mais geral conhecido como Teorema de Dirichlet ou Teorema dos Primos em Progressão Aritmética:

Teorema 7. (Teorema dos Primos em Progressão Aritmética). Se $a$ e $b$ são inteiros relativamente primos entre si, então a progressão aritmética $a n+b, n=1,2,3, \cdots$ contém um número infinito de primos.

A demonstração usual deste teorema usa variáveis complexas. Muitos casos particulares admitem demonstrações elementares mais ou menos simples. É possível encontrar a demonstração em http://www.mat.puc-rio.br/nicolau/papers/mersenne/node10.html.

\subsection{Congruência e Propriedades}

Seja $m$ um número natural. Diremos que dois números inteiros $a$ e $b$ são congruentes módulo $m$ se os restos de sua divisão euclidiana por $m$ são iguais. Quando os inteiros $a$ e $b$ são congruentes módulo $m$, escreve-se

$$
a \equiv b \bmod m \text {. }
$$

Por exemplo, $6 \equiv 11 \bmod 5$, já que quando dividimos 6 por 5 o resto é 1 e quando dividimos 11 por 5 o resto também é 1 . Outro exemplo é $241 \equiv 1 \bmod 2$.

Observa-se que todo número inteiro é congruente módulo $m$ ao seu resto $0 \leq r<m$ da divisão euclidiana por $m$, como no exemplo acima.

Quando a relação $a \equiv b \bmod m$ for falsa, diremos que $a$ e $b$ não são congruentes, ou que são incongruentes, módulo $m$. Escrevemos, nesse caso, $a \not \equiv b \bmod m$.

Como o resto da divisão de um número inteiro por 1 é sempre nulo, implica que $a \equiv b \bmod 1$ para quaisquer $a$ e $b \in \mathbb{Z}$. Portanto, consideraremos sempre $m>1$.

Proposição 13. Suponha que $a, b, m \in \mathbb{Z}$, com $m>1$. Tem-se que $a \equiv b \bmod m$ se, e somente se, $m \mid b-a$. 
Demonstração. Sejam $a=m q+r$, com $0 \leq r<m$ e $b=m q^{\prime}+r^{\prime}$, com $0 \leq r^{\prime}<m$, as divisões euclidianas de $a$ e $b$ por $m$, respectivamente. Logo,

$$
b-a=m\left(q^{\prime}-q\right)+\left(r^{\prime}-r\right) .
$$

Portanto, $a \equiv b \bmod m$ se, e somente se, $r=r^{\prime}$, o que, em vista da igualdade acima, é equivalente a dizer que $m \mid b-a$, já que $\left|r-r^{\prime}\right|<m$.

Temos as propriedades de congruência:

Proposição 14. Seja $n \in \mathbb{N}$ e $n>1$, Para todos $a, b, c \in \mathbb{Z}$, tem-se que:

(1) (Reflexividade) $a \equiv a \bmod n$;

(2) (Simetria) se $a \equiv b \bmod n$ então $b \equiv a \bmod n$;

(3) (Transitividade) se $a \equiv b \bmod n$ e $b \equiv c \bmod n$, então $a \equiv c \bmod n$;

(4) (Compatibilidade com a soma e a diferença) se $a \equiv b \bmod n$ e $c \equiv d \bmod n$, então $a+c \equiv b+d \bmod n$ e $a-c \equiv b-d \bmod n$,

Desta pode ser concluida uma propriedade em particular: se $a \equiv b \bmod n$, então $k a \equiv k b \bmod n$ para todo $k \in \mathbb{Z}$;

(5) (Compatibilidade com o produto) se $a \equiv b \bmod n$ e $c \equiv d \bmod n$, então $a c \equiv b d \bmod n$.

Em particular, se $a \equiv b \bmod n$, então $a^{m} \equiv b^{m} \bmod n$ para todo $m \in \mathbb{N}$;

(6) (Cancelamento) se $(c, n)=1$, então $a c \equiv b c \bmod n \Leftrightarrow a \equiv b \bmod n$.

(7) Se $c \neq 0$, então $a c \equiv b c \bmod n \Leftrightarrow a \equiv b \bmod \frac{n}{(c, n)}$.

Demonstração. (4): Suponha que $a \equiv b \bmod n$ e $c \equiv d \bmod n$. Deste modo $n \mid(b-a)$ e $n \mid(d-c)$ isso implica que $n \mid(b-a) \pm(d-c)$ e $n \mid(b \pm d)-(a \pm c)$.

(5): como $n \mid(b-a)$ e $n \mid(d-c)$ segue que $n \mid d(b-a)$ e $n \mid a(d-c)$. Desta forma pode-se concluir que $n \mid d(b-a)+a(d-c)$, ou seja, $n \mid b d-a c$.

Deixamos os itens (1) - (3) e (6) - (7) como um exercício ao leitor.

Algumas propriedades adicionais que serão utilizadas:

Proposição 15. Sejam $a, b \in \mathbb{Z}$ e $m, n, m_{1}, \cdots, m_{r}$ inteiros maiores que 1 . Tem-se que:

(1) se $a \equiv b \bmod m$ e $n \mid m$ então $a \equiv b \bmod n$;

(2) $a \equiv b \bmod m_{i}, \forall i=1, \cdots, r \Leftrightarrow a \equiv b \bmod \left[m_{1}, \cdots, m_{r}\right]$;

(3) se $a \equiv b \bmod m$, então $(a, m)=(b, m)$. 
Demonstração. (1) Se $a \equiv b \bmod m$, então $m \mid b-a$. Como $n \mid m$, segue-se que $n \mid b-a$. Logo, $a \equiv b \bmod n$.

(2) Se $a \equiv b \bmod m_{i}, i=1, \cdots, r$, então $m_{i} \mid b-a$, para todo $i$. Sendo $b-a$ um múltiplo de cada $m_{i}$, segue-se que $\left[m_{1}, \cdots, m_{r}\right] \mid b-a$, o que prova que $a \equiv b \bmod \left[m_{1}, \cdots, m_{r}\right]$. A recíproca decorre do primeiro item.

(3) Se $a \equiv b \bmod m$, então $m \mid b-a$ e, portanto, $b=a+t m$ com $t \in \mathbb{Z}$. Logo, pelo Lema 2 , tem-se que

$$
(a, m)=(a+t m, m)=(b, m)
$$

O Pequeno Teorema de Fermat pode ser escrito na seguinte forma:

Corolário 3. Se $p$ é um número primo e $a \in \mathbb{Z}$, então

$$
a^{p} \equiv a \bmod p
$$

Se $p \nmid a$, isso implica que

$$
a^{p-1} \equiv 1 \bmod p
$$

A prova segue do Teorema 6 e do Corolário 2.

\subsection{Congruências Lineares}

A resolução de problemas de congruências do tipo:

$$
a X \equiv b \bmod m, \text { onde } a, b, m \in \mathbb{Z}, m>1,
$$

é o problema de determinar se existem números $x \in \mathbb{Z}$ tais que $a x \equiv b \bmod m$.

É preciso inicialmente um critério para decidir se tais congruência admitem solução

Proposição 16. Dados $a, b, m \in \mathbb{Z}$, com $m>1$, a congruência

$$
a X \equiv b \bmod m
$$

possui solução se, e somente se, $(a, m) \mid b$.

Demonstração. Suponha que a congruência $a X \equiv b \bmod m$ tenha uma solução $x$; logo, temos que $m \mid(a x-b)$, o que equivale à existência de $y$ pertencente aos inteiros tal que $a x-b=m y$. Portanto, a equação $a X-m Y=b$ admite solução. A Proposição 8 implica que $(a, m) \mid b$.

Reciprocamente, suponha que $(a, m) \mid b$. Logo, em virtude das Proposições 8 e 9 a equação $a X-m Y=b$ admite uma solução $x, y$. Portanto, $a x=b+m y$ e, consequentemente, $x$ é solução da congruência pois, $a x \equiv b \bmod m$. 
Nota-se que se $x_{0}$ é solução da congruência $a X \equiv b \bmod m$, então todo $x$ tal que $x \equiv x_{0} \bmod m$ é também solução da congruência, pois

$$
a x \equiv a x_{0} \equiv b \bmod m \text {. }
$$

Portanto, toda solução particular determina, automaticamente, uma infinidade de soluções da congruência. Essas soluções serão identificadas (módulo $m$ ), já que são congruentes entre si, e, consequentemente, se determinam mutuamente.

O seguinte resultado nos fornece uma coleção completa de soluções duas a duas incongruentes módulo $m$, as quais serão chamadas de sistema completo de soluções incongruentes da congruência.

Teorema 8. Sejam $a, b, m \in \mathbb{Z}$, com $m>1$ e $(a, m) \mid b$. Se $x_{0}$ é uma solução da congruência $a X \equiv b \bmod m$, então

$$
x_{0}, x_{0}+\frac{m}{d}, x_{0}+2 \frac{m}{d}, \cdots, x_{0}+(d-1) \frac{m}{d},
$$

onde $d=(a, m)$ formam um sistema completo de soluções incongruentes da congruência.

Demonstração. Pela Proposição 16, sabe-se que a congruência admite solução.

É preciso mostrar que os números $x_{0}+i \frac{m}{d}$, com $i \in \mathbb{N}$, são soluções. De fato,

$$
a\left(x_{0}+i \frac{m}{d}\right)=a x_{0}+i \frac{a}{d} m \equiv a x_{0} \equiv b \bmod m \text {. }
$$

Além disso, esses números são dois a dois incongruentes módulo $m$. De fato, se, para $i, j<d$,

$$
x_{0}+i \frac{m}{d} \equiv x_{0}+j \frac{m}{d} \bmod m
$$

então

$$
i \frac{m}{d} \equiv j \frac{m}{d} \bmod m
$$

Pelo item 7 da Proposição 14 e como

$$
\frac{m}{\left(\frac{m}{d}, m\right)}=d
$$

segue-se que $i \equiv j \bmod d$, implicando que $i=j$.

Finalmente, é preciso mostrar que toda solução $x$ da congruência $a X \equiv b \bmod m$ é congruente, módulo $m$, a $x_{0}+i \frac{m}{d}$ para algum $i<d$. De fato, seja $x$ uma solução qualquer da congruência. Logo,

$$
a x \equiv a x_{0} \bmod m,
$$

e

$$
\frac{a}{d} x \equiv \frac{a}{d} x_{0} \bmod \frac{m}{d}
$$


Como $\left(\frac{a}{d}, \frac{m}{d}\right)=1$, segue do item (6) da Propriedade 14 que

$$
x \equiv x_{0} \bmod \frac{m}{d} .
$$

Logo, $x-x_{0}=k m / d$. Pela divisão euclidiana, existe $i<d$ tal que $k=q d+i$ e, portanto,

$$
x=x_{0}+q m+i \frac{m}{d} \equiv x_{0}+i \frac{m}{d} \bmod m
$$

\subsection{Teorema Chinês do Resto}

Considere o sistema de congruências da forma:

$$
X \equiv c_{i} \bmod m_{i}, i=1, \cdots, r
$$

O resultado seguinte nos fornece um método para resolvê-lo:

Teorema 9. Se $\left(m_{i}, m_{j}\right)=1$, para todo par $m_{i}, m_{j}$ com $i \neq j$, então o sistema (2.4) possui uma única solução módulo $M=m_{1} m_{2} \cdots m_{r}$. As soluções são

$$
x=M_{1} y_{1} c_{1}+\cdots+M_{r} y_{r} c_{r}+t M,
$$

onde $t \in \mathbb{Z}, M_{i}=M / m_{i}$ e $y_{i}$ é a solução de $M_{i} Y \equiv 1 \bmod m_{i}, i=1, \cdots, r$.

Demonstração. Primeiramente será provado que $x$ é uma solução simultânea do sistema (2.4). De fato, como $m_{i} \mid M_{j}$, se $i \neq j$, e $M_{i} y_{i} \equiv 1 \bmod m_{i}$, segue-se que

$$
x=M_{1} y_{1} c_{1}+\cdots+M_{r} y_{r} c_{r} \equiv M_{i} y_{i} c_{i} \equiv c_{i} \bmod m_{i} .
$$

Por outro lado, se $x^{\prime}$ é outra solução do sistema (2.4), então

$$
x \equiv x^{\prime} \bmod m_{i}, \forall i, i=1, \cdots, r .
$$

Como $\left(m_{i}, m_{j}\right)=1$, para $i \neq j$, segue-se que

$$
\left[m_{1}, \cdots, m_{r}\right]=m_{1} \cdots m_{r}=M
$$

e, consequentemente, pela Proposição 15 item (2), tem-se que $x \equiv x^{\prime} \bmod M$.

Proposição 17. O sistema de congruências

$$
X \equiv c_{1} \bmod m_{1}, X \equiv c_{2} \bmod m_{2}
$$

admite solução se, e somente se $c_{2} \equiv c_{1} \bmod \left(m_{1}, m_{2}\right)$. Além disso, dada uma solução $a$ do sistema, um número $a^{\prime}$ é também uma solução se, e somente se, $a^{\prime} \equiv a \bmod \left[m_{1}, m_{2}\right]$. 
Demonstração. O sistema (2.5) admite uma solução se, e somente se, existem $a, y, z \in$ $\mathbb{Z}$ tais que $a-c_{1}=y m_{1}$ e $a-c_{2}=z m_{2}$. Assim, a existência de soluções do sistema é equivalente à soluções da equação diofantina $y m_{1}-z m_{2}=c_{2}-c_{1}$. Por sua vez, essa equação diofantina possui solução se, e somente se, $\left(m_{1}, m_{2}\right)$ divide $c_{2}-c_{1}$, o que equivale a $c_{2} \equiv$ $c_{1} \bmod \left(m_{1}, m_{2}\right)$.

Suponhamos que $a$ seja uma solução do sistema (2.5). Se $a^{\prime}$ é uma outra solução do sistema, então $a^{\prime} \equiv c_{1} \equiv a \bmod m_{1}$ e $a^{\prime} \equiv c_{2} \equiv a \bmod m_{2}$, o que, em vista da Proposição 15 ítem (2), implica que $a^{\prime} \equiv a \bmod \left[m_{1}, m_{2}\right]$.

Por outro lado, se um número $a^{\prime}$ é tal que $a^{\prime} \equiv a \bmod \left[m_{1}, m_{2}\right]$, então $a^{\prime} \equiv a \equiv$ $c_{1} \bmod m_{1}$ e $a^{\prime} \equiv a \equiv c_{2} \bmod m_{2}$. Portanto, $a^{\prime}$ é solução do sistema (2.5).

Teorema 10. (Teorema Chinês dos Restos Generalizado) O sistema de congruências

$$
X \equiv c_{i} \bmod m_{i}, i=1, \cdots, r
$$

admite solução se, e somente se,

$$
c_{i} \equiv c_{j} \bmod \left(m_{i}, m_{j}\right), \forall i, j=1, \cdots, r .
$$

Nesse caso, a solução é única módulo $\left[m_{1}, \cdots, m_{r}\right]$.

Demonstração. Esta prova será feita por indução sobre $r$. O caso $r=2$ é dado pela Proposição 17.

Suponhamos que a propriedade seja válida para $r-1$. Pela hipótese de indução, temos que o sistema $X \equiv c_{i} \bmod m_{i}, i=1, \cdots, r-1$, admite uma única solução $c$ módulo $\left[m_{1}, \cdots, m_{r-1}\right]$. Temos que mostrar agora que o sistema

$$
\begin{gathered}
X \equiv c \bmod \left[m_{1}, \cdots, m_{r-1}\right] \\
X \equiv c_{r} \bmod m_{r}
\end{gathered}
$$

possui uma solução única módulo $\left[m_{1}, \cdots, m_{r}\right]$. Para estabelecer isso, em vista do caso $r=2$, só falta mostrar que

$$
c_{r} \equiv c \bmod \left(m_{r},\left[m_{1}, \cdots, m_{r-1}\right]\right)
$$

Como temos que $c \equiv c_{i} \bmod m_{i}$ para $i=1, \cdots, r-1$, seque-se, por mais forte razão, que $c \equiv c_{i} \bmod \left(m_{r}, m_{i}\right)$. Por outro lado, por hipótese, sabemos que $c_{r} \equiv c_{i} \bmod \left(m_{r}, m_{i}\right)$, para todo $i, \log 0 c_{r} \equiv c \bmod \left(m_{r}, m_{i}\right)$, para todo $i=1, \cdots, r-1$, e pelo item 2 da Proposição 15 segue que

$$
c_{r} \equiv c \bmod \left[\left(m_{r}, m_{1}\right),\left(m_{r}, m_{2}\right), \cdots,\left(m_{r}, m_{r-1}\right)\right] .
$$

O resultado agora segue da Proposição 7, que garante que

$$
\left(m_{r},\left[m_{1}, \cdots, m_{r-1}\right]\right)=\left[\left(m_{r}, m_{1}\right),\left(m_{r}, m_{2}\right), \cdots,\left(m_{r}, m_{r-1}\right)\right] .
$$


Temos também que a solução do sistema é única módulo

$$
\left[m_{r},\left[m_{1}, \cdots, m_{r-1}\right]\right]=\left[m_{1}, \cdots, m_{r-1}, m_{r}\right] .
$$

\subsection{Métodos Para Achar Números Primos}

Um método conhecido na escola, no final do Ensino Fundamental I e início do Ensino Fundamental II é o Crivo de Eratóstenes, criado por Erastóstenes no século II A.C., deve ser composto por todos os números menores que $n$ (dado de maneira arbitraria) (CARNEIRO; SPIRA; SABATUCCI, 2016). Ele foi o primeiro matemático que tentou sistematizar o conjunto dos números primos (COUTINHO, 2008). Este método consiste no seguinte: escreve-se todos os números, por exemplo, para $n=250$, deve ser escrito os números de 2 à 250, risca-se primeiro os múltiplos de 2 superiores à ele, depois todos os múltiplos de 3 superiores à ele, e assim por diante: cortando todos os múltiplos do próximo primo, menos ele mesmo até o primo $p$ tal que $p^{2}$ não ultrapasse $n$, neste caso em particular: $p^{2}<250$, ou seja, até o número 15 . Observe a figura 1 , de acordo com (HEFEZ, 2005, p. 35).

Desta forma, foi retirado todos os múltiplos dos primos 2, 3, 5, 7, 11, 13, 14, 15 $<\sqrt{251}$, ficando os números primos inferiores à 250: $2,3,5,7,11,13,17,19,23,29,31$, $37,41,43,47,53,59,61,67,71,73,79,83,89,97,101,103,107,109,113,127,131,137$, $139,149,151,157,163,167,173,179,181,191,193,197,199,211,223,227,229,233$, $239,241$.

Este critério é baseado no seguinte teorema:

Teorema 11. Se $n$ não é primo, então $n$ possui, necessariamente, um fator primo menor do que ou igual a $\sqrt{n}$.

Demonstração. Sendo $n$ composto então $n=n_{1} \times n_{2}$ onde $1<n_{1}<n, 1<n_{2}<n$. Sem perda de generalidade suponha $n_{1} \leq n_{2}$. Logo $n_{1}$ tem que ser $\leq \sqrt{n}$ pois, caso contrário, teríamos $n=n_{1} \times n_{2}>\sqrt{n} \times \sqrt{n}=n$ o que é absurdo. Logo, como pelo Teorema $4, n_{1}$ possui algum fator primo $p$, este deve ser $\leq \sqrt{n}$. Como $p$, sendo um fator primo de $n_{1}$ é também um fator de $n$, logo a demonstração está completa.

Como consequência, se $n$ não possui um fator primo $\leq \sqrt{n}$, então $n$ é primo.

\subsection{Como Encontrar Números Primos Grandes}

Os números primos são procurados até hoje, quanto maior o número achado mais difícil de quebrar o código na criptografia RSA, assim tem-se alguns recordes de primos, 


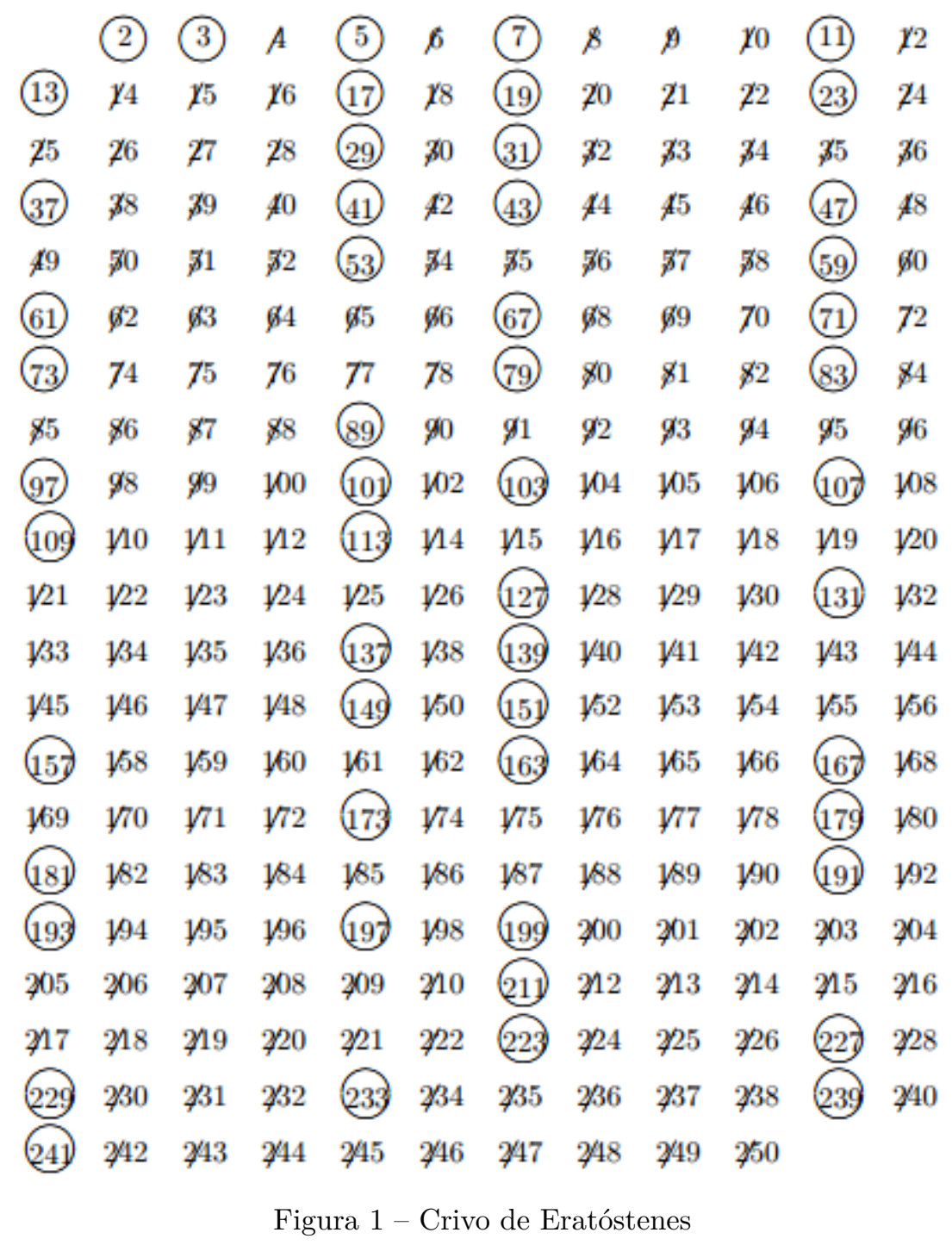

observe a tabela 2, que contém récordes de primos gêmeos ( $p$ e $q$ são primos e $|p-q|=2$ ) (MARTINEZ et al., 2013, p. 367).

Contudo estas tabelas podem se tornar obsoletas em um curto período de tempo, por isso o site https://primes.utm.edu/largest.html mantêm uma tabela atualizada dos dez maiores primos, consultada no dia 15 de outubro de 2015 o maior número primo era $2^{57885161}-1$, com 17.425.170 dígitos, descoberto no ano de 2013. Mas em 19 de janeiro de 2016 foi publicado um novo recorde: $2^{74207281}$ - 1 com 22.338 .618 dígitos ambos descobertos por GIMPS (Great Internet Mersenne Prime Search by Woltman e Kurowski) (CALDWELL, 2016).

Estes primos foram descobertos em um projeto para encontrar primos de Mersenne, que são da forma: $2^{n}-1$ (WOLTMAN; KUROWSKI, 2016).

Em criptografia RSA, é fundamental, para a criação da chave pública, que saiba-se encontrar números primos grandes. Para garantir a segurança da codificação, o ideal é 


\begin{tabular}{|c|c|c|}
\hline Primo & Número de dígitos & Data \\
\hline $3756801695685 \times 2^{666669} \pm 1$ & 200700 & 2011 \\
$65516468355 \times 2^{333333} \pm 1$ & 100355 & 2009 \\
$2003663613 \times 2^{195000} \pm 1$ & 58711 & 2007 \\
$194772106074315 \times 2^{171960} \pm 1$ & 51780 & 2007 \\
$100314512544015 \times 2^{171960} \pm 1$ & 51780 & 2006 \\
$16869987339975 \times 2^{171960} \pm 1$ & 51779 & 2005 \\
$33218920 \times 2^{169690} \pm 1$ & 51090 & 2002 \\
$22835841624 \times 7^{54321} \pm 1$ & 45917 & 2010 \\
$1679081223 \times 2^{151618} \pm 1$ & 45651 & 2012 \\
$84966861 \times 2^{140219} \pm 1$ & 42219 & 2012 \\
$12378188145 \times 2^{140002} \pm 1$ & 42155 & 2010 \\
$23272426305 \times 2^{140001} \pm 1$ & 42155 & 2010 \\
$8151728061 \times 2^{125987} \pm 1$ & 37936 & 2010 \\
\hline
\end{tabular}

Tabela 2 - Maiores pares de primos gêmeos conhecidos

que cada número primo possua mais de cem algarismos.

De acordo com Martinez et al. (2013) existem progressões aritméticas arbitrariamente grandes formadas exclusivamente por números primos, isso foi provado por Ben Green e Terence Tao, onde a maior conhecida é:

$$
43142746595714191+5283234035979900 \times n
$$

para todo $n=0,1, \cdots, 25$, que foi descoberta em 12 de abril de 2010 por Benoãt Perichon em um projeto do PrimeGrid disponível no site http://www.primegrid.com/ (RACKSPACE, 2016).

De acordo com OEIS (2016) e Ballinger e Rodenkirch (2016) existem outros projetos para procurar primos grandes, provando algumas conjecturas, como a de Sierpinski, a de Riesel, ou os números de Brier (que são simultaneamente de Sierpinski e de Riesel).

Dada esta necessidade de encontrar primos grandes, de acordo com Martinez et al. (2013, p. 332):

\footnotetext{
A relevância desse problema tem crescido imensamente em anos recentes devido à utilização intensa de números primos em algoritmos de criptografia, como os algoritmos RSA e El Gamal para criptografia pública. Dessa forma o problema do teste de primalidade se tornou um importante problema para a ciência da computação teórica. Sobre esse ponto de vista duas coisas são requiridas: um certificado de prova que o algoritmo realmente produz a resposta correta; e uma medida da eficiência do algoritmo, isto é, quão bem o algoritmo faz uso dos recursos computacionais (como o tempo ou número de passos executados, espaço ou memória utilizada) em função do tamanho da entrada do problema para a obtenção da solução.
}

Para encontrar primos que possuam esse tamanho, a aplicação de algoritmos de- 
terminísticos ${ }^{1}$ como o Crivo de Eratóstenes é inviável, pois o tempo gasto é muito grande. A solução para esse problema é utilizar algoritmos randomizados ${ }^{2}$ que forneçam números primos grandes.

A base desses algoritmos randomizados são testes de primalidade fundamentados no Pequeno Teorema de Fermat/Euler: Teorema 6 e Corolário 2.

\subsection{Teste de Primalidade}

Para os testes de primalidade, será utilizado o Pequeno Teorema de Fermat:

"Sejam $a$ e $n$ números inteiros tais que $n \nmid a$, se $a^{n-1} \not \equiv 1 \bmod n$, então $n$ é composto."

$\mathrm{Na}$ prática, o algoritmo escolhe um número natural $n$ (tão grande quanto for necessário) e um inteiro $a$, tal que $n \nmid a$, em seguida, analisa-se a congruencia $a^{n-1} \bmod p$.

Se $a^{n-1} \not \equiv 1 \bmod n$, concluí-se que $n$ é composto e passa-se para o próximo número a ser testado. Entretanto, se $a^{n-1} \equiv 1 \bmod n$, não pode-se afirmar que $n$ é primo, isso ocorre porque a recíproca do Pequeno Teorema de Fermat não é verdadeira. Um contra exemplo:

$7^{24} \equiv 1 \bmod 25$, porém 25 é um número composto.

Sempre que um número $n$ não é primo e satisfaz o Pequeno Teorema de Fermat para uma base $a, n$ é chamado de pseudoprimo na base $a$.

Sempre que $a^{n-1} \equiv 1 \bmod n$, é preciso decidir se $n$ é primo ou se é um pseudoprimo na base $a$, para isso, escolhe-se outra base $b$ e testa-se se $b^{n-1} \equiv 1 \bmod n$, caso $b^{n-1} \not \equiv$ $1 \bmod n$, pode-se concluir que $n$ é composto e pseudoprimo na base $a$, entretanto se $b^{n-1} \equiv 1 \bmod n$, repete-se o processo para outra base $c$.

O problema é que existem números que são pseudoprimos para todas as bases menores que $n$ que são relativamente primas com $n$, esses números são chamados de números de Carmichael, cujo menor exemplo conhecido é $561=3 \cdot 11 \cdot 17$, ou seja, $a^{560} \equiv$ 1 mod 561 para todo $a$ relativamente primo com 561. Sendo demonstrado recentemente por Alford, Granville e Pomerance que se $C N(x)$ é considerado a quantidade de números de Carmichael menores que $x$, então $C N(x) \geq x^{2 / 7}$, onde $x$ é suficientemente grande, ou seja, existem infinitos números de Carmichael, para a lista destes números de Carmichael menores que $10^{6}$ consulte ftp:/ftp.dpmms.cam.ac.uk/pub/Carmichael.

Entretanto, pseudoprimos e números de Carmichael são bem raros quando testa-se

$\overline{1}$ Usado em Ciência da Computação, é o nome do algoritmo que sempre produz o mesmo resultado dado determinadas entradas de dados.

2 são aqueles que utilizam experimentos randômicos para decidir, em um ou mais momentos durante sua execução, o que fazer ou para onde ir. Por motivo de clareza, algoritmos clássicos (nãorandomizados) são também ditos determinísticos. É possível compreender melhor sobre o assunto em http://www.impa.br/opencms/pt/biblioteca/cbm/26CBM/26CBM $7 . p d f$ 
números da ordem $10^{9}$, por exemplo, existem 50.847.534 primos de 1 até 1.000.000.000, mas apenas 5587 pseudoprimos para a base $2(0,01 \%)$, caso sejam utilizadas as bases 2 e 3 , esse número cai para $1271(0,0025 \%)$, se houver o teste de outras bases, essa porcentagem cai ainda mais.

A pequena probabilidade de um número ser pseudoprimo, quando testa-se várias bases, é o que fundamenta o teste de primalidade mais utilizado por programas de computação algébrica, o Teste de Miller-Rabin. Rabin provou que quando se testa uma base aleatória $a$, a probabilidade de que o teste acuse um pseudoprimo é menor que $\frac{1}{4}$, ou seja, se aplica o teste para $k$ bases distintas, a probabilidade de que o teste acuse um pseudoprimo é menor do que $\left(\frac{1}{4}\right)^{k}$, por exemplo, se o teste for aplicado para 10 bases distintas, a probabilidade de encontrar um pseudoprimo é igual a $\left(\frac{1}{4}\right)^{10} \simeq 0,0000954 \%$.

Esse teste está fundamentado na Hipótese de Riemman Generalizada, que afirma ser suficiente testar um número pequeno de bases para se garantir a primalidade de um número. 

CAPÍTULO

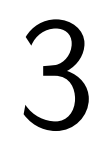

CRIPTOGRAFIA

A criptografia está no cotidiano de cada pessoa. A linguagem de escrever em códigos é usada atualmente em celulares, bancos, computadores, carros, alarmes, na internet para proteger compras on line ou seus dados bancários, dentre outros.

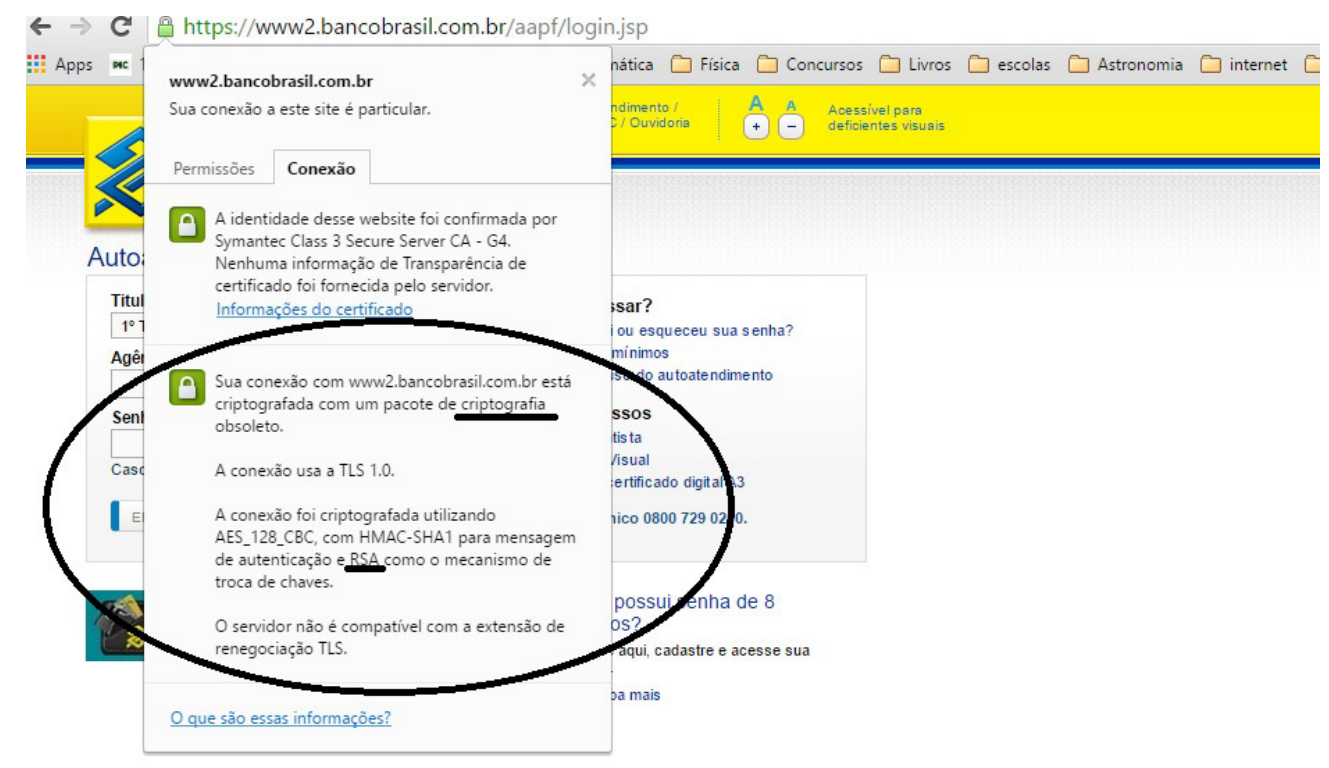

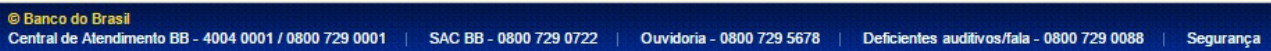

Figura 2 - Criptografia em sites

Nas figuras 2 e 3 é possível observar a criptografia em um site bancário para a proteção dos dados da conta do usuário, bem como a proteção de sua conta e seu dinheiro.

Nos carros também é encontrada a linguagem dos códigos, que pode ser usada no alarme, como na nova chave keyless que permitem a partida apenas com o acionamento de um botão (ATMEL, 2016). ${ }^{1}$

\footnotetext{
1 Fonte disponível em: http://www.atmel.com
} 


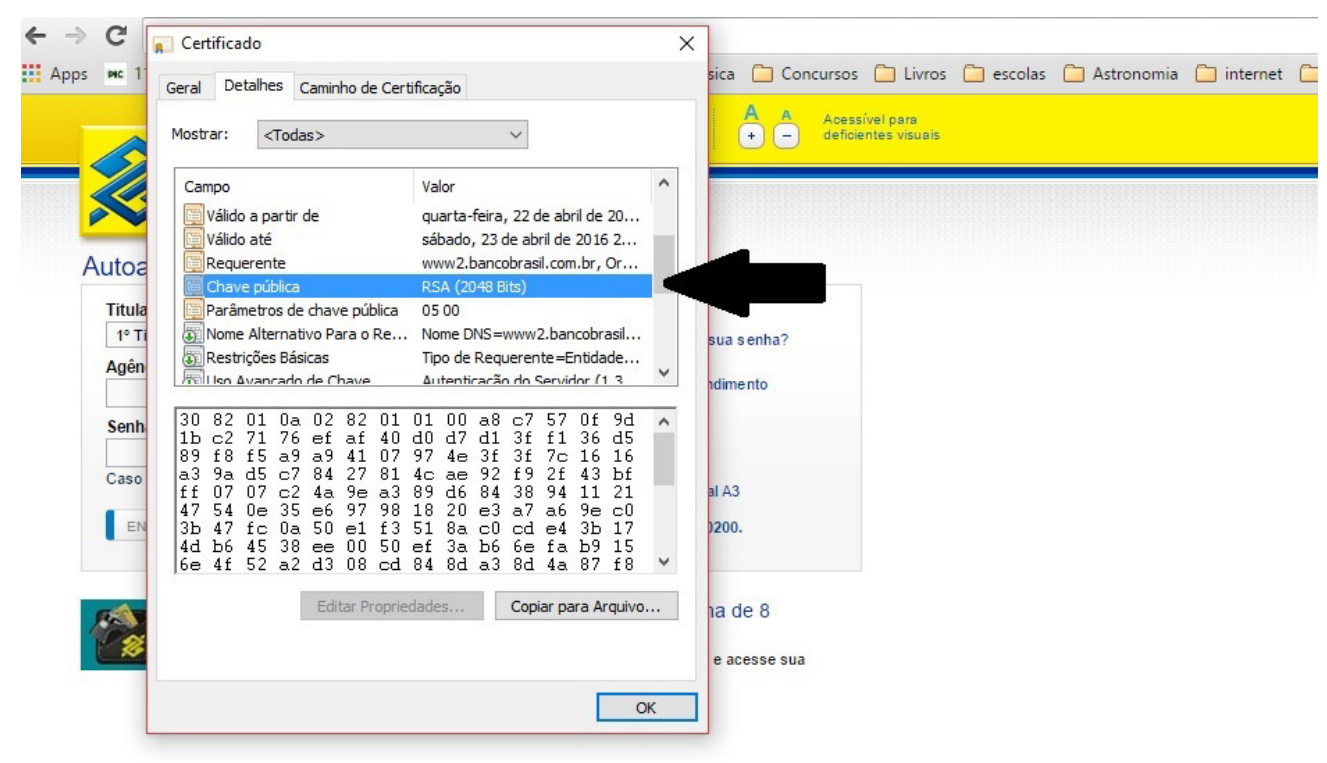

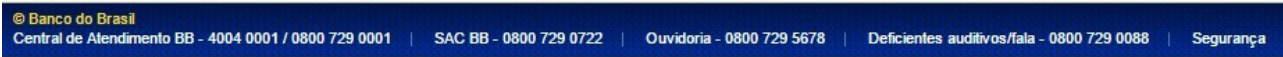

Figura 3 - Criptografia em sites

A natureza humana tem uma necessidade à privacidade, mesmo que seja para guardar simples segredos. É possível observar na história que a linguagem de códigos sempre foi muito usada como recurso militar, político, em questões comerciais, em guerras e até mesmo motivos sentimentais (SINGH, 2005).

Os indícios são que a criptografia começou a ser usada no antigo Egito quando o faraó Amenemhet II governava, por volta de 1900 a.C. pelo arquiteto Khnumhotep II. Em documentos que indicavam a localização de tesouros, o escriba de Khnumhotep II, para dificultar que ladrões os encontrassem, substituiu alguns trechos e palavras de documentos importantes por símbolos estranhos.

O filósofo Heródoto demonstrou que a criptografia já era usada há muito tempo nas guerras, um dos métodos era raspar a cabeça do mensageiro, escrever a mensagem e esperar que o cabelo crescesse novamente, mas dada a facilidade de ser descoberta houve a necessidade de ferramentas que guardassem melhor a mensagem ou de métodos mais difíceis de serem descobertos (LARCHER, 1950).

Nos séculos XVIII e XIX surgiram as Câmeras Escuras, onde a arte de quebrar códigos era usada para decifrar mensagens diplomáticas, empregando muitos matemáticos famosos, a de Viena era conhecida como a mais eficiente, quebrando cerca de 100 mensagens internacionais por dia.

Com isso os métodos foram aprimorando: escrita na madeira com cera por cima, embaralhamento das letras, Bastão de Licurgo, método de substituição (como o usado por Júlio César, imperador de Roma), disco de Alberti, máquina Enigma (Segunda Guerra 
Mundial), máquina Colossos, criptografia RSA e criptografia quântica.

A criptografia tem sido aprimorada e estado presente desde antes de Cristo, seu desenvolvimento é marcado por três grandes fases: artesanal, mecânica e digital (SINGH, 2005).

A Criptografia artesanal surge paralelamente com o surgimento da escrita, durante as idades antiga e média, onde a utilização das técnicas é fácil com lápis e papel, sendo fáceis de serem quebradas como: a de Heródoto, Bastão de Licurgo, O código de César, Cifrário de Francis Bacon, Criptoanalistas Árabes, A Cifra de Vigenère, Braille, microponto são alguns exemplos.

Inclusive Thomas Jefferson (1743-1826), que foi presidente dos Estados Unidos da América de 1801 a 1809 desenvolveu seu próprio sistema de criptografia chamado de Cilindro de Jefferson, que ele usou durante a revolução americana, onde ele precisava enviar cartas importantes por mensageiros (KAHN, 1996).

A mecânica começa no início da Idade Moderna, a partir da Revolução Industrial as máquinas tomaram conta do mundo e da criptografia, tendo seu apogeu na Segunda guerra Mundial, como o Disco de cifras, o código morse, a máquina Enigma, Colossus, etc.

Segundo Diffie e Hellman (2007, p. 39): "Antes deste século, sistemas de criptografia foram limitados a cálculos que poderiam ser realizadas à mão ou com dispositivos simples".

Depois da Primeira Guerra Mundial já era possível ver o avanço das máquinas para criptografar mensagens, inclusive como sistemas eletromecânicos, mas foi o desenvolvimento dos computadores digitais que permitiu que métodos mais seguros fossem desenvolvidos (DIFFIE; HELLMAN, 2007).

A criptografia Digital veio com o aperfeiçoamento dos computadores, fazendo cálculos extremamente grandes em pouco tempo, se tornaram uma ferramenta valiosa na criptografia, com códigos mais complicados de serem quebrados, pode-se observar a criptografia simétrica, DES, AES, IDEA, Assimétrica, RSA, ElGamal, Curvas Elípticas, dentre outras (SINGH, 2005).

Do mesmo modo que a arte de criptografar mensagens envoluiu a arte de tentar desvendá-las também, um exemplo famoso de decifração é a contagem de frequência, onde a decifração de alguns hieróglifos egípcios feitos por J.F. Champollion no ano de 1822 ficou famoso, a chave para decifrar era a pedra de Roseta, atualmente no museu Britânico, em Londres (COUTINHO, 2011).

Alguns destes métodos serão descritos abaixo. 


\subsection{Tipos}

A criptografia é usada quando o remetente pretende escrever mensagens ou textos com o objetivo de que somente a pessoa interessada na mensagem possa lê-la. Um esquema de seu funcionamento segundo Stallings (2008, p. 172):

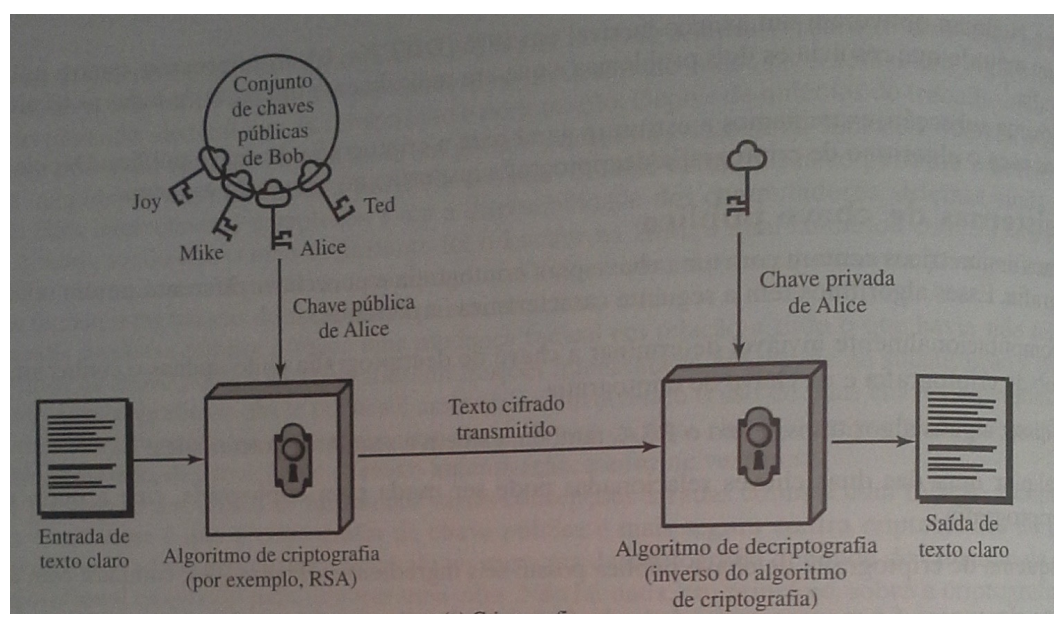

Figura 4 - Como funciona a criptografia

O texto claro é aquele que tem informação legível, o texto codificado ou texto ilegível, é aquele que foi gerado pela codificação de um texto claro. O ato de codificar ou cifrar é tranformar um texto claro em um texto ilegível, e, o ato de decodificar ou decifrar é transformar um texto codificado em um texto claro - uma mensagem pode ser quebrada, ou seja, decodificada, se aplicada as técnicas corretas.

A criptografia pode ser dividida em simétrica (convencional) e assimétrica (de chave Pública), na primeira a mesma chave que criptografa a mensagem é a que descriptografa, desta forma se uma pessoa tem a chave para criptografar uma mensagem automaticamente ela consegue descriptografar. Na segunda há uma chave para criptografar a mensagem: chave pública, e uma para descriptografar: chave privada, logo mesmo que uma pessoa tenha a chave para a criptografia da mensagem ela não consegue decodificar uma sem a outra chave: privada.

Quando há as duas chaves: pública e privada, a primeira pode ser divulgada e deve ser feita de tal forma que mesmo que uma pessoa tenha ela não conseguirá descobrir a privada. A chave privada deve permanecer em segredo, afinal é ela que decodifica a mensagem.

Quando há somente uma chave, no caso da criptografia simétrica, esta deve permanecer secreta e quem a tem pode codificar ou decodificar qualquer mensagem.

O nível de segurança de uma criptografia é medido de acordo com o número de bits, desta forma, quanto mais bits forem usados, mais difícil será quebrar a criptografia usada. 
Bit é a sigla para Binary Digit, que significa dígito binário, assim 1 bit só pode assumir dois valores: 0 ou 1, essa quantidade de valores é medida de acordo com: $2^{n}$, onde o $n$ é o número de bits. Dez bits tem assim $2^{10}$ possíveis valores.

\subsubsection{Heródoto}

Heródoto viveu de 484 a.C. a 425 a.C. e adotou alguns métodos para comunicação chamados esteganografia (derivado das palavras gregas steganos, que significa coberto, e graphein, que significa escrever) arte de ocultar o que está escrito, os que mais se destacaram foram: raspar o cabelo do mensageiro, escrever a mensagem, deixar o cabelo crescer e enviá-lo para o destino; e escrever mensagens em tabletes e cobri-los com cera (LARCHER, 1950).

Existem outros métodos de esteganografia, alguns usam processos físico-químico, como a tinta invisível, basta escrever com suco de limão sobre uma folha de papel branca, para que a mensagem apareça basta colocar a folha em contato com uma fonte de calor.

\subsubsection{Bastão de Licurgo}

Bastão de Licurgo ou Cítala foi o primeiro aparelho criptográfico militar, presente no século $\mathrm{V}$ a.C., foi usado pelos espartanos para envio de mensagens secretas.

Era formada por dois bastões de madeira de espessura semelhante e uma tira de couro (cítala) que era usada como cinto para a transmissão da mensagem.

Cada uma das varas fica em posse de um dos participantes da mensagem: uma com o mensageiro e outra com o destinatário. Para enviar a mensagem era enrolado a tira de couro de forma espiral em um dos bastões, depois se escrevia a mensagem longitudinalmente, aparecendo uma letra em cada parte da volta. Depois da mensagem escrita bastava desenrolar a tira e enviar, de posse da cítala o mensageiro enroladava a tira em seu bastão para ler a mensagem original (OLGIN, 2011).

Esta criptografia também é conhecida como cifra de transposição que pode ser aplicada com uma função bijetiva para cifrar e a sua inversa para decifrar. A figura 5, segundo (FIARRESGA, 2010, p. 47), é um exemplo de Citale Espartano.

\subsubsection{Método de César}

O próprio imperador romano, general Júlio César usava a criptografia, mais simples, para se comunicar. Ele trocava cada letra da mensagem original pela terceira letra que a segue no alfabeto, assim quem pegasse a mensagem e não soubesse o código não conseguiria lê-la (MALAGUTTI, 2015). 


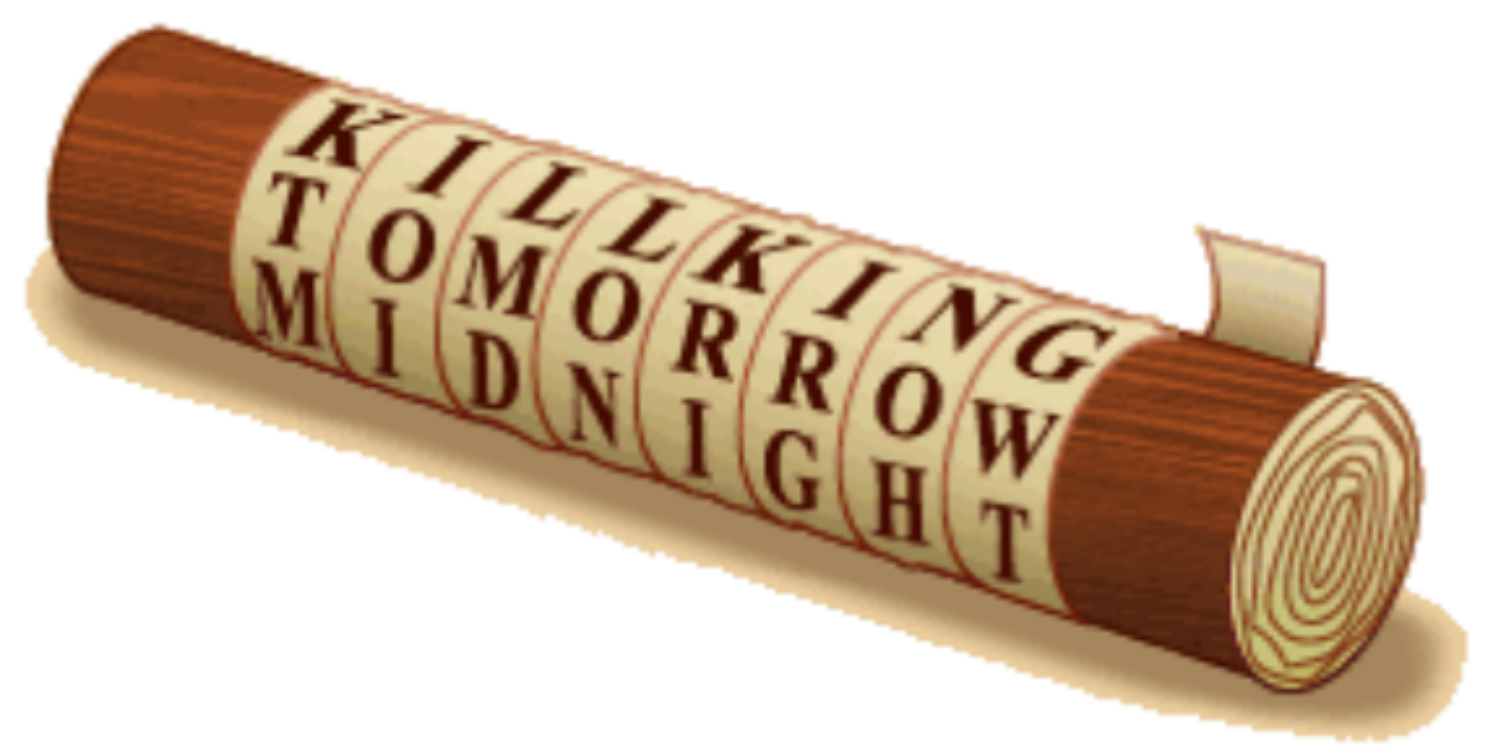

Figura 5 - Citale Espartano

Contudo esse método não é difícil de ser quebrado, isso é possível aplicando uma análise probabilística de cada letra. No Brasil, por exemplo, a letra mais usada é $a$ e a menos usada é $x$, logicamente nem todos os textos tem a letra $a$ em maior frequência, como a frase: O impossível é inexistente, nela a letra a não aparece (COUTINHO, 2008).

Mesmo assim quebrar frases criptografadas com este método são mais simples, mas às vezes pode dar muito trabalho. Observe a Figura 6 que mostra a distribuição de frequência das letras no alfabeto Brasileiro de acordo com Almeida (2015):

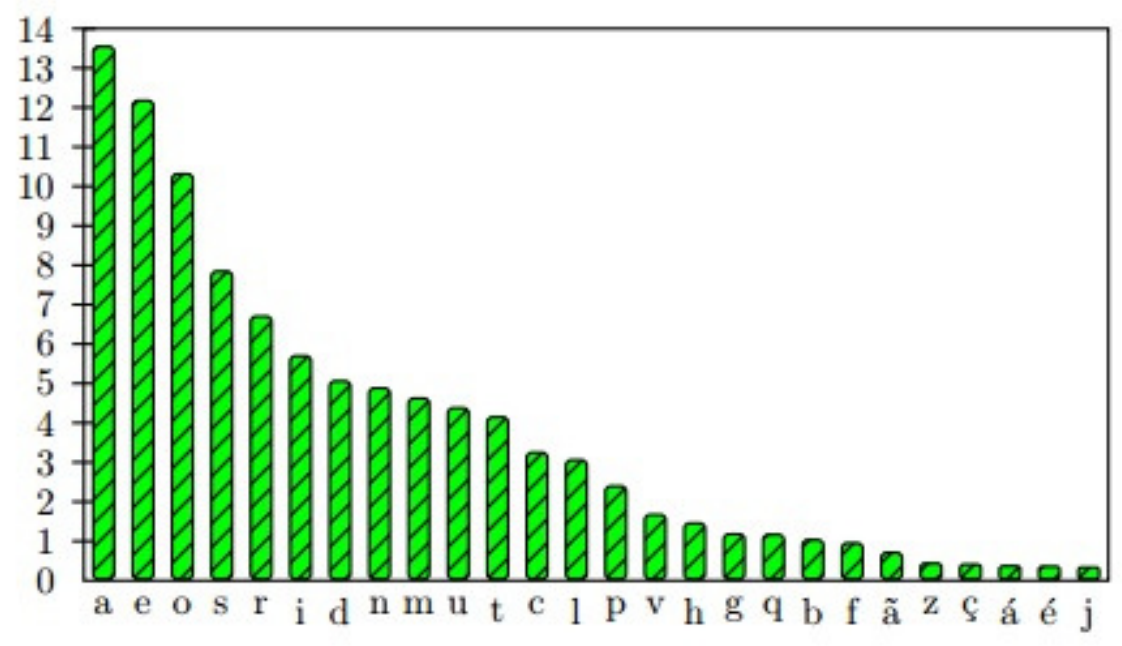

Figura 6 - Frequência das letras no alfabeto (Brasil) 


\subsubsection{Anagrama}

É possível criptografar uma mensagem retirando os espaços entre as palavras e embaralhando as letras (anagrama), ou trocar letras por números, é possível criar vários métodos, quanto mais complexo o método for mais difícil será quebrá-lo (COUTINHO, 2008).

Também conhecida como cifra de transposição, é eficaz, pois caso a frase seja muito grande torna-se quase impossível reorganizar sem que se tenha a regra, uma frase com $n$ letras têm $n$ ! modos de arranjo (lembrando que este caso é com $n$ letras distintas, pois quando há repetição o cálculo é outro), este tipo de criptografia é interessante para se trabalhar contagem com os alunos.

\subsubsection{Blaise de Vigenère}

Inventada por Giovan Batista Belaso, em 1553, é um sistema polialfabético, foi conhecida como cifra indecifrável, apesar de ser facilmente decifrada com a aplicação de análise estatística.

A cifra recebe este nome por ter sido atribuída erroneamente a Blaise de Vigenère, contudo apesar de não criá-la, ele criou a noção de auto-chave, que é usado ainda hoje (como no sistema DES).

Para criptografar uma mensagem nesta cifra usa-se a tabela (3), que é uma representação das 26 possibilidades da cifra de César, e uma palavra chave a escolha. Para criptografar repete-se a palavra escolhida em cima ou em baixo da mensagem, a letra da palavra escolhida deve ser localizada na linha e a letra da mensagem na coluna ( ou viceverso), o encontro delas corresponde à letra da mensagem criptografada, como mostrado na tabela 4 que usa a palavra chave mágica.

Na tabela 4 para criptografar a mensagem Cifra de Blaise com a palavra chave mágica relaciona-se pela tabela 3 a letra $C$ com a $m$, encontrando a letra $o$, o encontro das letras $i$ e $a$ é $i$, e assim por diante, obtendo a frase: oilzc do briksq.

\subsubsection{A cifra de Beale}

No ano de 1885 foi publicado um livro chamado The Beale Papers por James B. Ward, informando tudo sobre um tesouro que ele havia enterrado juntamente com um grupo, o qual ele chefiou, de 30 pessoas. As imagens abaixo foram tiradas de um documento publicado pela Agência Nacional de Segurança (NSA, 2015).

Beale sumiu em 1822, muitas pessoas desde então, criptoanalistas ou não, tentaram desvendar as três cifras que ele deixou, deixando a especulação de que o tesouro de Beale é uma farsa (KRUH, 1982). 


\begin{tabular}{|c|c|c|c|c|c|c|c|c|c|c|c|c|c|c|c|c|c|c|c|c|c|c|c|c|c|c|}
\hline & $\mathrm{A}$ & B & $\mathrm{C}$ & D & $\mathrm{E}$ & $\mathrm{F}$ & $\mathrm{G}$ & $\mathrm{H}$ & 1 & $J$ & $\mathrm{~K}$ & $\mathrm{~L}$ & $\mathrm{M}$ & $\mathrm{N}$ & $\mathrm{O}$ & $\mathrm{P}$ & $\mathrm{Q}$ & $\mathrm{R}$ & $\mathrm{S}$ & $\mathrm{T}$ & $\mathrm{U}$ & $\mathrm{V}$ & $\mathrm{W}$ & $\mathrm{X}$ & $Y$ & $\bar{Z}$ \\
\hline $\mathrm{A}$ & $\mathrm{A}$ & B & $\mathrm{C}$ & $\mathrm{D}$ & $\mathrm{E}$ & $\mathrm{F}$ & $\mathrm{G}$ & $\mathrm{H}$ & I & $\mathrm{J}$ & $\mathrm{K}$ & $\mathrm{L}$ & $\mathrm{M}$ & $\mathrm{N}$ & $\mathrm{O}$ & $\mathrm{P}$ & Q & $\mathrm{R}$ & $\mathrm{S}$ & $\mathrm{T}$ & $\mathrm{U}$ & $\mathrm{V}$ & W & $\mathrm{X}$ & $\mathrm{Y}$ & \\
\hline B & B & $\mathrm{C}$ & $\mathrm{D}$ & $\mathrm{E}$ & $\mathrm{F}$ & $\mathrm{G}$ & $\mathrm{H}$ & I & $\mathrm{J}$ & K & $\mathrm{L}$ & $\mathrm{M}$ & $\mathrm{N}$ & $\mathrm{O}$ & $\mathrm{P}$ & $\mathrm{Q}$ & $\mathrm{R}$ & $\mathrm{S}$ & $\mathrm{T}$ & $\mathrm{U}$ & V & W & X & $\mathrm{Y}$ & Z & \\
\hline $\mathrm{C}$ & $\mathrm{C}$ & D & $\mathrm{E}$ & $\mathrm{F}$ & $\mathrm{G}$ & $\mathrm{H}$ & I & $\mathrm{J}$ & $\mathrm{K}$ & $\mathrm{L}$ & $\mathrm{M}$ & $\mathrm{N}$ & $\mathrm{O}$ & $\mathrm{P}$ & $\mathrm{Q}$ & $\mathrm{R}$ & S & $\mathrm{T}$ & $\mathrm{U}$ & V & $\mathrm{W}$ & $\mathrm{X}$ & $\mathrm{Y}$ & Z & A & \\
\hline D & D & $\mathrm{E}$ & $\mathrm{F}$ & $\mathrm{G}$ & $\mathrm{H}$ & I & $\mathrm{J}$ & K & L & $\mathrm{M}$ & $\mathrm{N}$ & $\mathrm{O}$ & $\mathrm{P}$ & $\mathrm{Q}$ & $\mathrm{R}$ & $\mathrm{S}$ & $\mathrm{T}$ & $\mathrm{U}$ & V & W & $\mathrm{X}$ & Y & Z & A & B & \\
\hline $\mathrm{E}$ & $\mathrm{E}$ & $\mathrm{F}$ & $\mathrm{G}$ & $\mathrm{H}$ & I & $\mathrm{J}$ & K & $\mathrm{L}$ & $\mathrm{M}$ & $\mathrm{N}$ & $\mathrm{O}$ & $\mathrm{P}$ & $\mathrm{Q}$ & $\mathrm{R}$ & $\mathrm{S}$ & $\mathrm{T}$ & $\mathrm{U}$ & V & W & $\mathrm{X}$ & $\mathrm{Y}$ & Z & A & B & $\mathrm{C}$ & \\
\hline $\mathrm{F}$ & $\mathrm{F}$ & $\mathrm{G}$ & $\mathrm{H}$ & I & $\mathrm{J}$ & K & L & $\mathrm{M}$ & $\mathrm{N}$ & $\mathrm{O}$ & $\mathrm{P}$ & $\mathrm{Q}$ & $\mathrm{R}$ & S & $\mathrm{T}$ & $\mathrm{U}$ & V & $\mathrm{W}$ & $\mathrm{X}$ & $\mathrm{Y}$ & Z & A & B & $\mathrm{C}$ & D & \\
\hline $\mathrm{G}$ & $\mathrm{G}$ & $\mathrm{H}$ & I & $\mathrm{J}$ & K & $\mathrm{L}$ & $\mathrm{M}$ & $\mathrm{N}$ & $\mathrm{O}$ & $\mathrm{P}$ & $\mathrm{Q}$ & $\mathrm{R}$ & $\mathrm{S}$ & $\mathrm{T}$ & $\mathrm{U}$ & V & $\mathrm{W}$ & $\mathrm{X}$ & $\mathrm{Y}$ & Z & A & B & $\mathrm{C}$ & $\mathrm{D}$ & $\mathrm{E}$ & \\
\hline $\mathrm{H}$ & $\mathrm{H}$ & I & $\mathrm{J}$ & $\mathrm{K}$ & L & $\mathrm{M}$ & $\mathrm{N}$ & $\mathrm{O}$ & $\mathrm{P}$ & $\mathrm{Q}$ & $\mathrm{R}$ & S & $\mathrm{T}$ & $\mathrm{U}$ & V & $\mathrm{W}$ & $\mathrm{X}$ & $\mathrm{Y}$ & Z & A & B & $\mathrm{C}$ & $\mathrm{D}$ & $\mathrm{E}$ & & \\
\hline I & I & $\mathrm{J}$ & $\mathrm{K}$ & $\mathrm{L}$ & $\mathrm{M}$ & $\mathrm{N}$ & $\mathrm{O}$ & $\mathrm{P}$ & $\mathrm{Q}$ & $\mathrm{R}$ & S & $\mathrm{T}$ & $\mathrm{U}$ & V & $\mathrm{W}$ & $\mathrm{X}$ & Y & Z & A & B & $\mathrm{C}$ & D & $\mathrm{E}$ & $\mathrm{F}$ & $\mathrm{G}$ & \\
\hline $\mathrm{J}$ & $\mathrm{J}$ & $\mathrm{K}$ & L & $\mathrm{M}$ & $\mathrm{N}$ & $\mathrm{O}$ & $\mathrm{P}$ & $\mathrm{Q}$ & $\mathrm{R}$ & $\mathrm{S}$ & $\mathrm{T}$ & $\mathrm{U}$ & V & $\mathrm{W}$ & $X$ & $\mathrm{Y}$ & Z & A & B & $\mathrm{C}$ & D & $\mathrm{E}$ & $\mathrm{F}$ & G & $\mathrm{H}$ & \\
\hline K & $\mathrm{K}$ & L & $\mathrm{M}$ & $\mathrm{N}$ & $\mathrm{O}$ & $\mathrm{P}$ & $\mathrm{Q}$ & $\mathrm{R}$ & $\mathrm{S}$ & $\mathrm{T}$ & $\mathrm{U}$ & V & W & X & $\mathrm{Y}$ & Z & A & B & $\mathrm{C}$ & D & $\mathrm{E}$ & $\mathrm{F}$ & $\mathrm{G}$ & $\mathrm{H}$ & I & \\
\hline $\mathrm{L}$ & $\mathrm{L}$ & $\mathrm{M}$ & $\mathrm{N}$ & $\mathrm{O}$ & $\mathrm{P}$ & $\mathrm{Q}$ & $\mathrm{R}$ & S & $\mathrm{T}$ & $\mathrm{U}$ & V & $\mathrm{W}$ & $\mathrm{X}$ & Y & Z & A & B & $\mathrm{C}$ & D & $\mathrm{E}$ & $\mathrm{F}$ & $\mathrm{G}$ & $\mathrm{H}$ & & $J$ & \\
\hline $\mathrm{M}$ & $\mathrm{M}$ & $\mathrm{N}$ & $\mathrm{O}$ & $\mathrm{P}$ & $\mathrm{Q}$ & $\mathrm{R}$ & S & $\mathrm{T}$ & $\mathrm{U}$ & V & W & $\mathrm{X}$ & $\mathrm{Y}$ & Z & A & B & C & $\mathrm{D}$ & $\mathrm{E}$ & $\mathrm{F}$ & $\mathrm{G}$ & $\mathrm{H}$ & & $\mathrm{J}$ & K & \\
\hline $\mathrm{N}$ & $\mathrm{N}$ & $\mathrm{O}$ & $\mathrm{P}$ & $\mathrm{Q}$ & $\mathrm{R}$ & S & $\mathrm{T}$ & $\mathrm{U}$ & $\mathrm{V}$ & W & $\mathrm{X}$ & $\mathrm{Y}$ & Z & A & B & C & $\mathrm{D}$ & $\mathrm{E}$ & $\mathrm{F}$ & $\mathrm{G}$ & $\mathrm{H}$ & & J & $\mathrm{K}$ & $\mathrm{L}$ & \\
\hline $\mathrm{O}$ & $\mathrm{O}$ & $\mathrm{P}$ & $\mathrm{Q}$ & $\mathrm{R}$ & $\mathrm{S}$ & $\mathrm{T}$ & $\mathrm{U}$ & $\mathrm{V}$ & W & $\mathrm{X}$ & $\mathrm{Y}$ & Z & A & B & $\mathrm{C}$ & $\mathrm{D}$ & $\mathrm{E}$ & $\mathrm{F}$ & $\mathrm{G}$ & $\mathrm{H}$ & I & $\mathrm{J}$ & K & L & $\mathrm{M}$ & \\
\hline $\mathrm{P}$ & $\mathrm{P}$ & $\mathrm{Q}$ & $\mathrm{R}$ & S & $\mathrm{T}$ & $\mathrm{U}$ & V & W & $\mathrm{X}$ & $\mathrm{Y}$ & Z & A & B & $\mathrm{C}$ & $\mathrm{D}$ & $\mathrm{E}$ & $\mathrm{F}$ & $\mathrm{G}$ & $\mathrm{H}$ & & $J$ & K & L & $\mathrm{M}$ & $\mathrm{N}$ & \\
\hline $\mathrm{Q}$ & $\mathrm{Q}$ & $\mathrm{R}$ & S & $\mathrm{T}$ & $\mathrm{U}$ & V & W & $X$ & $\mathrm{Y}$ & $\mathrm{Z}$ & A & B & $\mathrm{C}$ & D & $\mathrm{E}$ & $\mathrm{F}$ & $\mathrm{G}$ & $\mathrm{H}$ & I & $\mathrm{J}$ & $\mathrm{K}$ & L & $\mathrm{M}$ & $\mathrm{N}$ & $\mathrm{O}$ & \\
\hline $\mathrm{R}$ & $\mathrm{R}$ & S & $\mathrm{T}$ & $\mathrm{U}$ & $\mathrm{V}$ & W & $\mathrm{X}$ & $\mathrm{Y}$ & $\mathrm{Z}$ & $A$ & B & C & $\mathrm{D}$ & $\mathrm{E}$ & $\mathrm{F}$ & $\mathrm{G}$ & $\mathrm{H}$ & & $\mathrm{J}$ & $\mathrm{K}$ & $\mathrm{L}$ & $\mathrm{M}$ & $\mathrm{N}$ & $\mathrm{O}$ & $\mathrm{P}$ & \\
\hline S & S & $\mathrm{T}$ & $\mathrm{U}$ & $\mathrm{V}$ & W & $\mathrm{X}$ & $\mathrm{Y}$ & Z & A & B & C & D & $\mathrm{E}$ & $\mathrm{F}$ & $\mathrm{G}$ & $\mathrm{H}$ & & & K & $\mathrm{L}$ & $\mathrm{M}$ & $\mathrm{N}$ & $\mathrm{O}$ & $\mathrm{P}$ & $\mathrm{Q}$ & \\
\hline $\mathrm{T}$ & $\mathrm{T}$ & $\mathrm{U}$ & V & W & $\mathrm{X}$ & $\mathrm{Y}$ & Z & A & B & C & $\mathrm{D}$ & $\mathrm{E}$ & $\mathrm{F}$ & $\mathrm{G}$ & $\mathrm{H}$ & I & $\mathrm{J}$ & K & $\mathrm{L}$ & $\mathrm{M}$ & $\mathrm{N}$ & $\mathrm{O}$ & $\mathrm{P}$ & $\mathrm{Q}$ & $\mathrm{R}$ & \\
\hline $\mathrm{U}$ & $\mathrm{U}$ & V & W & $\mathrm{X}$ & $\mathrm{Y}$ & $\mathrm{Z}$ & A & B & $\mathrm{C}$ & $\mathrm{D}$ & $\mathrm{E}$ & $\mathrm{F}$ & $\mathrm{G}$ & $\mathrm{H}$ & I & $\mathrm{J}$ & K & L & $\mathrm{M}$ & $\mathrm{N}$ & $\mathrm{O}$ & $\mathrm{P}$ & $\mathrm{Q}$ & $\mathrm{R}$ & S & \\
\hline $\mathrm{V}$ & $\mathrm{V}$ & W & $X$ & Y & $\mathrm{Z}$ & A & B & $\mathrm{C}$ & D & $\mathrm{F}$ & $\mathrm{F}$ & $\mathrm{G}$ & $\mathrm{H}$ & I & $\mathrm{J}$ & $\mathrm{K}$ & $\mathrm{L}$ & M & $\mathrm{N}$ & $\mathrm{O}$ & $\mathrm{P}$ & $\mathrm{Q}$ & $\mathrm{R}$ & & $\mathrm{T}$ & \\
\hline W & V & $\mathrm{X}$ & $\mathrm{Y}$ & $\mathrm{Z}$ & $\mathrm{A}$ & B & C & D & $\mathrm{F}$ & $F$ & $\mathrm{G}$ & $\mathrm{H}$ & I & & $\mathrm{K}$ & $\mathrm{L}$ & $\mathrm{M}$ & $\mathrm{N}$ & $\mathrm{O}$ & $\mathrm{F}$ & $\mathrm{Q}$ & $\mathrm{R}$ & S & T & $\mathrm{U}$ & \\
\hline $\mathrm{X}$ & $\mathrm{X}$ & $\mathrm{Y}$ & Z & A & B & C & $\mathrm{D}$ & E & $\mathrm{F}$ & $c$ & $\mathrm{H}$ & 1 & . & $\mathrm{K}$ & $\mathrm{L}$ & $\mathrm{M}$ & $\mathrm{N}$ & $\mathrm{O}$ & $\mathrm{P}$ & $\mathrm{Q}$ & $\mathrm{R}$ & S & $\mathrm{T}$ & $\mathrm{U}$ & $\mathrm{V}$ & \\
\hline $\mathrm{Y}$ & Y & Z & A & B & C & $\mathrm{D}$ & $\mathrm{E}$ & $\mathrm{F}$ & G & $\mathrm{H}$ & I & $\mathrm{J}$ & $\mathrm{K}$ & L & $\mathrm{M}$ & $\mathrm{N}$ & $\mathrm{O}$ & $\mathrm{P}$ & $\mathrm{Q}$ & $\mathrm{R}$ & S & $\mathrm{T}$ & $\mathrm{U}$ & V & $\mathrm{W}$ & \\
\hline Z & $\mathrm{Z}$ & A & B & $\mathrm{C}$ & $\mathrm{D}$ & $\mathrm{E}$ & $\mathrm{F}$ & $\mathrm{G}$ & $\mathrm{H}$ & 1 & $\mathrm{~J}$ & $\mathrm{~K}$ & $\mathrm{~L}$ & $\mathrm{M}$ & $\mathrm{N}$ & $\mathrm{O}$ & $\mathrm{P}$ & $\mathrm{Q}$ & $\mathrm{R}$ & S & $\mathrm{T}$ & $\mathrm{U}$ & V & $\mathrm{W}$ & $\mathrm{X}$ & \\
\hline
\end{tabular}

Tabela 3 - Tabela para Cifra de Blaise de Vigenère

\begin{tabular}{|r|ccccc|cc|cccccc|}
\hline Mensagem & C & i & f & r & a & d & e & B & l & a & i & s & e \\
\hline Palavra chave & m & a & g & i & c & a & m & a & g & i & c & a & m \\
\hline Mensagem & o & i & l & z & c & d & o & b & r & i & k & s & q \\
\hline
\end{tabular}

Tabela 4 - Criptografando com a Cifra de Blaise

Nas figuras 7, 8 e 9 é possível observar suas mensagens cifradas que ainda não foram decifradas.

É possível encontrar vários documentos sobre este caso no site: www.nsa.gov, em Declassification and Transparency (NSA, 2016).

\subsubsection{Braille}

A linguagem Braille também é uma maneira de codificação, foi desenvolvido como um método de escrita para que as pessoas com deficiência visual possam ler através do sentido do tato. O criador foi Louis Braille, um francês que com três anos de idade perdeu a visão após um ferimento no olho que infeccionou.

Esta linguagem consiste em um arranjo $3 \times 2$ de pontos, dispostos como uma pedra de dominó:

De acordo com a localização do ponto ou pontos em auto relevo é possível decodificar a mensagem, na figura 10, por exemplo, é representado a letra $A$, onde apenas o primeiro ponto da primeira coluna é em relevo. Observe a Figura 10 (Disponível na Apostila 10 - Atividades de contagem a partir da criptografia - do Programa de Iniciação 


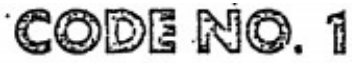

This codo-which a eryptographic team elaims it has partially deciphered -describes tho exact locality of the vauk vitiere the tressure is buried

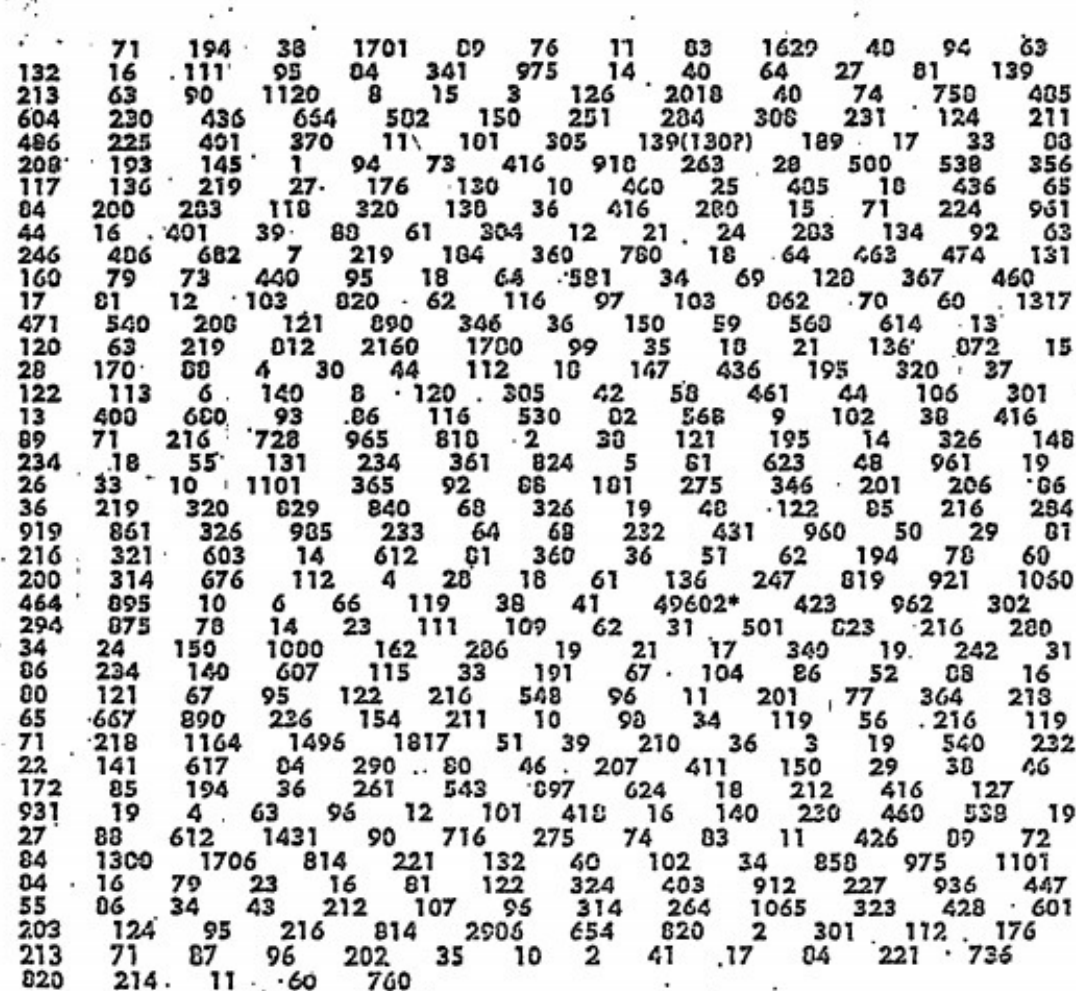

Figura 7 - Cifra 1

\section{COD更 NO. 2}

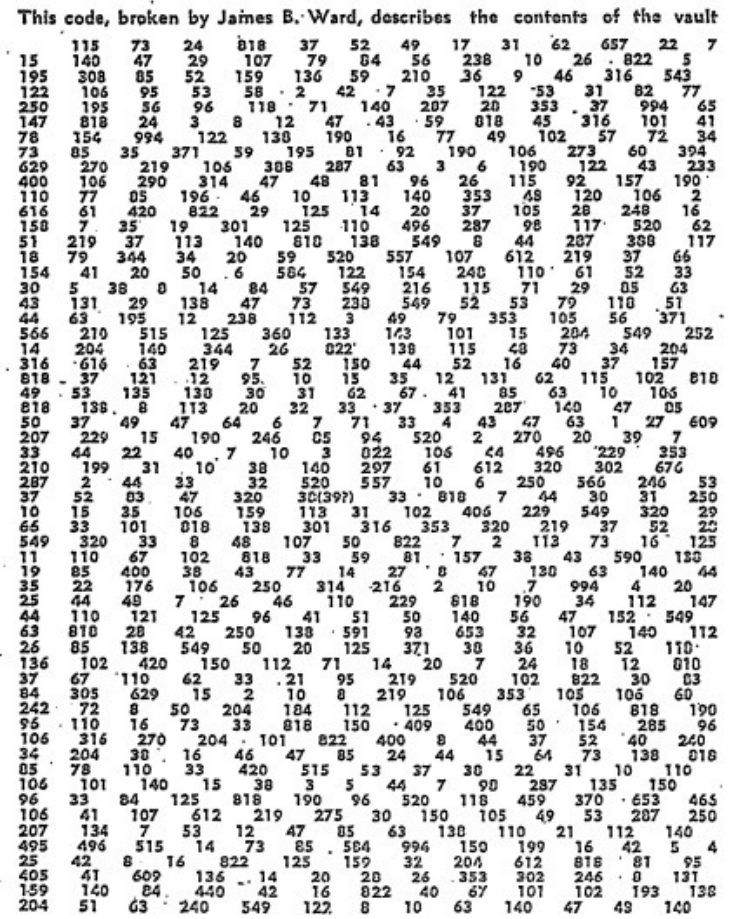

Figura 8 - Cifra 2 


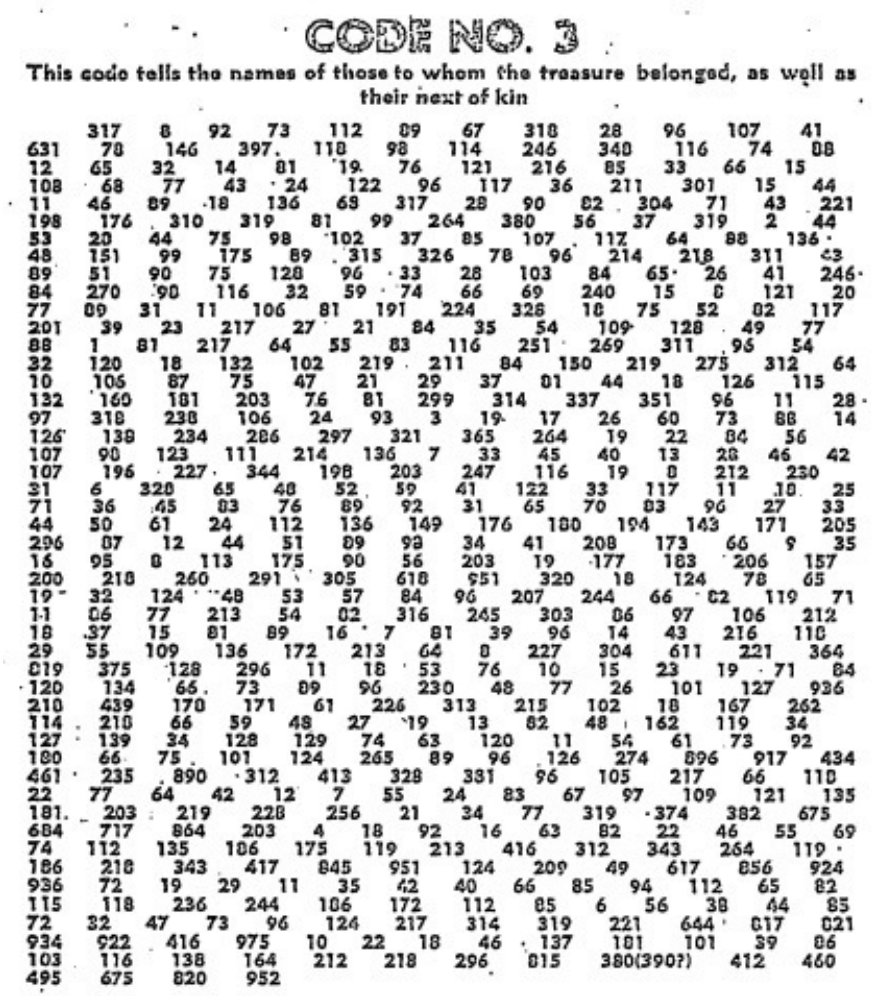

Figura 9 - Cifra 3

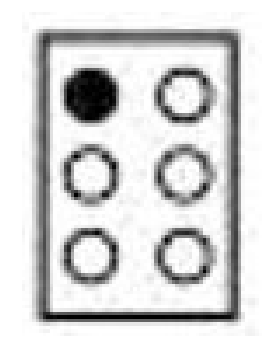

Figura $10-3 \times 2$ - Três linhas por duas colunas

Científica OBMEP, Malagutti (2015, p. 45)) :

O Instituto Benjamin Constant oferece cursos e informações sobre o assunto (BRASIL, 2016).

\subsubsection{Disco de Alberti}

O disco de Alberti ou Disco de Cifras, foi a primeira máquina criptográfica, criada por Leon Battista Alberti em 1466, que ficou conhecido como "O pai da criptologia Ocidental"por ter criado a substituição polialfabética, método que permite que diferentes símbolos cifrados representem o mesmo símbolo no texto.

Criou também o método de recifragem, onde ele fabricou uma tabela com combinações possíveis dos números 1, 2, 3 e 4, com valores entre 11 e 4444, obtendo 336 grupos. Estes eram utilizados como um dicionário de códigos que correspondia a uma palavra, 


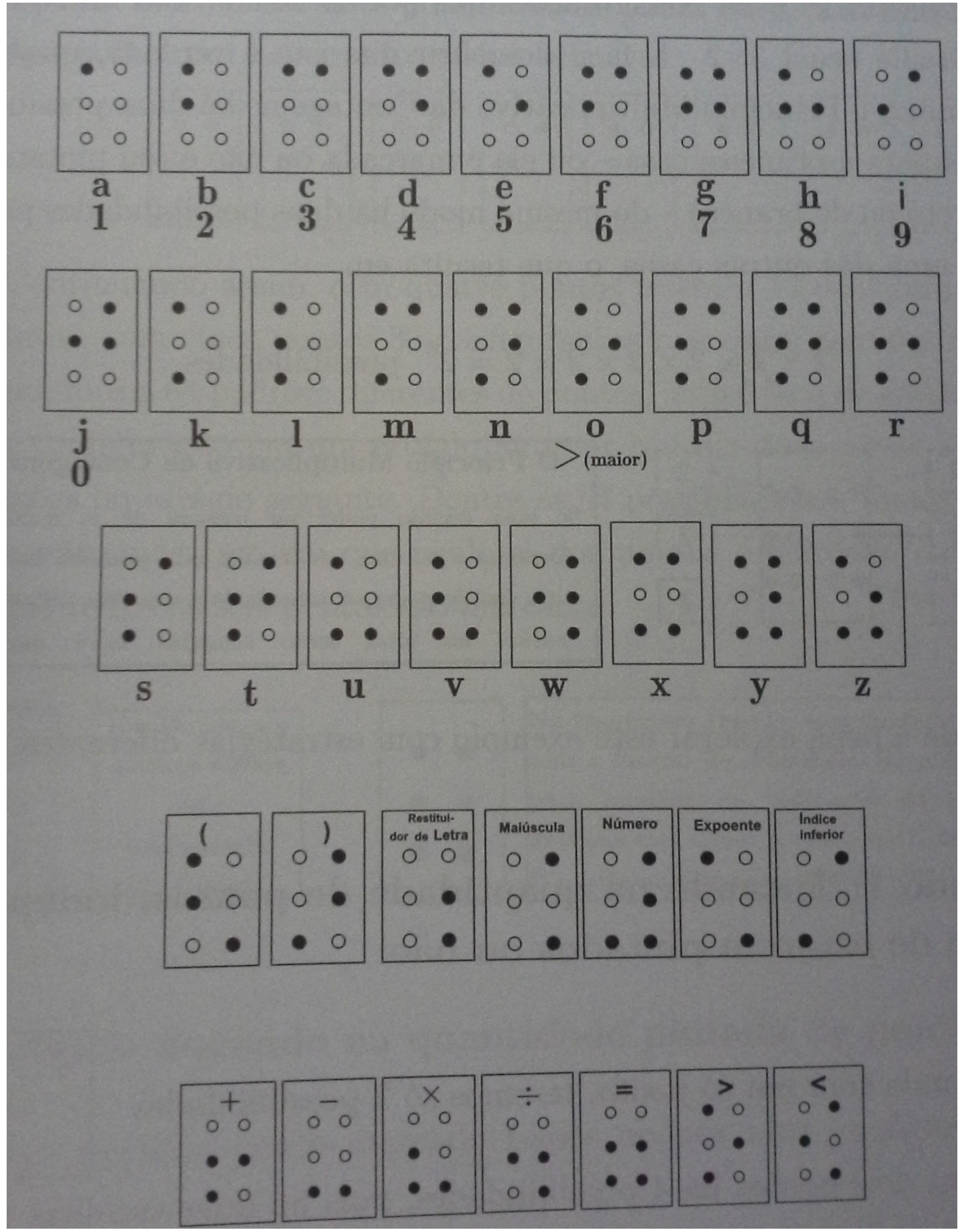

Figura 11 - Tabela de consulta para letras e números em Braille

quando aparecia em um texto era substituída pelo número e criptografada novamente junto com a mensagem.

O disco é uma das cifras mais seguras, composto por dois anéis concentricos, onde o externo é fixo e contém 24 casas (20 letras latinas maiúsculas em ordem alfabética e os números 1, 2, 3 e 4) que corresponderá ao texto claro, e o anél interno móvel com 24 letras minúsculas desordenadas para o texto cifrado. 
Fixada uma letra maiúscula como índice, o disco deve ser ajustado e a frase cifrada, podendo ser trocada a qualquer momento no texto se escrevendo uma nova letra maiúscula cifrante, indicando ao destinatário que o disco deve ser movido novamente, os números servem de nulos, ou seja, não tem significado prático na mensagem, são apenas para confundir ou dificultar a quebra do código, eles também podem servir para uma nova chave (indicando ao destinatário com antecendência qual deles significaria a nova chave), este método acelerava o trabalho de criptografar ou descriptografar mensagens e reduzia erros (SINGH, 2005).

No site http://www.numaboa.com.br/criptografia/127-substituicao-polialfabetica/164alberti é possível encontrar um aplicativo que cifra mensagens pelo método do Disco de Alberti (TKOTZ, 2016).

\subsubsection{Máquina Enigma}

Foi uma série de máquinas de cifra, patenteada em 1918 por Arthur Scherbius, desenvolvida quando percebeu-se que o sistema criptográfico da Alemanha estava atrasado, embora não tenha sido atrativa em um primeiro momento, após várias modificações conquistou a marinha alemã em 1926 (Enigma-D), e o exército com sua própria versão (Enigma G) em 1928. Seu funcionamento é baseado em rotores, em uma combinação de sistemas mecânicos e elétricos (WINTERBOTHAM, 1978).

Na Segunda Guerra Mundial, foi usada pela Alemanha, Itália e Japão (Eixo) para enviar mensagens codificadas que eram facilmente interceptadas, mas difícil de serem quebradas, impedindo que Inglaterra, Estados Unidos, França e URSS (Aliados) soubessem de seus planos.

Segundo WINTERBOTHAM (1978) até então era usado um livro de códigos que relacionava palavras ou frases com números, mas não eram considerados completamente secretos, já que se um fosse capturado todas as mensagens podiam ser decifradas.

Havia também o bloco com folhas descartáveis, que era um auxiliar ao livro de códigos, ele indicava números a serem somados na mensagem, cada página usada deveria ser destruída, mas se tornou inviável para ser utilizado em grande escala e com muita frequência.

A máquina Enigma se tornou um grande instrumento de guerra, muitos criptógrafos foram contratados para tentar quebrar seu código, pois isso seria decisivo. Apesar dos esforços o código só foi quebrado em 1933 com a ajuda de uma máquina eletromecânica, desenvolvida por Alan Turing e Gordon Welchman, durante o trabalho em Bletchley Park, juntamente com os poloneses.

Recentemente (2015) foi lançado um filme: O Jogo da Imitação, baseado na vida do matemático Alan Turing, mostrando como ele e sua equipe do Bletchley Park deci- 
fraram a Máquina enigma na Segunda Gerra Mundial. Foi adaptado de um livro Alan Turing: The Enigma escrito por Andrew Hodges, sendo criado um site com notas do autor: http://www.turing.org.uk/.

Contudo a vida de Alan Turing já havia sido parcialmente retratada no filme Breaking the Code de 1996, dirigido por Herbert Wise, e no filme Codebreaker de Clare Beavan e Nic Stacey, lançado em 2011.

\subsubsection{Máquina Colossus}

Projetado em 1943 por Tommy Flowers, engenheiro elétrico, foi um computador digital eletrônico usado na Segunda Guerra Mundial para quebrar códigos da máquina de cifras Lorenz SZ-40, uma das muitas máquinas usadas pelo governo alemão para criptografar suas mensagens. Tinha mais de 1700 válvulas e é referido muitas vezes como o primeiro computador.

Após o fim da guerra muitas desta máquinas foram destruídas, mas em 1991 começou o pensamento de que era possível reconstruir Colossus de modo totalmente operacional.

No site http://www.cryptomuseum.com/crypto/colossus/index.htm é possível encontrar uma das poucas fotos tiradas dela.

\subsubsection{Código Morse}

É a representação das letras e números em forma de sinais de pontuação (ponto e traço). Foi desenvolvido por Samuel Morse em 1835, também inventor do telégrafo.

É um código fácil de ser enviado, pois pode ser utilizado pulsos elétricos transmitidos por um cabo, ondas mecânicas, sinais visuais ou ondas eletromagnéticas, o receptor reconhece quatro estados: voltagem-ligada longa (traço), voltagem-ligada curta (ponto), voltagem-desligada longa (espaço entre caracteres e palavras) e voltagem-desligada curta (espaço entre pontos e traços).

\subsubsection{Sistema Binário}

O sistema binário, usado em computadores, é outra forma de codificação, existe uma forma especial para este código chamada de American Standard Code for Information Interchange, sendo referida como ASCII (completo ou extendido) muito usada em microprocessadores onde o número $x$ de bits informa a quantidade de caracteres diferentes que podem ser usados aplicando: $2^{x}$ (SCOTTI; FERREIRA, 2011).

A ASCII relaciona cada letra do alfabeto com uma sequência de sete dígitos, zeros ou uns, mais um para verificação de erro (paridade), totalizando 8 bits. 


\begin{tabular}{|c|c|c|c|c|c|}
\hline $\begin{array}{c}\text { Letras } \\
\text { A }\end{array}$ & $\begin{array}{c}\text { Código Internacional } \\
\text {-- }\end{array}$ & $\begin{array}{c}\text { Letra } \\
\mathrm{N}\end{array}$ & $\begin{array}{c}\text { Código Internacional } \\
-.\end{array}$ & $\begin{array}{c}\text { Número } \\
1\end{array}$ & $\begin{array}{c}\text { Código Internacional } \\
\text {. - - - - }\end{array}$ \\
\hline B & $-\ldots$ & $\mathrm{O}$ & -- & 2 & .. - - \\
\hline $\mathrm{C}$ &.-- & $\mathrm{P}$ &.- & 3 & $\ldots{ }^{--}$ \\
\hline $\mathrm{D}$ &..- & Q &.--- & 4 & $\ldots . .-$ \\
\hline $\mathrm{E}$ & . & $\mathrm{R}$ &.- & 5 & $\ldots \ldots$ \\
\hline $\mathrm{F}$ & ..-. & S & $\ldots$ & 6 & $-\ldots$. \\
\hline G & -- & $\mathrm{T}$ & - & 7 & $--\ldots$ \\
\hline $\mathrm{H}$ & $\ldots$ & $\mathrm{U}$ &.${ }^{-}$ & 8 &..--- \\
\hline I & -- & V & ..- & 9 & $-\cdots$ \\
\hline $\mathrm{J}$ &.-- & $\mathrm{W}$ &.-- & 0 & $-\cdots$ \\
\hline K &.-- & $\mathrm{X}$ &..-- & & \\
\hline $\mathrm{L}$ &...- & $\mathrm{Y}$ &..$-^{-}$ & & \\
\hline $\mathrm{M}$ & -- & $\mathrm{Z}$ &..-- & & \\
\hline
\end{tabular}

Tabela 5 - Código Morse

O Data Encryption Standard (DES) foi criado pela International Business Machines (IBM) em 1977, permitia 72 quadrilhões de combinações (56 bits) e foi o algoritmo simétrico mais difuso no mundo até que foi padronisado a AES.

A Advanced Encryption Standard (AES) veio a partir de 2001, aplicada nas conexões de Wi-Fi, tem o tamanho de 128 bits, mas suas chaves variam de 128, 192 ou 256 bits, ficou popular por ser rápido, fácil de ser executado e ocupar pouca memória.

Ao se observar a história é possível ver que essa cifra surgiu com Francis Bacon, filósofo do século XVI, contudo ao invéz de 0 e 1 ele utilizava as letras $a$ e $b$, em um grupo de 5 caracteres ( 5 bits) que foi publicada no livro VI, capítulo I do The Advancement of Learning (ROSS, 1996).

\title{
3.2 RSA
}

O sistema mais usado e mais conhecido atualmente é o de criptografia RSA, que segundo Coutinho (2011, p. 3):

\begin{abstract}
Este código foi inventado em 1978 por R. L. Rivest, A. Shamir e L. Adleman, que na época trabalhavam no Massachussets Institute or Technology (M.I.T.). As letras RSA correspondem às iniciais dos inventores do código. Há vários outros códigos de chave pública, mas o RSA é, atualmente, o mais usado em aplicações comerciais. Este é o método utilizado, por exemplo, no Netscape, o mais popular dos softwares de navegação da Internet (COUTINHO, 2011, p. 3).
\end{abstract}

Existe diferença entre a criptografia convencional e a de chave pública (exemplo RSA), segundo Stallings (2008, p. 173) elas estão descritas na tabela 6 .

No site http://demonstrations.wolfram.com é possível encontrar programas que codificam e decodificam mensagens tanto no método de César quanto no de RSA. 


\begin{tabular}{|c|c|}
\hline Criptografia convencional & Criptografia de chave pública \\
\hline Necessário para funcionar: & Necessário para funcionar: \\
\hline $\begin{array}{l}\text { O mesmo algoritmo com a mesma } \\
\text { chave é usado para criptografia e des- } \\
\text { criptografia. }\end{array}$ & $\begin{array}{l}\text { Um algoritmo é usado para criptografia } \\
\text { e descriptografia com um par de chaves, } \\
\text { uma para criptografia e outra para des- } \\
\text { criptografia. }\end{array}$ \\
\hline $\begin{array}{l}\text { O emissor e o receptor precisam com- } \\
\text { partilhar o algoritmo e a chave. }\end{array}$ & $\begin{array}{l}\text { O emissor e o receptor precisam ter } \\
\text { uma das chaves do par casado de cha- } \\
\text { ves (não a mesma chave). }\end{array}$ \\
\hline Necessário para a segurança: & Necessário para a segurança: \\
\hline A chave precisa permanecer secreta. & $\begin{array}{l}\text { Uma da duas chaves precisa permane- } \\
\text { cer secreta. }\end{array}$ \\
\hline $\begin{array}{l}\text { Deverá ser impossível ou pelo menos } \\
\text { impraticável decifrar uma mensagem se } \\
\text { nenhuma outra informação estiver dis- } \\
\text { ponível. }\end{array}$ & $\begin{array}{l}\text { Deverá ser impossível ou pelo menos } \\
\text { impraticável decifrar uma mensagem se } \\
\text { nenhuma outra informação estiver dis- } \\
\text { ponível. }\end{array}$ \\
\hline $\begin{array}{l}\text { O conhecimento do algoritmo, com } \\
\text { amostras do texto cifrado precisam ser } \\
\text { insuficientes para determinar a chave. }\end{array}$ & $\begin{array}{l}\text { O conhecimento do algoritmo, com } \\
\text { uma das chaves, e amostras do texto } \\
\text { cifrado precisam ser insuficientes para } \\
\text { determinar a outra chave. }\end{array}$ \\
\hline
\end{tabular}

Tabela 6 - Criptografia convencional e de chave pública

\subsubsection{Como Funciona?}

O método de criptografia RSA funciona do seguinte modo:

1. Escolhe-se dois primos $p$ e $q$, distintos entre si.

2. Define-se $N=p q$ e $\varphi_{(N)}=(p-1)(q-1)$.

3. Deve-se escolher um número $e$, que faz parte da chave Pública, de forma que o máximo divisor comum (mdc) entre ele e $\varphi_{(N)}$ seja 1: $\left(e, \varphi_{(N)}\right)=1$ e $1<e<\varphi_{(N)}$.

4. Resolvendo a congruência $e d \equiv 1\left(\bmod \varphi_{(N)}\right)$ encontra-se $d$, que faz parte da chave Privada.

5. De acordo com uma tabela pré formulada e de domínio público é feita a transformação de todos os caracteres da mensagem em números (nesta tabela todos os números devem ter a mesma quantidade de dígitos), obtendo-se a mensagem numérica em um único bloco que será dividida em blocos $b$, de forma que: $1 \leq b<N$. Isso garante que ao utilizar congruência obtenha-se um único resultado na decodificação.

6. De posse da Chave Pública $(e, N)$ criptografa-se os blocos $b$ de acordo com a congruência: $b^{e} \equiv C(b)(\bmod N)$, onde $C(b)$ é a mensagem criptografada. 
7. De posse da Chave Privada $(d, N)$ descriptografa-se de acordo com a congruência: $C(b)^{d} \equiv D(C(b))(\bmod N)$, onde $D(C(b))$ é a mensagem descriptografada, $1 \leq$ $D(C(b))<N$.

8. Cada bloco $D(C(b))$ deve ser colocado em sequência e de acordo com a mesma tabela usada no ítem 5 os números devem ser convertidos em caracteres.

Exemplo 3. Neste exemplo será usado números primos menores, que facilitem o cálculo com o uso de uma calculadora comum. Dado os primos $p$ e $q$ da forma $6 n+5$, sendo $p=11$ e $q=17$, pode-se obter $N=11 \times 17=187$ e $\varphi_{N}=(11-1) \times(17-1)=160$.

Dada a tabela abaixo:

\begin{tabular}{|c|c|c|c|c|c|c|c|c|c|}
\hline $\mathrm{A}$ & $\mathrm{B}$ & $\mathrm{C}$ & $\mathrm{D}$ & $\mathrm{E}$ & $\mathrm{F}$ & $\mathrm{G}$ & $\mathrm{H}$ & $\mathrm{I}$ & $\mathrm{J}$ \\
21 & 22 & 23 & 24 & 25 & 26 & 27 & 28 & 29 & 31 \\
\hline $\mathrm{K}$ & $\mathrm{L}$ & $\mathrm{M}$ & $\mathrm{N}$ & $\mathrm{O}$ & $\mathrm{P}$ & $\mathrm{Q}$ & $\mathrm{R}$ & $\mathrm{S}$ & $\mathrm{T}$ \\
32 & 33 & 34 & 35 & 36 & 37 & 38 & 39 & 41 & 42 \\
\hline $\mathrm{U}$ & $\mathrm{V}$ & $\mathrm{W}$ & $\mathrm{X}$ & $\mathrm{Y}$ & $\mathrm{Z}$ & & & & \\
43 & 44 & 45 & 46 & 47 & 48 & & & & \\
\hline 0 & 1 & 2 & 3 & 4 & 5 & 6 & 7 & 8 & 9 \\
49 & 51 & 52 & 53 & 54 & 55 & 56 & 57 & 58 & 59 \\
\hline
\end{tabular}

Tabela 7 - Tabela Para Conversão

O valor de $e$ deve ser escolhido de modo que $\left(e, \varphi_{N}\right)=1$, deste modo será escolhido o número 3 e $d$ deverá seguir a congruência $e d \equiv 1\left(\bmod \varphi_{N}\right)$, assim:

$$
3 d \equiv 1(\bmod 160)
$$

Deste modo $160 k=3 d-1 \Leftrightarrow 1=3 d-160 k$, resolvendo pelo método do algoritmo de Euclides:

$$
160=3 \times 53+1 \Leftrightarrow 1=160-3 \times 53 .
$$

Como o valor de $d$ não pode ser negativo e as soluções desta equação são: $d=$ $-53+160 t$ e $k=-1-3 t$ :

$$
-53+160 t>0 \Leftrightarrow t>\frac{53}{160}
$$

Substituindo $t=1$ tem-se o menor valor possível para $d$ que é 107 . Deste modo já tem-se a chave para Ciptografar $(e, N)=(3,187)$ e para Descriptografar $(d, N)=$ $(107,187)$.

A mensagem é "CHAVE", primeiro é preciso transformar as letras em números de acordo com a tabela, assim tem-se $\mathrm{C}=23, \mathrm{H}=28, \mathrm{~A}=21, \mathrm{~V}=44$ e $\mathrm{E}=25$. Ficando: $23-28-21-44-25$. 
A mensagem deve ser separada em blocos $b$ de modo que cada bloco tenha números menores que 187. Como os primos escolhidos são pequenos, os blocos também devem ser, assim:

$$
2328214425=2-32-82-14-42-5
$$

Para codificar a mensagem usaremos a chave $(3,187)$ e a congruência $b^{e} \equiv C(b) \bmod N$ :

$$
\begin{gathered}
2^{3} \equiv C\left(b_{1}\right) \bmod N \Leftrightarrow C\left(b_{1}\right)=8 \\
32^{3} \equiv C\left(b_{2}\right) \bmod N \Leftrightarrow 32^{3} \equiv 32768 \bmod N \Leftrightarrow C\left(b_{2}\right)=43 \\
82^{3} \equiv C\left(b_{3}\right) \bmod N \Leftrightarrow 82^{3} \equiv 551368 \bmod N \Leftrightarrow C\left(b_{3}\right)=92 \\
14^{3} \equiv C\left(b_{4}\right) \bmod N \Leftrightarrow 14^{3} \equiv 2744 \bmod N \Leftrightarrow C\left(b_{4}\right)=126 \\
42^{3} \equiv C\left(b_{5}\right) \bmod N \Leftrightarrow 42^{3} \equiv 74088 \bmod N \Leftrightarrow C\left(b_{5}\right)=36 \\
5^{3} \equiv C\left(b_{6}\right) \bmod N \Leftrightarrow 5^{3} \equiv 125 \bmod N \Leftrightarrow C\left(b_{6}\right)=125
\end{gathered}
$$

O bloco codificado será:

$$
8-43-92-126-36-125 \text {. }
$$

Para decodificar é preciso da chave $(107,187)$ e da congruência:

$$
C(b)^{d} \equiv D(C(b)) \bmod N
$$

Como 107 é um número primo e usá-lo como expoente faz com que não seja possível usar uma calculadora comum será usado algumas propriedades de congruência citadas na Proposição 14.

Para decodificar o primeiro bloco: 8 deve-se usar:

$$
8^{107} \equiv D(C(b)) \bmod 187
$$

Assim como $107=3 \times 7 \times 5+2$ temos:

$$
8^{3} \equiv 512 \equiv 138 \bmod 187
$$

Pelo ítem 5 da Proposição 14:

$$
\left(8^{3}\right)^{5} \equiv 138^{5} \bmod 187
$$

e

$$
138^{5}=138^{2} \times 138^{2} \times 138=19044 \times 19044 \times 138,
$$

então:

$$
8^{15} \equiv 138^{5} \equiv 138^{2} \times 138^{2} \times 138 \bmod 187
$$




$$
\begin{gathered}
\Leftrightarrow 8^{15} \equiv 19044 \times 19044 \times 138 \bmod 187 \\
\Leftrightarrow 8^{15} \equiv 157 \times 157 \times 138 \bmod 187,
\end{gathered}
$$

pois

$$
19044 \equiv 157 \bmod 187
$$

Portanto

$$
\begin{gathered}
3401562 \equiv 32 \bmod 187 \\
\Leftrightarrow 8^{15} \equiv 32 \bmod 187 .
\end{gathered}
$$

Ainda,

$$
\begin{gathered}
\Leftrightarrow\left(8^{15}\right)^{7} \equiv 32^{7} \equiv 32^{3} \times 32^{3} \times 32 \bmod 187 \\
\Leftrightarrow 8^{105} \equiv 32768 \times 32768 \times 32 \equiv 43 \times 43 \times 32 \bmod 187 \\
\Leftrightarrow 8^{105} \equiv 59168 \equiv 75 \bmod 187 .
\end{gathered}
$$

Finalmente conclui-se que

$$
\begin{gathered}
\Leftrightarrow 8^{105} \times 8^{2} \equiv 76 \times 8^{2} \equiv 4864 \equiv 2 \bmod 187 . \\
\Leftrightarrow 8^{107} \equiv 2 \bmod 187 .
\end{gathered}
$$

Contudo com este método é gasto muito tempo e deve-se fazer muitos cálculos, um modo mais fácil é usar o Teorema Chinês do Resto.

Assim como sabe-se que $N=187=11 \times 17$, pelo Teorema 2 tem-se que:

$$
p \mid a^{p-1}-1 \Leftrightarrow a^{p-1} \equiv 1 \bmod p .
$$

Desta forma:

$$
8^{10} \equiv 1 \bmod 11
$$

e

$$
8^{16} \equiv 1 \bmod 17
$$

Assim:

$$
\begin{gathered}
\left(8^{10}\right)^{10} \equiv 1^{10} \bmod 11 \\
8^{100} \times 8^{7} \equiv 1 \times 8^{7} \equiv 2 \bmod 11 \\
8^{107} \equiv 2 \bmod 11
\end{gathered}
$$

e

$$
\begin{gathered}
\left(8^{16}\right)^{6} \equiv 1^{6} \bmod 17 \\
8^{96} \times 8^{5} \equiv 1 \times 8^{5} \bmod 17 \\
8^{101} \equiv 9 \bmod 17
\end{gathered}
$$




$$
\begin{gathered}
8^{101} \times 8^{5} \equiv 9 \times 8^{5} \equiv 9 \times 9 \equiv 13 \bmod 17 \\
8^{106} \times 8 \equiv 13 \times 8 \equiv 2 \bmod 17 \\
8^{107} \equiv 2 \bmod 17
\end{gathered}
$$

Substituindo $8^{107}$ por x tem-se um sistema de congruências:

$$
\begin{aligned}
& x \equiv 2 \bmod 11 \\
& x \equiv 2 \bmod 17 .
\end{aligned}
$$

Pelo Teorema Chinês do Resto:

$$
\begin{gathered}
M=11 \times 17=187 \\
M_{1}=\frac{187}{11}=17 \\
M_{2}=\frac{187}{17}=11
\end{gathered}
$$

Assim:

$$
\begin{gathered}
17 y_{1} \equiv 1 \bmod 11 \\
\Leftrightarrow y_{1}=2
\end{gathered}
$$

e:

$$
\begin{gathered}
11 y_{2} \equiv 1 \bmod 17 \\
\Leftrightarrow y_{2}=14 \\
X=17 \times 2 \times 2+11 \times 14 \times 2+t 187 \\
X=376+t 187 .
\end{gathered}
$$

O menor valor de $X$ no conjunto dos naturais para a equação é com $t=-2$, desta forma $X=2$.

Obtem-se assim o primeiro bloco decodificado. Para obter o segundo bloco decodificado o processo é o mesmo.

Repetindo o processo em todos os blocos será obtido a mensagem decodificada: 2 32 - 82 - 14 - 42 - 5. Como é conhecido a Tabela 7, basta reagrupar a mensagem e trocar os números pelas letras voltando à mensagem "CHAVE".

Exemplo 4. Para resolver este exemplo foi usado o software MAXIMA, que é livre e gratuito, pois os cálculos necessários não são feitos por uma calculadora normal e à mão levaria muito tempo.

Dado os primos $p$ e $q$ da forma $6 n+5$, sendo $p=857$ e $q=2207$, pode-se obter $N=857 \times 2207=1891399$ e $\varphi_{N}=(857-1) \times(2207-1)=1888336$. 
Considere a Tabela 7 já usada no Exemplo 1.

O valor de $e$ deve ser escolhido de modo que $\left(e, \varphi_{N}\right)=1$. Vejamos algumas opções: $3,5,7,11,13,15,17,19,25,29,31,35,55 \ldots$ O valor escolhido será $e=3$.

Para obter $d$ é preciso utilizar a congruência:

$$
e d \equiv 1\left(\bmod \varphi_{(N)}\right)
$$

Substituindo, temos:

$$
3 \times d \equiv 1(\bmod 1888336)
$$

ou seja $3 d-1=1888336 k \Leftrightarrow 3 d-1888336 k=1$.

Logo recaímos em uma equação diofantina, com solução nos inteiros já que $(3,1888336)=$ $1 \mid 1$.

Assim resolvendo a equação diofantina:

$$
\begin{gathered}
1888336=3 \times 629445+1 \\
\Leftrightarrow 1888336-3 \times 629445=1 .
\end{gathered}
$$

Logo, pela Proposição 9 as soluções para $d$ e $k$ nos inteiros é dada por: $d=$ $-629445+1888336 t$ e $k=1-3 t$. Contudo quer-se números inteiros positivos para $d$ desta forma:

$$
-629445+1888336 t>0
$$

encontra-se que $t>0,33 \ldots$ Substituindo $t$ por 1 obtem-se: $d=1258891$.

A chave Pública

$$
(e, N) \Rightarrow(3,1891399)
$$

e a chave Privada

$$
(d, N) \Rightarrow(1258891,1891399)
$$

Com a chave Pública será codificada a mensagem:

$$
\text { NÚMER0S D0M1N4M } 0 \text { MUND0. }
$$

De acordo com a tabela 7 a mensagem ficará:

$$
3543342539494124493451355434493443352449
$$

será dividida em blocos de três dígitos ficando: 354 - 334 - 253 - 949 - 412 - 449 - 345 135 - 543 - 449 - $344-335-244-9$. 
Bloco 354:

$354^{3} \equiv 859687 \bmod (1891399$.

Assim o primeiro bloco será: 859687.

Do mesmo modo:

Bloco 334:

$334^{3} \equiv 1323123 \bmod (1891399)$

Bloco 253:

$253^{3} \equiv 1063085 \bmod (1891399)$

Bloco 949:

$949^{3} \equiv 1649400 \bmod (1891399)$

Bloco 412:

$412^{3} \equiv 1844164 \bmod (1891399)$

Bloco 449:

$449^{3} \equiv 1623096 \bmod (1891399)$

Bloco 345:

$345^{3} \equiv 1344246 \bmod (1891399)$

Bloco 135:

$135^{3} \equiv 568976 \bmod (1891399)$

Bloco 543:

$543^{3} \equiv 1225491 \bmod (1891399)$

Bloco 449:

$449^{3} \equiv 1623096 \bmod (1891399)$

Bloco 344:

$344^{3} \equiv 988205 \bmod (1891399)$

Bloco 335:

$335^{3} \equiv 1658794 \bmod (1891399)$

Bloco 244:

$244^{33} \equiv 1286991 \bmod (1891399)$

Bloco 9:

$9^{3} \equiv 729 \bmod (1891399)$

Mensagem codificada: 859687 - 1323123 - 1063085 - 1649400 - 1844164 - 1623096

- 1344246 - 568976 - 1225491 - 1623096 - 988205 - 1658794 - 1286991 - 729.

Para decodificar a mensagem é preciso usar a chave Privada $(1258891,1891399)$. 
Para o primeiro bloco:

$859687^{1258891} \equiv 354 \bmod (1891399)$.

Fazendo todo o processo inverso volta-se à mensagem criptografada:

354 - 334 - 253 - 949 - 412 - 449 - 345 - 135 - 543 - 449 - 344 - 335 - 244 - 9

$\Rightarrow 3543342539494124493451355434493443352449$

$\Rightarrow 35-43-34-25-39-49-41-24-49-34-51-35-54-34-49-34-43-35-$ $24-49$

$\Rightarrow$ NÚMER0S D0M1N4M 0 MUND0

\subsubsection{Por que funciona?}

Mas por que o método funciona?

A mensagem $b$ deve ser igual à mensagem decodificada $D(C(b))$. De acordo com o processo:

$$
\begin{gathered}
b^{e} \equiv C(b) \bmod N, \\
C(b)^{d} \equiv D(C(b)) \bmod N, \\
e d \equiv 1 \bmod \varphi_{(N)},
\end{gathered}
$$

em que $N=p q, \varphi_{(N)}=(p-1)(q-1)$. Como $b<N, D(C(b))<N$, para provar que a criptografia RSA funciona é suficiente verificar que $D(C(b)) \equiv b \bmod N$ se verifica. Pela Proposição 14, quinto item e usando as equações (3.1) e (3.2), temos que:

$$
\left(b^{e}\right)^{d} \equiv D(C(b)) \bmod N
$$

De acordo com a equação (3.3), existe inteiro $k$ tal que

$$
e d=k \varphi_{(N)}+1 .
$$

Usando (3.4):

$$
b^{k \varphi_{(N)}+1} \equiv D(C(b)) \bmod N
$$

Se $p \mid b$ implica que

$$
b \equiv 0 \bmod p,
$$

então:

$$
b^{e d} \equiv 0 \bmod p .
$$


Implicando assim que

$$
b^{e d} \equiv b \bmod p
$$

provando que

$$
D(C(b)) \equiv b \bmod p
$$

Analogamente se $q \mid b$. Agora, supondo que $p$ e $q$ não dividam $b$, pelo Pequeno Teorema de Fermat tem-se que

$$
b^{p-1} \equiv 1 \bmod p
$$

e

$$
b^{q-1} \equiv 1 \bmod q
$$

o que implica

$$
\left(b^{(p-1)}\right)^{(q-1)} \equiv 1^{(q-1)} \bmod p,
$$

e

$$
\left(b^{(q-1)}\right)^{(p-1)} \equiv 1^{(p-1)} \bmod q .
$$

Usando (3.8) e (3.9), e o item 2 da Proposição 15, temos que

$$
b^{\varphi_{(N)}} \equiv 1 \bmod p q
$$

e $\log O$

$$
\left(b^{\varphi_{(N)}}\right)^{k} b \equiv b \bmod N .
$$

Usando transitividade e (3.5) obtem-se

$$
b \equiv D(C(b)) \bmod N \text {. }
$$

Logo a mensagem $b$ é igual à mensagem decodificada $D(C(b))$.

\subsubsection{Segurança}

Para quebrar o código é preciso ter a chave de decodificação $(d, N)$, acontece que a chave pública $(e, N)$ já fornece parte do que é preciso, a saber, o número $N$. Assim é preciso apenas encontrar $d$ e ter a mensagem em mãos.

O número $N$ é igual ao produto de dois números primos $p$ e $q$ que foram escolhidos, assim é preciso encontrar a fatoração de $N$ para que $p$ e $q$ sejam achados e assim encontrar $\left.\varphi_{(} N\right)=(p-1)(q-1)$, para que resolva-se a congruência $\left.e d \equiv 1 \bmod \varphi_{(} N\right)$, encontrando $d$. 
Parece simples, mas não é, na realidade é inviável já que não existe computadores rápidos o suficientes, nem algoritmos tão bons que nos permitam fatorar um número inteiro muito grande que não tenha fatores pequenos.

É preciso, neste caso, dar significado à palavra grande: o quão grande deve ser $N$ ? O RSA Laboratory pertence à uma empresa que detém os direitos do sistema de codificação RSA, já lançou desafios para a fatoração de possíveis chaves, uma delas com 193 algarismos foi finalizada no ano de 2005 por F. Bahr, M. Boehm, J. Franke e T. Kleinjung no Escritório Federal de Segurança de Informação da Alemanha. Eles usaram 80 computadores de $2.2 \mathrm{GHz}$ cada um, levando 5 meses para a tarefa.

Há chaves maiores, podendo chegar à 2467 algarismos.

De acordo com Garrett (2017) o novo Sunway TaihuLight é um supercomputador da China, o mais poderoso do mundo com mais de dez milhões de núcleos de processamento, sendo assim ele pode fazer 93 quatrilhões de cálculos por segundo, e tudo isso fabricado na China.

Existe uma listagem destes supercomputadores onde China e Estados Unidos lideram, com 167 e 165 computadores cada, respectivamente, no Brasil há 4 deles e o mais poderoso está no 265 lugar. 
CAPÍTULO

\section{4}

\section{APLICAÇÕES DA CRIPTOGRAFIA RSA NO PROGRAMA DE INICIAÇÃO CIENTÍFICA OBMEP}

A aula foi ministrada aos alunos do $10^{\circ}$ Programa de Iniciação Científica Júnior (PIC), Polo Passos - MG, da Olimpíada Brasileira de Matemática das Escolas Públicas (OBMEP).

Nesta turma em particular todos os estudantes já haviam feito o curso pelo menos uma vez anteriormente, assim a explicação da matéria podia ser mais aprofundada, pois muitos conteúdos eles já haviam tido uma introdução.

A programação do Grupo 4 deste ano traz Criptografia e Teoria dos Números nos três primeiros encontros, como mostra na figura 12 .

Como a turma é misturada, todos os alunos participaram da explanação dos conteúdos programados para os dois grupos, o planejamento do grupo 3 também aborda conhecimentos de Teoria dos Números, como é possível ver na figura 13.

A aula foi ministrada no encontro 6, depois de ter sido abordado todos os conteúdos básicos para se compreender Criptografia RSA.

\subsection{Planejamento}

Primeiramente foi apresentado um resumo da história da criptografia com a cifra de César, que é mais simples, para isso foi usada as apostilas 7: Criptografia de Severino Collier Coutinho, a apostila 10: Atividades de contagem a partir da Criptografia de Pedro Luiz Malagutti, disponíveis no site http://www.obmep.org.br/.

Depois foi falado um pouco sobre os tópicos: 
$10^{\circ}$ PIC (2015) - G4
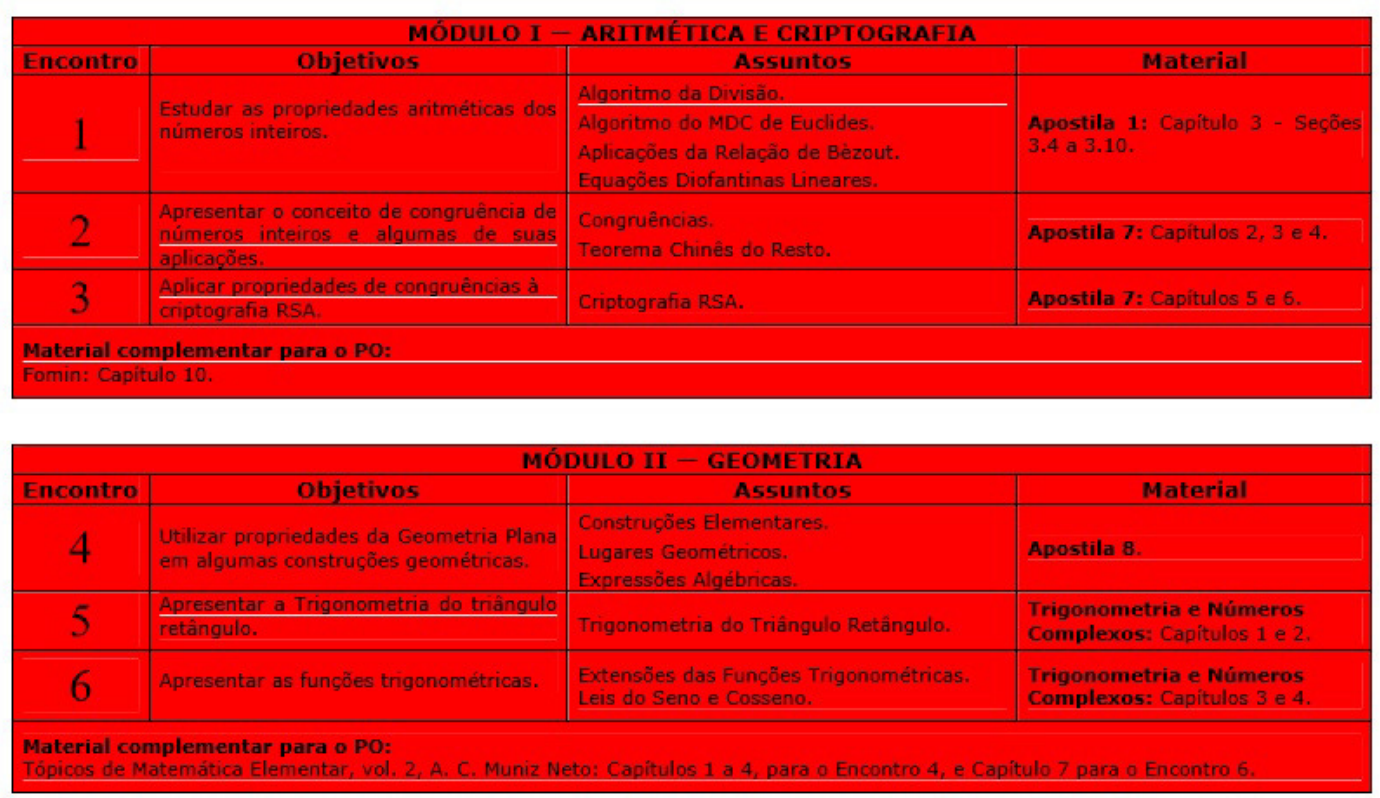

Programação do PIC 2015

Figura 12 - Programação dos Primeiros Encontros do G4

Grupo 3: Programação do PIC 2015 - G3

\begin{tabular}{|c|c|c|c|c|}
\hline \multicolumn{5}{|c|}{ MÓDULO I －ARITMÉTICA ELEMENTAR } \\
\hline Encontro & Objetivos & Assuntos & Material & $\begin{array}{c}\text { Vídeos do } \\
\text { YouTube/DVD do PIC }\end{array}$ \\
\hline 1 & $\begin{array}{l}\text { Compreender formalmente o } \\
\text { conjunto dos números naturais } \\
\mathrm{e} \text { as principais propriedades } \\
\text { algébricas de seus elementos. } \\
\text { Entender o sistema decimal } \\
\text { posicional e suas associações } \\
\text { com critérios de divisibilidade. } \\
\text { Compreender formalmente } \\
\text { conceito de números primos e } \\
\text { sua associação com o Teorema } \\
\text { Fundamental da Aritmética. }\end{array}$ & $\begin{array}{l}\text { Números naturais. Sistema } \\
\text { decimal posicional. Múltiplos e } \\
\text { divisores. Critérios de } \\
\text { divisibilidade: } 2,3,5,9 \text { e } 10 . \\
\text { Potenciação. Números primos e o } \\
\text { Crivo de Erastóstenes. O Teorema } \\
\text { Fundamental da Aritmética. }\end{array}$ & $\begin{array}{l}\text { Apostila 1: Capítulos } 1 \text { e } \\
2 . \\
\text { Fomin: Capítulo } 3 \text { - Seção } \\
3.1 \text {. } \\
\text { OBS. No livro do Fomin, } \\
\text { capítulo } 8 \text {, há vários } \\
\text { problemas que envolvem } \\
\text { os conteúdos abordados } \\
\text { nesse encontro. }\end{array}$ & $\begin{array}{l}2,10,33,34,40 \text { e } 41 \\
\text { (Aritmética) }\end{array}$ \\
\hline 2 & $\begin{array}{l}\text { Compreender formalmente } \\
\text { conjunto dos inteiros e } \\
\text { propriedades algébricas de seus } \\
\text { elementos, em especial os } \\
\text { algoritmos da divisão e de } \\
\text { Euclides. Modelar e resolver } \\
\text { problemas utilizando equações } \\
\text { diofantinas lineares. }\end{array}$ & $\begin{array}{l}\text { Números inteiros (múltiplos, } \\
\text { divisores, algoritmo da divisão, } \\
\text { paridade, MMC, MDC). Algoritmo } \\
\text { de Euclides. Relação de Bezout. } \\
\text { Equações diofantinas lineares. }\end{array}$ & $\begin{array}{l}\text { Apostila 1: Capítulo } 3 . \\
\text { Fomin: Capitulo } 3 \\
\text { Seções } 3.1,3.2 \text { e } 3.4 ; \\
\text { Capitulo } 10-\text { Seção } 10.3 \text {. } \\
\text { OBS. No livro do Fomin, } \\
\text { Capítulo } 8 \text {, há vários } \\
\text { problemas que envolvem } \\
\text { os conteúdos abordados } \\
\text { neste encontro. }\end{array}$ & $\begin{array}{l}3,8,9,1021,22,23, \\
24,25,26,28,32,38 \\
\text { (Aritmética) }\end{array}$ \\
\hline 3 & $\begin{array}{l}\text { Entender formalmente o } \\
\text { conceito de congruência e suas } \\
\text { propriedades operacionais. } \\
\text { Utilizar congruência para } \\
\text { abordar alguns critérios de } \\
\text { divisibilidade: } 6,7,11 \text { e } 13 . \\
\text { Determinar restos via } \\
\text { congruências. Analisar casos } \\
\text { especiais de equações } \\
\text { diofantinas não lineares. }\end{array}$ & $\begin{array}{l}\text { Aritmética dos restos e critérios } \\
\text { de divisibilidade. Equações } \\
\text { diofantinas. }\end{array}$ & $\begin{array}{l}\text { Apostila 1: Capítulo } 4 . \\
\text { Fomin: Capítulo } 10- \\
\text { Seçốes 10.1, } 10.2 \text { e } 10.3 \text {. } \\
\text { OBS: No livro do Fomin, } \\
\text { Capitulo 8, há vários } \\
\text { problemas que envolvem } \\
\text { os conteúdos abordados } \\
\text { neste encontro. }\end{array}$ & $\begin{array}{l}28,29,30,35,42,43, \\
44,45,51,52 \text { e } 53 \\
\text { (Aritmética) }\end{array}$ \\
\hline
\end{tabular}

Figura 13 - Programação dos Primeiros Encontros do G3

1. a máquina enigma, usada na Segunda Guerra Mundial para as comunicações nazistas, e o site http://www.numaboa.com.br/criptografia/dispositivos/861-enigma que 
tem um simulador on line da máquina enigma onde é possível codificar mensagens, mas não decodificá-las;

2. O código morse;

3. codificação binária ASCII;

4. e, um breve resumo dos outros tipos de criptografia ao longo da história que estão presentes neste trabalho

Foi apresentado a criptografia RSA e um pouco de sua história, assim como onde ela é usada (foi mostrado sites de bancos e de compras), o porque ela funciona, como ela funciona e porque ela é segura, sendo feita as demostrações necessárias.

Foi discutido também as formas de se encontrar os números primos, onde foi apresentado o site http://primes.utm.edu/largest.html e os Problemas do Prémio Millennium (Hipótese de Riemann).

\subsection{A aplicação}

O Exemplo 1 da Seção 2.2 foi feito passo-a-passo com os alunos. A turma então foi dividida em duas equipes e para cada uma foi dada uma mensagem simples para que eles decodifiquem. Com as respostas em mãos foi dada a elas uma segunda mensagem que não pode ser resolvida apenas com calculadora (Exemplo 2), mas sim com algum software como, por exemplo, o MAXIMA.

Nesta parte da aula os alunos discutiram a importância dos recursos eletrônicos e foi apresentado o programa MAXIMA. Alguns deles cursam Técnico em Informática integrado ao Ensino Médio no Institudo Federal do Sul de Minas (IFSul), então foi uma conversa muito rica.

\subsection{MAXIMA}

O programa MAXIMA pode ser baixado gratuitamente, a versão usada foi a 5.30.0. Existe um tutorial em http://maxima.sourceforge.net. É possível usá-lo como auxiliar na criptografia RSA, além de outros campos como funções e matriz. Para mostrar como ele é usado será mostrado a resolução do Exemplo 2.

Depois de escolhido os números primos, é possível encontrar o produto com o comando: $p * q$, conforme a figura 14, onde $p$ e $q$ são os números primos escolhidos, depois é só dar enter ou a combinação de teclas [Shift][Enter].

É possível encontrar $\varphi_{N}$ de forma parecida como na figura 15 . 


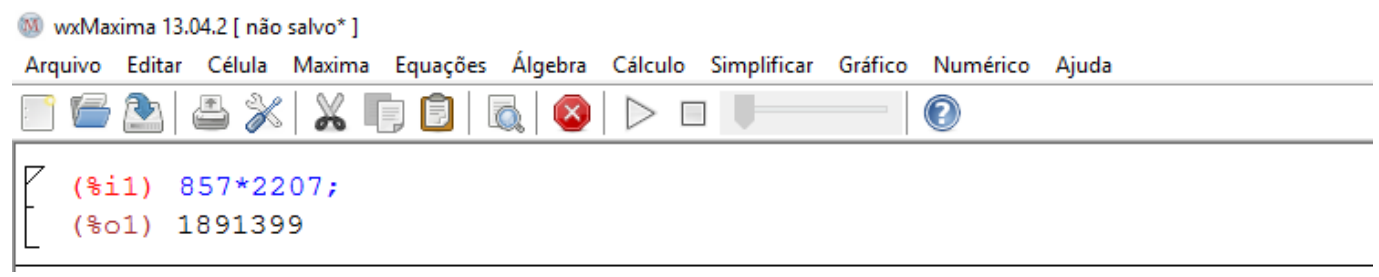

Figura 14 - Encontrando $N$

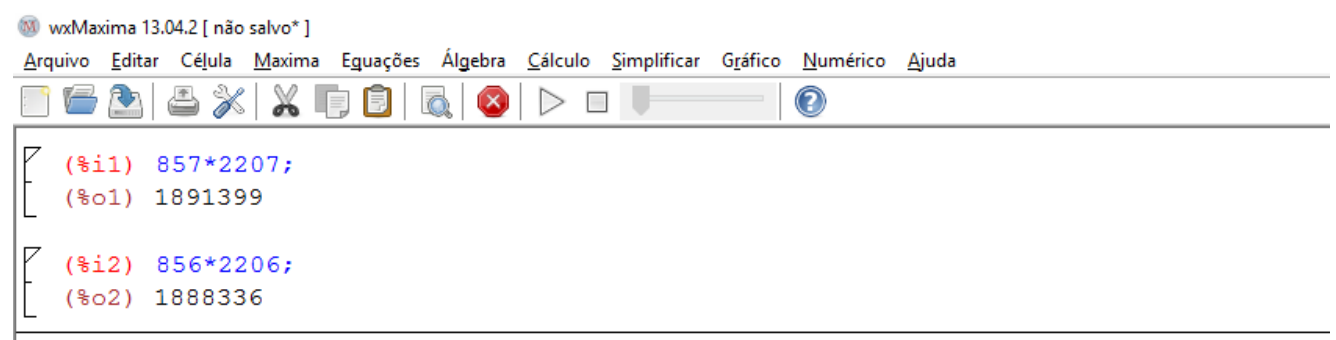

Figura 15 - Encontrando $\varphi_{N}$

Para encontrar $e$ temos que $\left(e, \varphi_{N}\right)$, por isso é possível usar o comando factor $(a)$ como na figura 16, onde $a$ é o número a ser fatorado, para garantir que o mdc entre eles seja 1 basta escolher um número primo que não pertença à fatoração de $\varphi_{N}$ e seja menor possível. Como os números primos usados são da forma $6 k+5$ isso implica que $\varphi_{N}$ nunca será divisível por 3.

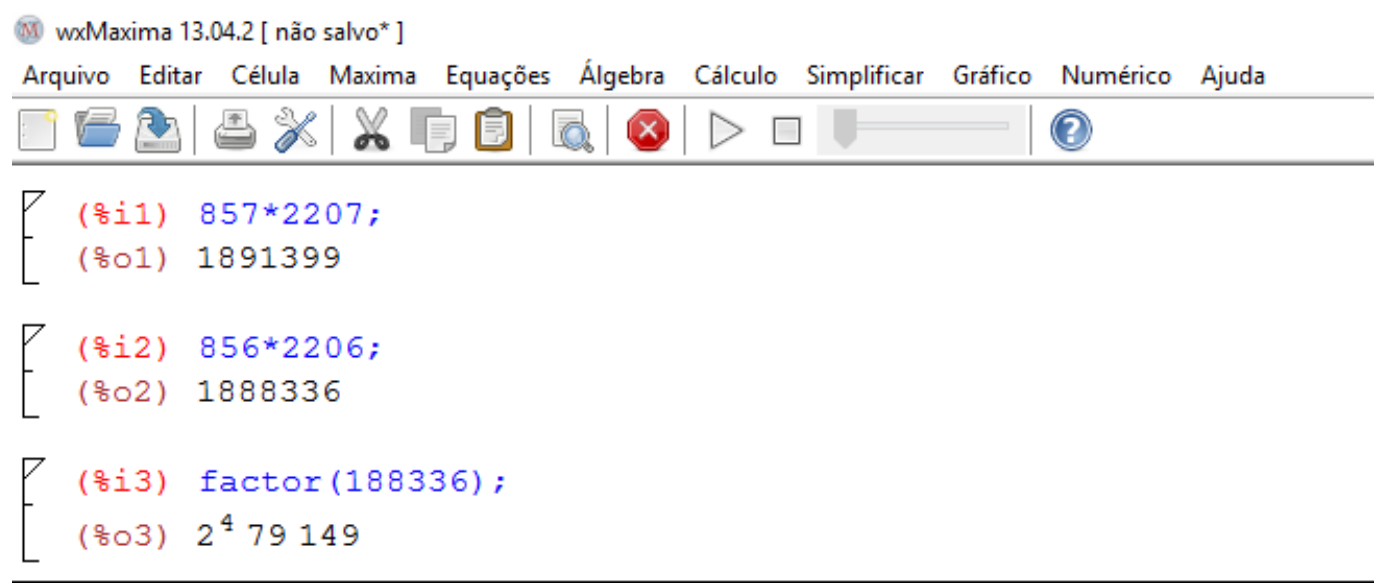

Figura 16 - Fatoração de $\varphi_{N}$

Além disso o comando de fatoração, é útil na criptoanálise para descobrir quais números primos estão sendo usados na codificação e assim poder decodificar a mensagem (quando não se tem a chave privada), afinal basta descobrir a fatoração de $N$ para descobrir a Chave Privada.

É possível encontrar $d$ também, que seria o inverso multiplicativo, para isso é 
preciso usar o comando inv_mod $\left(e, \varphi_{N}\right)$ como na figura 17.

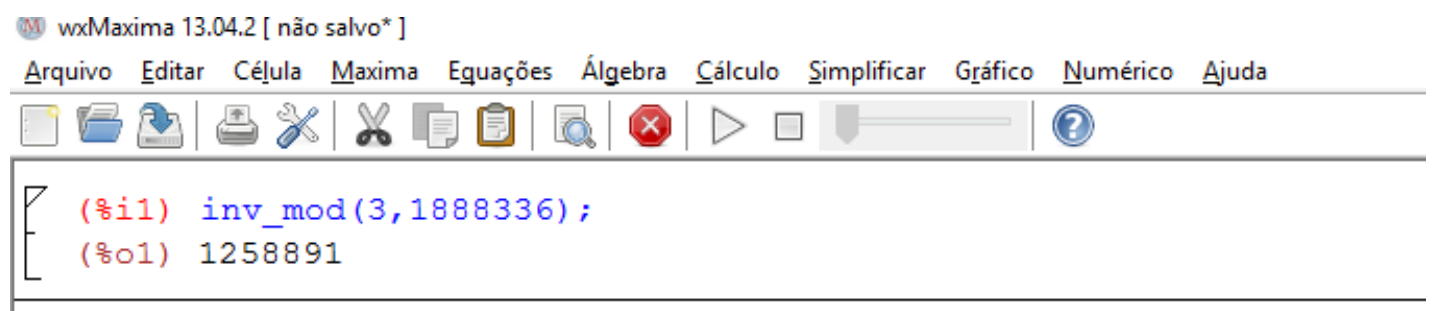

Figura 17 - Encontrando $d$

Para potência é usado^, por exemplo: $10^{5}$ ficaria " $10^{\wedge} 5$ ". O comando $\bmod (m, n)$ dá o resto da divisão de $m$ por $n$, o que é preciso nas congruências usadas.

Assim ao se utilizar as formulas $b^{e} \equiv C(b) \bmod N$ e $[C(b)]^{d} \equiv D(C(b)) \bmod N$, basta colocar o comando mod $\left(b^{e}, N\right)$ e terá o resultado $C(b)$ como nas figuras 18 e 19 , o comando $\bmod \left([C(b)]^{d}, N\right)$ obtendo $D(C(b))$ como nas figuras 20 e 21.

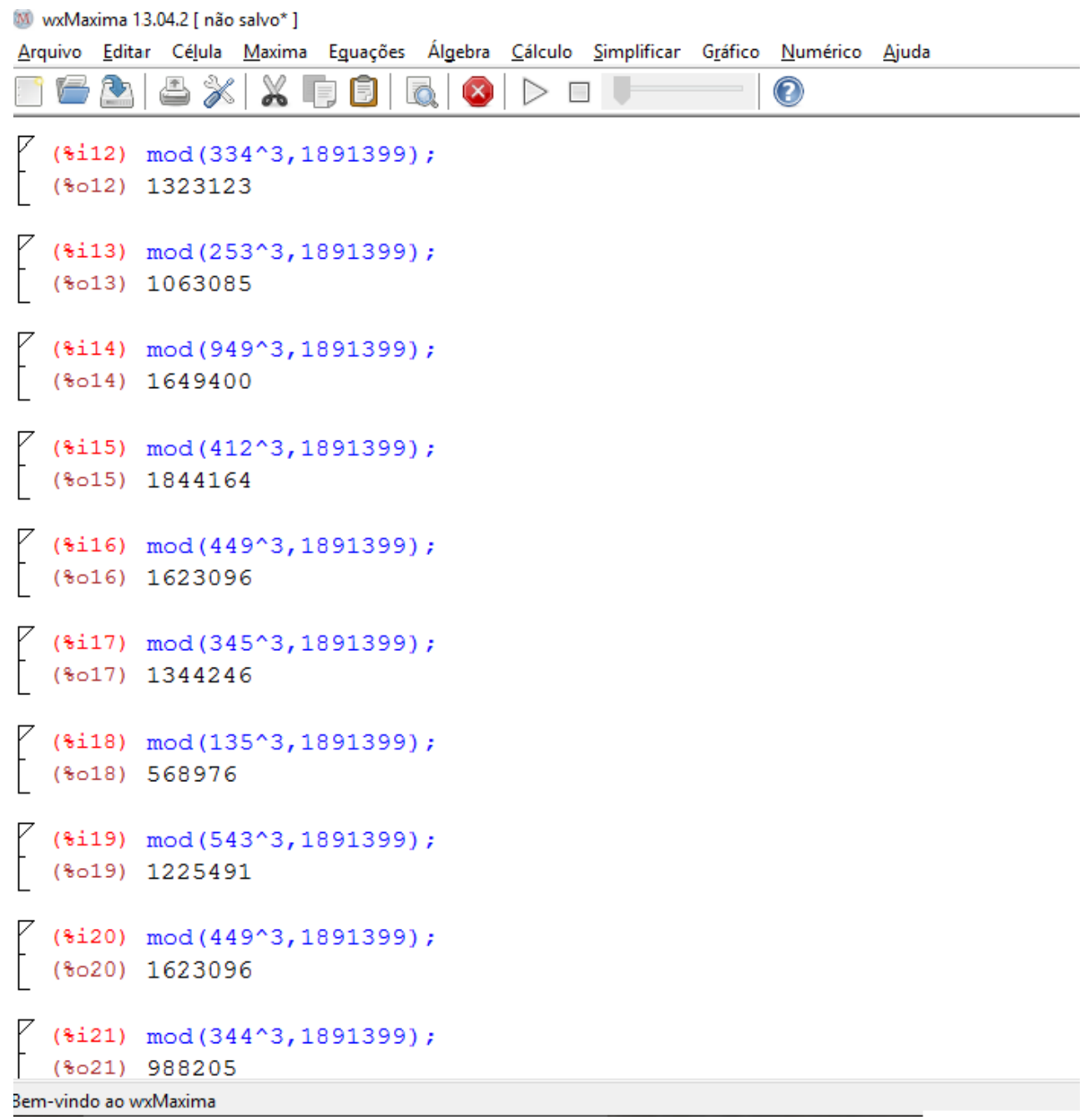

Figura 18 - Codificando a mensagem 


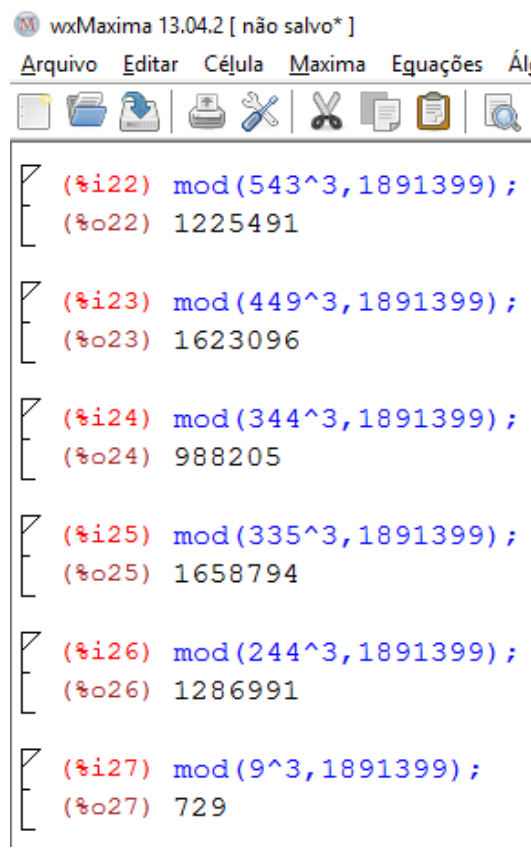

Figura 19 - Codificando a mensagem

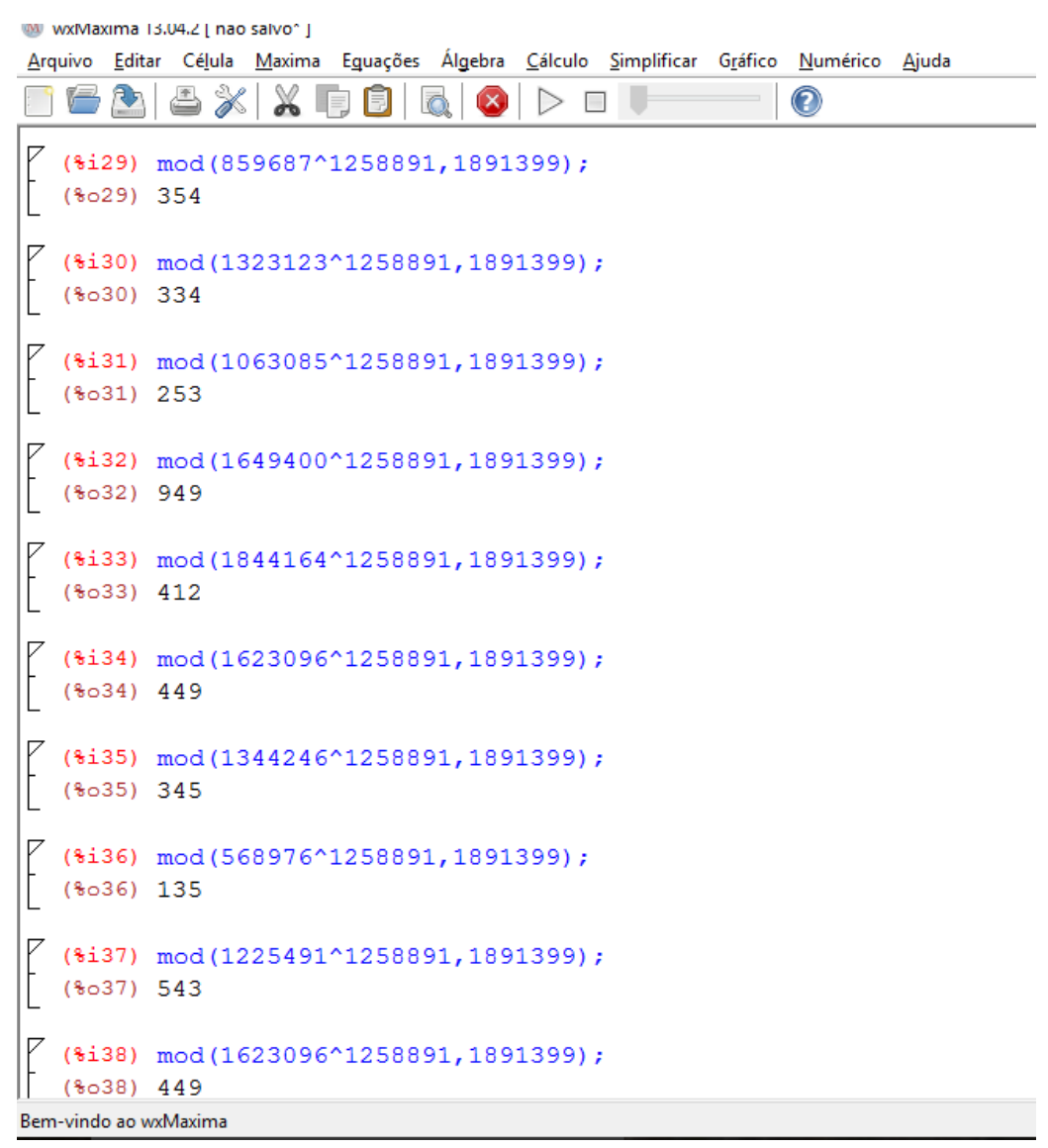

Figura 20 - Decodificando a mensagem 


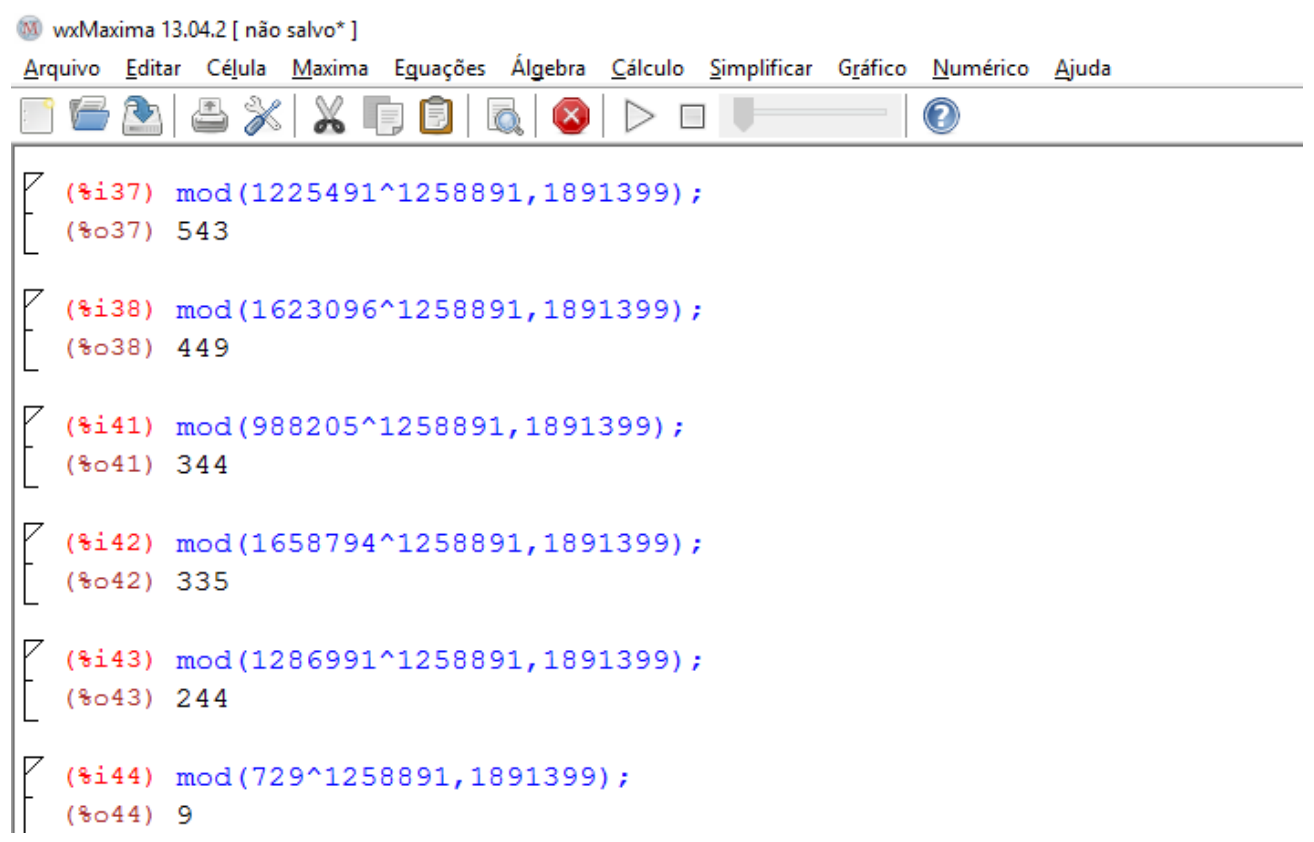

Figura 21 - Decodificando a mensagem

\subsection{Resultados}

Primeiramente foi feita a separação dos dois grupos para o desafio final, ficando cada grupo com 10 alunos. Durante a explanação da história da criptografia, foram feitas muitas observações interessantes por parte dos alunos, como: as maneiras de se interceptar a mensagem, as dificuldades que podiam ser encontradas na decifração, como deixar um código simples mais difícil de ser quebrado, dentre outros, funcionando como uma mesa redonda.

Alguns alunos mostraram que já tinham um código próprio para comunicação com amigos, assim foram desafiados a construirem um código único e simples baseado no de César e depois trocar uma mensagem criptografada com este código, foi dado quinze minutos para que eles tentassem quebrar o código, sem nenhum exito, então eles pediram mais tempo e com trinta minutos decorridos um grupo já havia quebrado o código.

Quatro dos alunos que fazem o curso também fazem técnico em informática, assim a discussão sobre códigos binários e programas computacionais foi muito aprofundada, um dos alunos mostrou um programa simples que ele havia criado para cálculo de números primos.

Alguns tópicos que foram introduzidos pelos alunos:

1. O assassino em série Zodiaco que escreveu cartas codificadas, onde algumas não foram decifradas até hoje.

2. Cicada 3301, um desafio que surgiu em um site com vários enigmas e códigos a serem decifrados. 
3. 11B x 1371, um vídeo onde aparecem mensagens para serem decodificadas, incluindo algumas em código morse.

4. criptografia quântica.

O fato desta aplicação ter sido em um programa de iniciação científica próprio para alunos que gostam de matemática não significa que ela não possa ser aplicada na sala de aula, afinal não é preciso explanar cada teorema com os alunos, porque a criptografia RSA usa restos de divisões (congruência) e potênciação. 
ALMEIDA, P. Q. de. Página sobre Criptologia (Criptografia e Criptoanálise). Portugal, 2015. Departamento de Matemática - Faculdade de Ciências e Tecnologia - Universidade de Coimbra. Disponível em: <http://www.mat.uc.pt/ pedro/cientificos/Cripto/>. Citado na página 54.

ATMEL. Entrada remota sem chave. http://www.atmel.com: [s.n.], 2016. Disponível em: <http://www.atmel.com>. Citado na página 49.

BAllinger, R.; RODEnKIRCH, M. Proth Search Page. http://prothsearch.net/: [s.n.], 2016. Disponível em: <http://www.prothsearch.net/>. Citado na página 45.

BRASIL. Parâmetros Curriculares Nacionais: matemática. Brasília: MEC/SEF, 1997. Citado 2 vezes nas páginas 21 e 22.

BRASIL, A. INSTITUTO BENJAMIN CONSTANT. http://www.ibc.gov.br/, 2016. Disponível em: <http://www.ibc.gov.br/>. Citado na página 58.

CALDWELL, C. K. The Largest Known Primes. https://primes.utm.edu/largest.html: [s.n.], 2016. Disponível em: <https://primes. utm.edu/largest.html>. Citado na página 44.

CANTORAL, R. Desarrollo del pensamiento matemático. México: Trillas: ITESM, Universidade Virtual, 2003. Citado na página 22.

CARnEIRO, M. J. D.; SPIRA, M.; SABATUCCI, J. Conteúdo Básico Comum (CBC) de Matemática no Ensino Médio. 2016. Disponível em: <www.crv.educacao. mg.gov.br $>$. Citado 3 vezes nas páginas 21, 22 e 43.

CLAY, L. D.; CLAY, L. T. Clay Mathematics Institute (CMI). 2016. Http://www.claymath.org/. Disponível em: <http://www.claymath.org/>. Citado na página 87.

COUTINHO, S. C. Criptografia. Rio de Janeiro: IMPA, 2008. v. 7. (Programa de Iniciação Científica - OBMEP, v. 7). Citado 4 vezes nas páginas 21, 43, 54 e 55.

Números Inteiros e Criptografia RSA. Rio de Janeiro: IMPA, 2011. (Coleção Matemática e Aplicações). Citado 2 vezes nas páginas 51 e 62.

D'AMBROSIO, U. Educação Matemática: da teoria à prática. Campinas: Papirus, 1997. (Coleção Perspectiva em Educação Matemática). Citado na página 22.

DIFFIE, W.; HELLMAN, M. E. New Directions in Cryptography. New York, 2007. IEEE Xplore. Disponível em: <ieeexplore.ieee.org>. Citado 2 vezes nas páginas 21 e 51.

FIARRESGA, V. M. C. Criptografia e matemática. Universidade de Lisboa Faculdade de Ciências, Departamento de Matemática, 2010. Citado na página 53. 
FONSECA, M. C. Por que ensinar Matemática. Belo Horizonte: Presença Pedagógica, 1995. v. 1. Citado na página 22.

GARRETT, F. Computador mais poderoso do mundo calcula 93 quatrilh es de dados por segundo. 2017. Techtudo. Disponível em: <http://www.techtudo.com.br/noticias/noticia/2016/06/ pc-mais-poderoso-do-mundo-calcula-93-quatrilhoes-de-dados-por-segundo.html $>\quad$ Citado na página 72 .

HEFEZ, A. Iniciação à Aritmética. Rio de Janeiro, 2005. OBMEP. Disponível em: $<$ http://www.obmep.org.br/docs/apostila1.pdf>. Citado na página 43.

KAHN, D. The codebreakers: The story of Secret Writing. New York: Scribner, 1996. Citado na página 51.

KRUH, L. A Basic Probe of the Beale Cipher as a Bamboozlement. http://www.tandfonline.com/doi/abs/10.1080/0161-118291857190: [s.n.], 1982. v. 6 and 12. Citado na página 55 .

LARCHER, P. H. História Heródoto (484 A.C. - 425 A.C.). Rio de Janeiro: W. M. Jackson Inc., 1950. XXIII e XXIV. (Clássicos Jackson, XXIII e XXIV). Disponível em: <http://www.ebooksbrasil.org/eLibris/historiaherodoto.html>. Citado 2 vezes nas páginas 50 e 53.

MAlagUtTI, P. L. Atividades de Contagem a partir da Criptografia. Rio de Janeiro: IMPA, 2015. v. 10. (Programa de Iniciação científica - OBMEP, v. 10). Disponível em: < http://www.obmep.org.br/docs/apostila10.pdf>. Citado 2 vezes nas páginas 53 e 58 .

MALAGUTTI, P. L. A. P versus NP. 2017. UFSCAR. Disponível em: < http://www. dm.ufscar.br/hp/hp501/hp501001/hp501001.html> . Citado na página 89.

MARTineZ, F. B.; MOREIRA, C. G.; SALDANHA, N.; TENGAN, E. Teoria dos números: um passeio com primos e outros números familiares pelo mundo inteiro. 3. ed. Rio de Janeiro: IMPA, 2013. (Projeto Euclides). Citado 2 vezes nas páginas 44 e 45 .

NSA, N. S. A. Has The Beale Treasure Code Been Solved. 2015. Disponível em: <https://www.nsa.gov/news-features/declassified-documents/beale-papers/ assets/files/doc656743.pdf $>$. Citado na página 55.

The Beale Papers. https://www.nsa.gov/news-features/declassifieddocuments/beale-papers/index.shtml: [s.n.], 2016. Disponível em: <https://www. nsa.gov/news-features/declassified-documents/beale-papers/index.shtml>. Citado na página 56.

OEIS. Brier numbers: numbers that are both Riesel and Sierpinski, or odd $\mathbf{n}$ such that for all $\mathbf{k}>=1$ the numbers $n \times 2^{k}+1$ and $n \times 2^{k}-1$ are composite. http://oeis.org/A076335: [s.n.], 2016. Disponível em: <http://oeis.org/A076335>. Citado na página 45.

OLGIN, C. D. A. Currículo no Ensino Médio: uma experiência com o tema criptografia. Canoas: Universidade Luterana do Brasil, 2011. Citado na página 53. 
RACKSPACE. PrimeGrid. http://www.primegrid.com/: [s.n.], 2016. The first managed cloud company. Disponível em: <http://www.primegrid.com/>. Citado na página 45.

RIBENBOIM, P. Números Primos: Velhos mistérios e novos recordes. 1. ed. Rio de Janeiro: IMPA, 2012. (Coleção Matemática Universitária). Citado na página 35.

ROSS, T. The Code that Failed: Testing a Bacon-Shakespeare Cipher. 1996. The Shakespeare Authorship Page. Disponível em: <http://shakespeareauthorship.com/ bacpenl.html>. Citado na página 62.

SANTOS, J. C. A hipótese de Riemann 150 anos. 2017. Disponível em: <http: //www.fc.up.pt/mp/jcsantos/PDF/artigos/Riemann_150.pdf $>$. Citado na página 88.

SCOTTI, H. de S.; FERREIRA, R. F. Sistemas de numeração. UFSC, 9 2011. Disponível em: < http://www.inf.ufsc.br/ bosco.sobral/extensao/sistemas-de-numeracao.pdf $>$. Citado na página 61.

SINGH, S. O livro dos códigos. Rio de Janeiro: Record, 2005. Citado 3 vezes nas páginas 50, 51 e 60.

STALLINGS, W. Criptografia e segurança de redes. 4. ed. São Paulo: Pearson Prentice, 2008. Citado 2 vezes nas páginas 52 e 62.

TAMAROZZI, A. C. Codificando e decifrando mensagens. Brasília: Ministério da Educação, Secretaria de Educação Básica, 2004. Citado na página 22.

TKOTZ, V. O Disco de Alberti. 2016. Disponível em: < http://www.numaboa.com.br/ criptografia/127-substituicao-polialfabetica/164-alberti>. Citado na página 60.

TRIVINOS, A. N. Introdução à pesquisa em Ciências Sociais. São Paulo: Atlas, 1987. Citado na página 22.

WINTERBOTHAM, F. W. Enigma: o segredo de Hitler. Rio de Janeiro: Biblioteca do exército, 1978. Citado na página 60.

WOLTMAN, G.; KUROWSKI, S. GIMPS (Great Internet Mersenne Prime Search). http://www.mersenne.org/primes/: [s.n.], 2016. Disponível em: <http://www. mersenne.org/primes/>. Citado na página 44. 

APÊNDICE

A

PROPRIEDADE ARQUIMEDIANA

A Propriedade Arquimediana é uma propriedade do conjunto dos números $\mathbb{R}$ que diz que $\forall x \in \mathbb{R}, \exists n \in \mathbb{N} / x<n$. A propriedade arquimediana diz simplesmente que o conjunto $\mathbb{N}$ não admite cota superior.

Proposição 18. (A Propriedade Arquimediana). Dados números reais $0<a<b$, existe um número natural $n$ tal que $b<n a$.

Demonstração. Suponhamos, por contradição, que $n a \leq b$, para todo $n \in \mathbb{N}$. Isto implica que o conjunto $A=\{n a ; n \in \mathbb{N}\}$ é limitado superiormente ( $b$ é uma de suas cotas superiores). De acordo com o Postulado de Dedekind, $A$ possui supremo, digamos $\alpha$. Assim, $n a \leq \alpha$, para todo $n \in \mathbb{N}$, de onde $(n+1) a \leq \alpha$, de modo que $n \leq \alpha-a$. Como $a>0, \alpha-$ $a$ seria cota superior de $A$, menor que o seu supremo $\alpha$ o que é impossível. Então, existe $n \in \mathbb{N}$ tal que $n a>b$. 

APÊNDICE

$\mathrm{B}$

\section{OS PROBLEMAS DO PRÊMIO MILLENNIUM}

Os Problemas do Prêmio Millennium são sete problemas matemáticos. Até o fechamento deste trabalho havia seis problemas que ainda não tinham solução. A solução correta de um destes problemas contempla um prêmio de um milhão de dólares que o Instituto Clay de Matemática em Massachusetts, nos Estados Unidos, oferece. O site do Instituto é http://www.claymath.org/.

Este instituto é um fundação privada fundada em 1998 e que não tem fins lucrativos. Seu objetivo é ampliar e disseminar o conhecimento matemático promovendo premiações e patrocinando matemáticos promissores, além de organizar oficinas, conferências, etc.

Seu fundador é o empresário Landon T. Clay com sua esposa Lavinia D. Clay, financiadores (CLAY; CLAY, 2016).

Os Problemas são:

1. $\mathrm{P}$ versus NP;

2. A conjectura de Hodge;

3. A conjectura de Poincaré (resolvido por Grigori Perelman);

4. A hipótese de Riemann;

5. A existência de Yang-Mills e a falha na massa;

6. A existência e suavidade de Navier-Stokes;

7. A conjectura de Birch e Swinnerton-Dyer.

A conjectura de Poincaré foi resolvida pelo matemático russo Gregori Perelman no ano de 2006. 


\section{B.1 A hipótese de Riemann}

Esta conjectura matemática foi publicada pela primeira vez em 1859 pelo matemático Bernhard Riemann. De acordo com Santos (2017) para que seja possível compreender o problema devemos voltar à 1650 quando foi publicado o livro Novae quadraturae arithmeticae seu se additione fractionum, de Pietro Mengoli.

Neste livro está presente duas séries:

$$
\zeta(1)=1+\frac{1}{2}+\frac{1}{3}+\frac{1}{4}+\ldots
$$

$\mathrm{e}$

$$
\zeta(2)=1+\frac{1}{2^{2}}+\frac{1}{3^{2}}+\frac{1}{4^{2}}+\ldots,
$$

que são importantes para a hipótese de Riemann.

No livro é demonstrado que a primeira série é divergente, levantando o problema: qual é a soma da segunda?

O problema foi proposto depois por Jacob Bernoulli, sendo intitulado na época como problema de Basileia, que alguns anos após este questionamento iniciou a estudar séries como:

$$
\zeta(n)=1+\frac{1}{2^{n}}+\frac{1}{3^{n}}+\frac{1}{4^{n}}+\ldots
$$

para cada $n \in \mathbb{N} \backslash 1 .^{1}$

Euler provou que $\zeta(2)=\frac{\pi^{2}}{6}$ e calculou $\zeta(n)$ para cada número natural par $n$, para além de ter obtido o produto euleriano:

$$
\zeta(n)=\prod_{p}\left(1-p^{-n}\right)^{-1}
$$

para qualquer $n \in \mathbb{N} \backslash 1$. Aqui o símbolo $\prod_{p}$ denota o produto sobre todos os números primos. Desta forma ele mostrou que existe uma relação entre a função $\zeta$ e a distribuição dos números primos.

Assim o problema da hipótese de Riemann se resume à provar que apesar da distribuição de números primos no conjunto dos números naturais não seguir nenhum padrão regular, o matemático alemão GFB Riemann (1826-1866) observou que a frequência de números primos está muito intimamente relacionada ao comportamento da função

$$
\zeta(s)=1+\left(\frac{1}{2}\right)^{s}+\left(\frac{1}{3}\right)^{s}+\left(\frac{1}{4}\right)^{s}+\ldots, \quad s \in \mathbb{C} .
$$

\footnotetext{
$1 \quad \backslash$ : significa menos; sem; exceto.
} 
Esta função é chamada de função Zeta de Riemann, e a afirmação de que todas as soluções interessantes da equação $\zeta(s)=0$ estão sobre a reta vertical $\operatorname{Re}(s)=1 / 2$ é conhecida como a famosa hipótese de Riemann. A prova desta hipótese lançará luz sobre muitos dos mistérios em torno da distribuição de números primos.

\title{
B.2 P versus NP
}

É um problema ligado à Ciências da Computação, entrelaçando campos desde a engenharia até a criptografia.

De acordo com Malagutti (2017):

\begin{abstract}
A classe de algoritmos $P$ é formada pelos procedimentos para os quais existe um polinômio $p(n)$ que limita o número de passos do processamento se este for iniciado com uma entrada de tamanho $n$. [...] Os algoritmos $N P$ não se referem a procedimentos não polinomiais (na verdade isto é uma conjectura). A leitura correta para procedimentos $N P$ é dizer que se referem a algoritmos "não-determinísticos polinomiais"no tempo.[...] A classe dos problemas NP é aquela para as quais podemos verificar, em tempo polinomial, se uma possível solução é correta.
\end{abstract}

Como exemplo: queremos descobrir se um número é primo ou composto, mas não existe um modo rápido para descobrir isso ou descobrir sua fatoração, um dos métodos é o Crivo de Eratóstenes que testa os possíveis divisores, mas isso dá muito trabalho até para um computador, demandando muito tempo, contudo se fosse possível uma certificação que apenas validasse se algo é resposta ou não isso seria mais simples que testar todos os resultados possíveis.

Outro exemplo: suponha que precisaremos dividir um grupo de pessoas em duplas, mas nem todas são compatíveis umas com as outras, tentar todas as possibilidades não é uma alternativa, este é um problemas em que há algoritmos eficientes para solucioná-lo e por isso está na classe $\boldsymbol{P}$ de "Tempo Determinístico Polinomial". Inclusive foi resolvido por Jack Edmonds em 1965 ajudando a definir o que é computação eficiente.

Agora vamos reformular o mesmo problema: queremos dividir as pessoas em trios nos quais todos os pares delas são compatíveis (partição em triângulos). Neste caso não há um algoritmo eficiente, dada uma solução qualquer, é possível conferir a solução de maneira eficiente: este tipo de problema que possue soluções verificáveis em tempo polinomial define a classe NP: de "Tempo Polinomial Não Determinístico". Além disso somente uma Máquina de Turing Não Determinística pode resolvê-lo.

O problema $N$ versus $N P$ se refere à prova de que $P \neq N P$ dado as descobertas que foram feitas através do tempo é o que grande parte dos cientistas da computação passou a acreditar, mas é preciso provar. Por isso é um dos problemas mais importante da ciência da computação e da matemática. 
Há a possibilidade de $P=N P$ : "O que ganharíamos com $P=N P$ faria com que a Internet inteira parecer apenas um rodapé na história" - Fortnow, L. 2009. Neste caso muitas tarefas de logística se tornariam triviais como: o transporte de pessoas ou produtos seria mais rápido e mais barato, previsões de tempo, terremoto e tsunamis, sem contar que a criptografia não teria mais função, isso porque ela se baseia em problemas difíceis de serem resolvidos, no caso da RSA: a fatoração de números muito grandes em números primos, mas se isso for um problema trivial ela é quebrada facilmente.

Um filme que retrata o impacto deste problema é Travelling Salesman ou O caixeiro viajante, de 2012, dirigido por Timothy Lanzone, conta a história de quatro matemáticos que descobrem um algoritmo eficiente para o Problema do Caixeiro Viajante, um problema NP-Completo, implicando em consequências drásticas para qualquer sistema de segurança virtual no planeta.

\section{B.3 Curiosidades}

Estes problemas já apareceram em alguns seriados famosos, como $N U M B 3 R S$, produzido pela rede americana CBS, seriado estrelado em 2005 onde um matemático ajuda agentes do FBI a solucionar crimes. Foi produzido somente seis temporadas, representando a matemática e como ela pode ser aplicada.

Em sua primeira temporada, no episódio 5, a filha de um matemático que supostamente havia resolvido a hipótese de Riemann é sequestrada, abordando assim os temas: criptografia, a Hipótese de Riemann e as consequências de sua solução, assim como os problemas do Millennium. Para amantes de números é um seriado interessante, explorando vários campos da matenática.

Também apareceu em Elementary, também produzido pela rede americana CBS, iniciada em 2012 ela representa uma nova versão de Sherlock Holmes, criado por Arthur Conan Doyle, contudo desta vez as histórias se passam nos Estados Unidos. Possui até o momento cinco temporadas.

A criptografia aparece no episódio 2 (Solve for $X$ ) da segunda temporada, onde o episódio começa com a morte de um matemático, abordando o problema $P$ versus $N P$, criptografia, suas implicações para a comunidade científica.

Sherlock é outro seriado baseado no detetive criado por Sir Arthur Conan Doyle, sendo uma co-produção da British Broadcasting Corporation (BBC), a segunda temporada tem em seu primeiro episódio uma mensagem aparentemente indecifrável, contudo Holmes a decifra em oito segundos.

No seriado Bones, exibido pela FOX nos Estados Unidos, a criptografia é abordada na sétima temporada, episódio 6 , onde é preciso decifrar vários códigos deixados por um 
assassino em série.

Já no seriado Hawaii Five-0 o tema é abordado na primeira temporada, episódio 19, onde falam sobre a facilidade em quebrar uma criptografia de 64 bits e novamente na terceira temporada, episódio 7, onde eles lidam com hackers e precisam de uma senha para quebrar uma criptografia de 1024 bits (que levaria meses para ser quebrada e era preciso urgentemente), além de outros.

No seriado Prison Break, segunda temporada, episódio 15, um dos protagonistas precisa enviar uma mensagem, então ele codifica-a para que só seu destinatário compreenda, além disso é abordado o código morse.

O livro Zodíaco escrito por Robert Graysmith, aborda sobre um serial killer que aterrorizou a cidade de São Francisco em 1968, deixou várias cartas codificadas, algumas não foram decodificadas até hoje, a revista Mundo Estranho traz uma reportagem sobre isso: http://mundoestranho.abril.com.br/cultura/as-outras-cartas-do-serial-killer-zodiaco/. Um filme também foi feito: Zodíaco, lançado em 2007 com direção de David Fincher.

Os clássicos livros sobre o investigador Sherlock Holmes e seu parceiro Watson, escrito por Arthur Conan Doyle, também trazem o tema, no livro O vale do Terror os investigadores são chamados à uma casa de campo através de uma mensagem codificada. $\mathrm{O}$ investigador Holmes adora quebra-cabeças, outra mensagem assim aparece em $O$ regresso de Sherlock Holmes.

A revista Super Interessante fez uma reportagem em 31/10/2016 intitulada $O$ segredo da criptografia, é possível acessá-la em http://super.abril.com.br/tecnologia/osegredo-da-criptografia/, que traz algumas curiosidades sobre o tema. Em abril de 2016 foi udado 9500 computadores e quatro meses para quebrar um código, mostrando o quanto um bom código é importante para que seja possível guardar um segredo ou algo importante através da criptografia. 